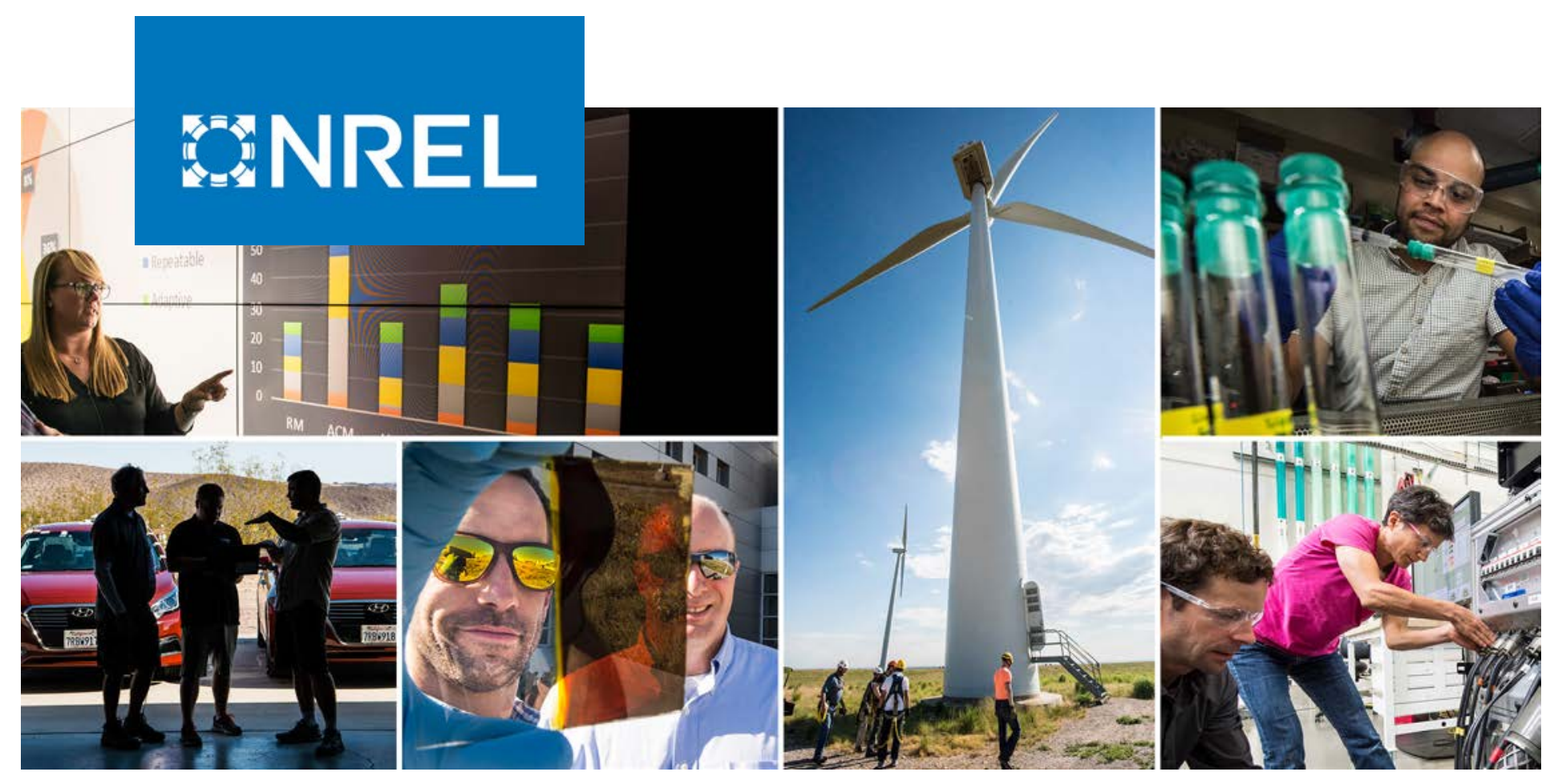

\title{
GeoVision Analysis Supporting Task Force Report: Electric Sector Potential to Penetration
}

Chad Augustine, Jonathan Ho, and Nate Blair

National Renewable Energy Laboratory

NREL is a national laboratory of the U.S. Department of Energy

Office of Energy Efficiency \& Renewable Energy

Operated by the Alliance for Sustainable Energy, LLC

This report is available at no cost from the National Renewable Energy Laboratory (NREL) at www.nrel.gov/publications.

\section{Technical Report}

NREL/TP-6A20-71833

May 2019 


\section{FANREL}

\section{GeoVision Analysis Supporting Task Force Report: Electric Sector Potential to Penetration}

Chad Augustine, Jonathan Ho, and Nate Blair

National Renewable Energy Laboratory

\section{Suggested Citation}

Augustine, Chad, Jonathan Ho, and Nate Blair. 2019. GeoVision Analysis Supporting Task Force Report: Electric Sector Potential to Penetration. Golden, CO: National Renewable Energy Laboratory. NREL/ TP-6A20-71833.

https://www.nrel.gov/docs/fy19osti/71833.pdf.

NREL is a national laboratory of the U.S. Department of Energy Office of Energy Efficiency \& Renewable Energy Operated by the Alliance for Sustainable Energy, LLC

This report is available at no cost from the National Renewable Energy Laboratory (NREL) at www.nrel.gov/publications.

Contract No. DE-AC36-08GO28308
Technical Report NREL/TP-6A20-71833 May 2019

National Renewable Energy Laboratory 15013 Denver West Parkway Golden, CO 80401

303-275-3000 • www.nrel.gov 


\section{NOTICE}

This work was authored by the National Renewable Energy Laboratory, operated by Alliance for Sustainable Energy, LLC, for the U.S. Department of Energy (DOE) under Contract No. DE-AC36-08G028308. Funding provided by the U.S. Department of Energy Office of Energy Efficiency and Renewable Energy Geothermal Technologies Office. The views expressed herein do not necessarily represent the views of the DOE or the U.S. Government.

This report is available at no cost from the National Renewable Energy Laboratory (NREL) at www.nrel.gov/publications.

U.S. Department of Energy (DOE) reports produced after 1991 and a growing number of pre-1991 documents are available free via www.OSTI.gov.

Cover Photos by Dennis Schroeder: (clockwise, left to right) NREL 51934, NREL 45897, NREL 42160, NREL 45891, NREL 48097, NREL 46526.

NREL prints on paper that contains recycled content. 


\section{Foreword}

This report describes research and analysis performed in support of the U.S. Department of Energy Geothermal Technologies Office for its Geothermal Vision Study. A summary of the study is captured in DOE's report, GeoVision: Harnessing the Heat Beneath Our Feet (DOE 2019) and included ground-breaking, detailed research on geothermal technologies. The study projects and quantifies the future electric and nonelectric deployment potentials of these geothermal technologies within a range of scenarios in addition to their impacts on U.S. jobs, the economy, and environment. Coordinated by the U.S. Department of Energy Geothermal Technologies Office, the Geothermal Vision Study development relied on collecting, modeling, and analyzing robust data sets through seven national laboratory partners that were organized into eight technical task force groups. These task forces and their respective principal leading national laboratory are listed in Table F-1. The table also provides a guide to the final research documents produced by each GeoVision task force. In most cases, these were prepared as laboratory reports, and they are referenced accordingly. Consult these external reports for detailed discussions of the topics contained within, which form the basis of the GeoVision analysis.

Table F-1. Guide to Technical Research Documents Providing the Basis of the GeoVision Analysis

\begin{tabular}{lll}
\hline GeoVision Task Force & $\begin{array}{l}\text { Lead National } \\
\text { Laboratory }\end{array}$ & Report Number/Citation \\
\hline Exploration and Confirmation & $\begin{array}{l}\text { Lawrence Berkeley } \\
\text { National Laboratory }\end{array}$ & $\begin{array}{l}\text { LBNL-2001120 } \\
\text { (Doughty et al. 2018) }\end{array}$ \\
\hline Potential to Penetration (this report) & $\begin{array}{l}\text { National Renewable } \\
\text { Energy Laboratory }\end{array}$ & $\begin{array}{l}\text { NREL/TP-6A20-71833 } \\
\text { (Augustine et al. 2018) }\end{array}$ \\
\hline Thermal Applications: Direct Use & $\begin{array}{l}\text { National Renewable } \\
\text { Energy Laboratory }\end{array}$ & $\begin{array}{l}\text { NREL/TP-6A20-71715 } \\
\text { (McCabe et al. 2019) }\end{array}$ \\
\hline Thermal Applications: Geothermal & $\begin{array}{l}\text { Oak Ridge National } \\
\text { Laboratory }\end{array}$ & $\begin{array}{l}\text { ORNL/TM-2019/502 } \\
\text { (Liu et al. 2019) }\end{array}$ \\
\hline $\begin{array}{l}\text { Reservoir Maintenance and } \\
\text { Development }\end{array}$ & $\begin{array}{l}\text { Sandia National } \\
\text { Laboratories }\end{array}$ & $\begin{array}{l}\text { SAND2017-9977 } \\
\text { (Lowry et al. 2017a) }\end{array}$ \\
\hline Hybrid Systems & $\begin{array}{l}\text { Idaho National } \\
\text { Laboratory }\end{array}$ & $\begin{array}{l}\text { INL/EXT-17-42891 } \\
\text { (Wendt et al. 2018) }\end{array}$ \\
\hline Institutional Market Barriers & $\begin{array}{l}\text { National Renewable } \\
\text { Energy Laboratory }\end{array}$ & $\begin{array}{l}\text { NREL/PR-6A20-71641 } \\
\text { (Young et al. 2019) }\end{array}$ \\
\hline Social and Environmental Impacts & $\begin{array}{l}\text { Lawrence Berkeley } \\
\text { National Laboratory }\end{array}$ & $\begin{array}{l}\text { NREL/TP-6A20-71933 } \\
\text { (Millstein et al. 2019) }\end{array}$ \\
\hline
\end{tabular}




\section{Acknowledgments}

The authors thank the Geothermal Technologies Office (GTO) for primary funding support of this analysis. In particular, we thank Holly Thomas (GTO), Eric Hass (GTO), and Jeffrey Winick (BCS Inc.) for their guidance and overall management of the GeoVision analysis. We thank the GeoVision Visionary Team for their input and advice through the course of the analysis effort. We also thank Doug Blankenship (Sandia National Laboratory [SNL]), Tom Lowry (SNL), Pat Dobson (Lawrence Berkeley National Laboratory), Colin Williams (U.S. Geological Survey), Maria Richards (Southern Methodist University), and Greg Mines (formerly Idaho National Laboratory) for providing vital data for the analysis. 


\section{List of Acronyms}

\begin{tabular}{|c|c|}
\hline $\mathrm{AEO}$ & Annual Energy Outlook \\
\hline ATB & Annual Technology Baseline \\
\hline BAA & balancing authority area \\
\hline BAU & Business-as-Usual \\
\hline $\mathrm{CO}_{2}$ & carbon dioxide \\
\hline DOE & U.S. Department of Energy \\
\hline EGS & enhanced geothermal system \\
\hline EIA & U.S. Energy Information Administration \\
\hline FORGE & $\begin{array}{l}\text { Frontier Observatory for Research in Geothermal } \\
\text { Energy }\end{array}$ \\
\hline GCCU & geothermal combined-cycle units \\
\hline GEA & Geothermal Energy Administration \\
\hline GETEM & $\begin{array}{l}\text { Geothermal Electricity Technology Evaluation } \\
\text { Model }\end{array}$ \\
\hline IRT & Improved Regulatory Timeline \\
\hline $\mathrm{LCOE}$ & levelized cost of energy \\
\hline NF-EGS & $\begin{array}{l}\text { near-hydrothermal field enhanced geothermal } \\
\text { system }\end{array}$ \\
\hline $\mathrm{NG}-\mathrm{CC}$ & Natural Gas Combined Cycle \\
\hline NG-CT & Natural Gas Combustion Turbine \\
\hline $\mathrm{NOx}$ & nitrogen oxide \\
\hline NREL & National Renewable Energy Laboratory \\
\hline O\&M & operation and maintenance \\
\hline OGS & oil/gas steam turbine \\
\hline $\mathrm{RE}$ & renewable energy \\
\hline ReEDS & Regional Energy Deployment Systems \\
\hline SMU & Southern Methodist University \\
\hline $\mathrm{SO}_{2}$ & sulfur dioxide \\
\hline $\mathrm{TI}$ & Technology Improvement \\
\hline USGS & U.S. Geological Survey \\
\hline WACC & weighted average cost of capital \\
\hline
\end{tabular}




\section{Executive Summary}

The U.S. Department of Energy (DOE) GeoVision: Harnessing the Heat Beneath Our Feet report (DOE 2019) examines the potential for geothermal resources to play a key role in the nation's energy future. This Potential to Penetration Task Force report describes analysis done in support of the GeoVision. This report forecasts future growth and deployment potential of hydrothermal and EGS geothermal technologies in the electric sector that could be achieved by meeting the targets for technological improvement and by easing market and structural barriers described in the GeoVision. Three scenarios are considered:

- Business-as-Usual (BAU): assumes that the geothermal industry continues on its current trajectory

- Improved Regulatory Timeline (IRT): assumes an improved regulatory environment leading to accelerated geothermal permitting processes, increased rates of exploration and resource discovery, and shortened development timelines; uses BAU technology assumptions

- Technology Improvement (TI): assumes a future where technology advances, cost reductions, and favorable financing options reduce the cost of geothermal technologies; includes IRT assumptions.

The methodology used to project geothermal deployment is similar to that used in other Department of Energy vision ${ }^{1}$ studies. The U.S. hydrothermal and EGS resource potential is estimated using the best available data. The cost of developing these resources is estimated for each scenario using the Geothermal Electricity Technology Evaluation Model (GETEM). The resulting supply curves are then used as inputs in the Regional Energy Deployment System (ReEDS) model to project geothermal technology capacity deployment under each scenario out to 2050. Additional sensitivity scenarios are also considered.

The study considers two types of geothermal resources: hydrothermal and EGS. The hydrothermal resource consists of the naturally occurring geothermal sites used conventionally to produce electricity. The hydrothermal resource potential is based on the recently completed geothermal resource assessment of the United States performed by the U.S. Geological Survey (USGS) (Williams et al. 2008). The assessment divides the resources into identified sites and "undiscovered" resources. EGS are geothermal reservoirs that have been engineered to extract economic amounts of heat from geothermal resources that have low permeability and/or lack natural in-situ fluids for heat extraction. EGS technologies are still being developed and are not yet commercially available. EGS technologies are likely to be developed and deployed in stages, expanding from existing hydrothermal sites to greenfield sites. For this study, the EGS potential resource is divided into two groups: the near-field EGS (NF-EGS) resource and the deep EGS resource. The NF-EGS resource potential was developed by the USGS as part of the 2008 assessment. The deep EGS electricity generation resource potential estimate was recently updated for the GeoVision study (Augustine 2016) using the most recent temperature-at-depth

\footnotetext{
${ }^{1}$ Wind Vision study: https://www.energy.gov/eere/wind/wind-vision SunShot Vision study: https://www.energy.gov/eere/solar/sunshot-vision-study Hydropower Vision study: https:/www.energy.gov/eere/water/new-vision-united-states-hydropower
} 
maps available from SMU (Blackwell et al. 2011). The resource potential estimates are modified to reflect non-technical barriers such as land access restrictions identified as part of the GeoVision study (Young et al. 2019) that that prevent or inhibit the development of geothermal projects. The resulting geothermal resources available for deployment for each scenario are summarized in Table ES-1.

Table ES-1. Summary of Geothermal Resources Available (in $\mathbf{M W}_{\mathrm{e}}$ ) in ReEDS for Different GeoVision Scenarios

\begin{tabular}{lllll}
\hline GeoVision Scenario & $\begin{array}{l}\text { Identified } \\
\text { Hydrothermal }\end{array}$ & $\begin{array}{l}\text { Undiscovered } \\
\text { Hydrothermal }\end{array}$ & $\begin{array}{l}\text { NF- } \\
\text { EGS }\end{array}$ & $\begin{array}{l}\text { Deep } \\
\text { EGS }\end{array}$ \\
\hline $\begin{array}{l}\text { Land Access Assumptions Used by } \\
\begin{array}{l}\text { USGS (Williams et al. 2008) and } \\
\text { Augustine (2016) (Minimal barriers: only } \\
\text { federally protected lands excluded) }\end{array}\end{array}$ & 5,657 & 25,807 & 1,493 & $5,156,956$ \\
$\begin{array}{l}\text { Business-as-Usual (BAU) } \\
\text { Improved Regulatory Timeline (IRT) }\end{array}$ & 5,078 & 18,830 & 1,382 & $3,375,275$ \\
\hline $\begin{array}{l}\text { Technology Improvement (TI) } \\
\text { Teche }\end{array}$ & 5,128 & 23,038 & 1,443 & $4,248,879$ \\
\hline
\end{tabular}

A bottoms-up analysis is used to develop cost estimates for geothermal technologies in each scenario. Detailed cost and technology performance values for the exploration, drilling, power plant construction, and plant operation developed by GeoVision task forces across multiple national laboratories were input into the GETEM to estimate project development overnight capital costs and operation and maintenance costs for individual geothermal sites and classes of resources. The BAU and IRT scenarios use the same cost assumptions based on current technology. The TI scenario assumes technology advances in exploration (Doughty et al. 2018) and drilling (Lowry et al. 2017) that lower the cost and risk of geothermal development. It also assumes that EGS reservoir development technologies advance by 2030 to the point where their performance is assumed to be the same as conventional hydrothermal reservoirs. Reductions in construction timelines and increased rates of hydrothermal resource discovery for the IRT and TI scenarios are implemented in the ReEDS model, as are reduced project financing costs for the TI scenario. The scenario assumptions are summarized in Table ES-2.

Geothermal capacity deployment for the three scenarios through 2050 is projected using the ReEDS model. To represent the competition among the many electricity generation, storage, and transmission options throughout the contiguous United States, ReEDS identifies the cost-optimal mix of technologies that meet regional electric power demand requirements based on grid reliability (reserve) requirements, technology resource constraints, and policy constraints. GeoVision uses the Mid-case scenario from the 2016 version of the ATB (Cole, Kurup et al. 2016; NREL 2016) for other technology costs, fuel costs, electricity demand, and other required inputs. Geothermal capacity deployment results are shown in Figure ES-1. 
Table ES-2. Summary of GeoVision Analysis Electric-Sector Scenarios Assumptions

\begin{tabular}{|c|c|c|c|}
\hline Scenario & $\begin{array}{l}\text { Business-as- } \\
\text { Usual (BAU) }\end{array}$ & $\begin{array}{l}\text { Improved Regulatory } \\
\text { Timeline (IRT) }\end{array}$ & $\begin{array}{l}\text { Technology } \\
\text { Improvement } \\
\text { (TI) }\end{array}$ \\
\hline Description & $\begin{array}{l}\text { Reflects current } \\
\text { industry trends }\end{array}$ & $\begin{array}{l}\text { Streamlined permitting } \\
\text { increases the amount of } \\
\text { exploration, decreases project } \\
\text { timelines, increases resource } \\
\text { discovery rate }\end{array}$ & $\begin{array}{l}\text { IRT scenario + land } \\
\text { access and technology } \\
\text { improvements: } \\
\text { Advances in drilling, } \\
\text { exploration, and EGS } \\
\text { reservoir development } \\
\text { reduce costs and risks }\end{array}$ \\
\hline $\begin{array}{l}\text { Capital + O\&M } \\
\text { Costs }\end{array}$ & BAU & BAU & $\begin{array}{l}\text { Hydrothermal: some } \\
\text { reductions } \\
\text { EGS: large reductions }\end{array}$ \\
\hline $\begin{array}{l}\text { Construction } \\
\text { Time (years) }\end{array}$ & $\begin{array}{l}\text { Hydrothermal: } 8 \\
\text { EGS: } 10\end{array}$ & $\begin{array}{l}\text { Hydrothermal: } 4 \\
\text { EGS: } 5\end{array}$ & $\begin{array}{c}\text { Hydrothermal: } 4 \\
\text { EGS: } 5\end{array}$ \\
\hline Financing & $\begin{array}{l}\text { ReEDS Standard } \\
\text { WACC }+6 \%\end{array}$ & $\begin{array}{l}\text { ReEDS Standard } \\
\text { WACC }+6 \%\end{array}$ & ReEDS Standard WACC \\
\hline $\begin{array}{l}\text { Hydrothermal } \\
\text { Discovery Rate }\end{array}$ & $\begin{array}{c}1 \% \text { of } \\
\text { Undiscovered } \\
\text { Resource/Year }\end{array}$ & $\begin{array}{l}3 \% \text { of Undiscovered } \\
\text { Resource/Year }\end{array}$ & $\begin{array}{l}3 \% \text { of undiscovered } \\
\text { resource/year }\end{array}$ \\
\hline
\end{tabular}

Table Notes: O\&M refers to "operation and maintenance." WACC refers to "weighted-average cost of capital" and represents the financing rates that projects are able to achieve. Hydrothermal Discovery Rate refers to the amount of undiscovered hydrothermal resource that is assumed to be "discovered" and made available for deployment in

ReEDS each year. 1\%/year is equivalent to about $200 \mathrm{MW}_{\mathrm{e}} /$ year of undiscovered hydrothermal resources.

In the BAU scenario, installed geothermal capacity increases from 2,542 $\mathrm{MW}_{\mathrm{e}}$ in 2016 to 5,924 $\mathrm{MW}_{\mathrm{e}}$ by 2050 . This is consistent with the current industry growth trajectory. The IRT scenario estimates 12,891 MWe of total installed geothermal capacity by 2050 . This increase is more than double the 2050 installed capacity in the BAU scenario. Since the IRT scenario assumes BAU technology costs, this implies that the geothermal industry could increase deployment through regulatory reforms alone. Undiscovered hydrothermal resources make up the majority of the newly deployed geothermal capacity in both the BAU and IRT scenarios. This highlights the importance exploration and the impact that improved exploration techniques and technologies could have on the industry. In the TI scenario, total installed geothermal capacity reaches 60,701 $\mathrm{MW}_{\mathrm{e}}$ by 2050. The majority of the installed capacity comes from the rapid deployment of EGS resources starting in 2030 . Geothermal in the TI scenario generates $8.5 \%$ of all electricity generation, compared to $0.4 \%$ now. The TI scenario demonstrates the large impact that advancing EGS technologies could have on the geothermal industry.

The TI scenario was run with the suite of the National Renewable Energy Laboratory's Standard Scenarios, which consist of a range of power sector scenarios that capture a reasonable breadth of trajectories of costs, performance, policy, and other drivers, and thus enable the scenarios to cover a range of potential futures rather than a single outlook. The results of the High Natural Gas Prices and High RE Cost scenarios (Figure ES-1) show that geothermal deployment can exceed $100 \mathrm{GW}_{\mathrm{e}}$ in futures where the cost of competing electricity generation technologies (e.g., natural gas or other renewables) are high. Under these scenarios, geothermal makes up about 


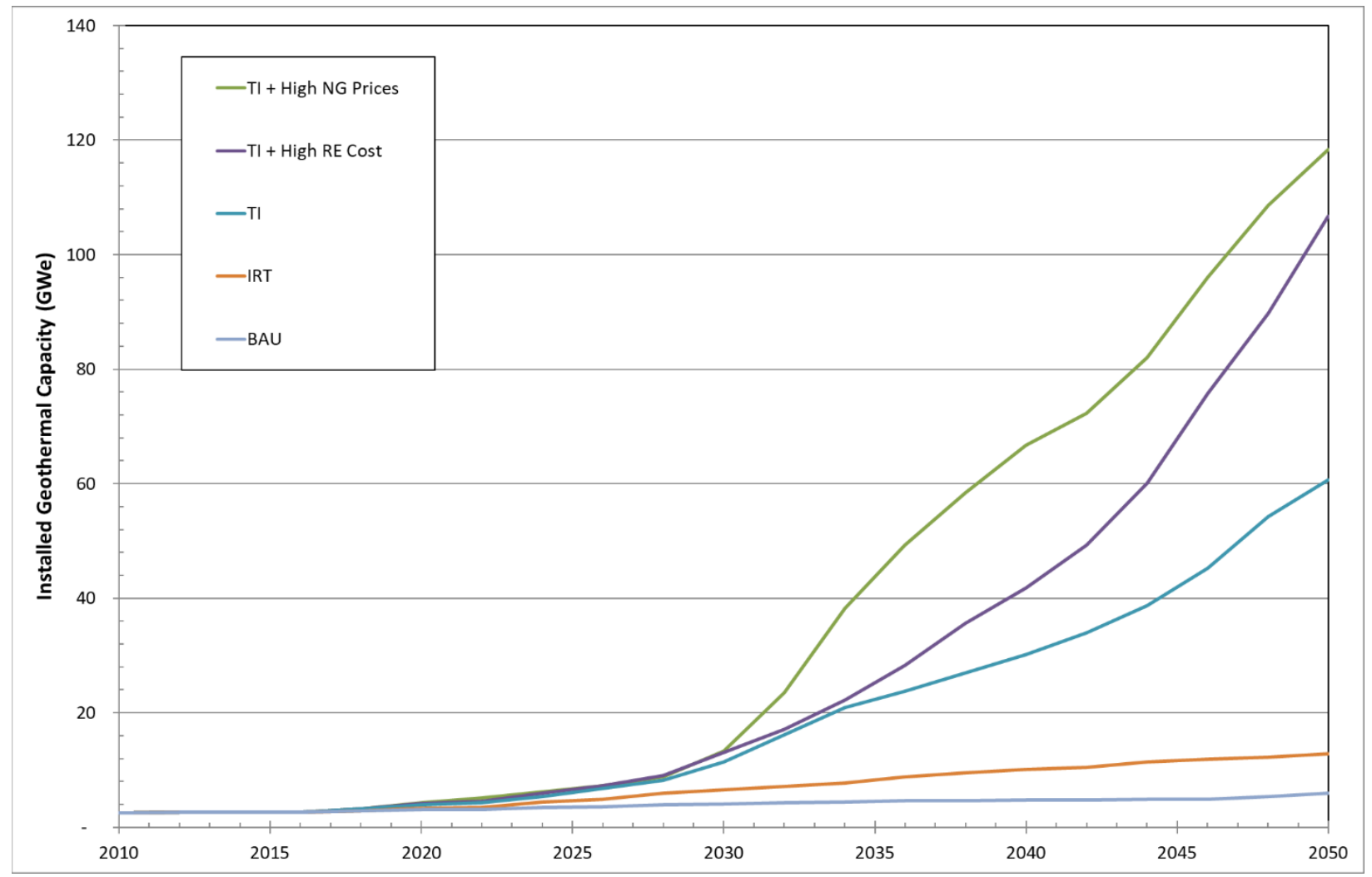

Figure ES-1. Installed geothermal capacity by year for GeoVision scenarios

$16 \%$ of total electricity generation in the United States by 2050, mostly from EGS resources. This demonstrates the abundance of EGS resources and shows that EGS deployment is demand limited, not supply limited. Conversely, in futures where the cost of competing renewable electricity generation technologies is low, total geothermal deployment in 2050 is limited to less than one-third of the value in the Mid-case scenario.

The TI scenario assumes aggressive technology improvements, especially in terms of drilling costs. Drilling cost sensitivity scenarios using less aggressive drilling cost improvement scenarios developed for the GeoVision study were performed to explore the impact of drilling costs on geothermal deployment. The results show that geothermal can still make significant gains without fully realizing the technology assumptions in the TI scenario. Even in these scenarios, the difference in deployment is almost entirely a result of EGS deployment.

Overall, the Potential to Penetration Task Force results show that in the near term, hydrothermal resources could experience increased rates of deployment from regulatory reforms and by focusing on exploration technologies and techniques to increase the rate of discovery of hydrothermal resources. In the long term, the geothermal industry could experience significant growth from EGS resources by focusing on research and development to enable and advance EGS technologies. 


\section{Table of Contents}

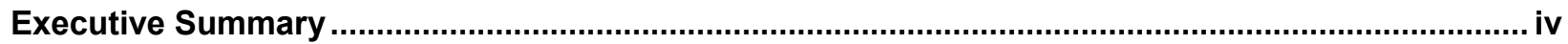

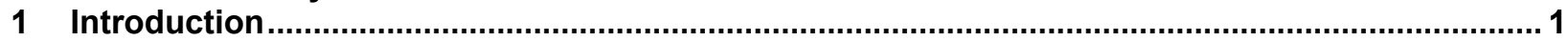

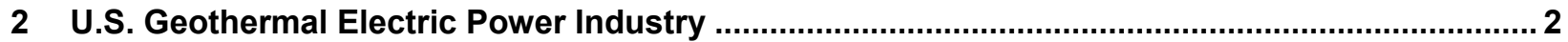

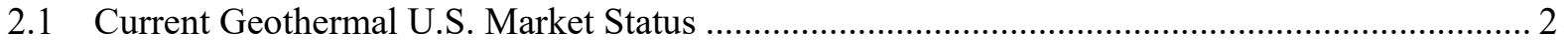

2.2 U.S. Geothermal Market Trajectory ............................................................................................. 6

3 GeoVision Model Summaries and Assessment Methods ...................................................... 8

3.1 Geothermal Electricity Technology Evaluation Model (GETEM) ......................................... 8

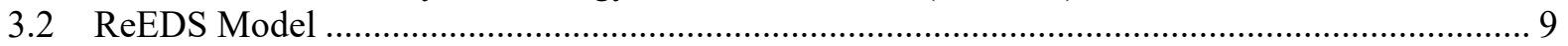

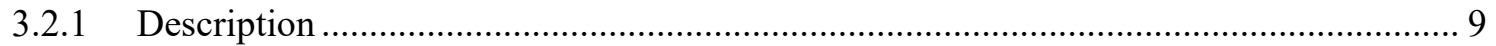

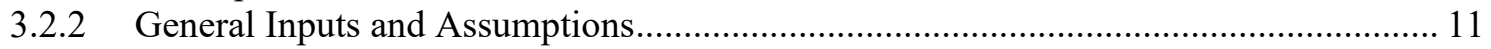

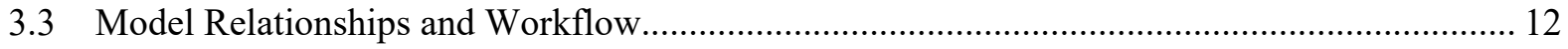

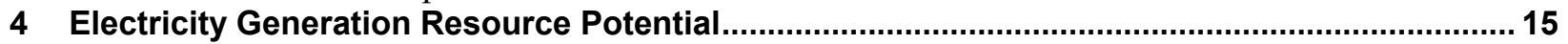

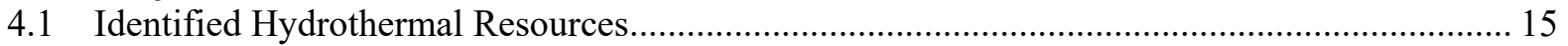

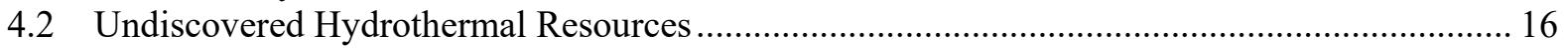

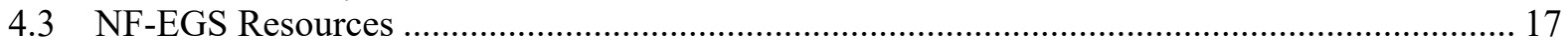

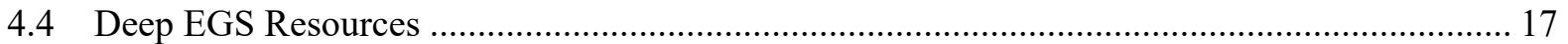

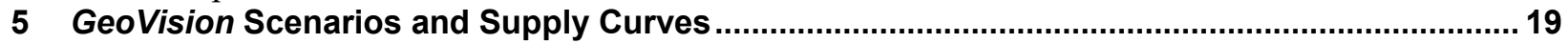

5.1 Geothermal Resource Potential Used in GeoVision Scenarios ................................................. 19

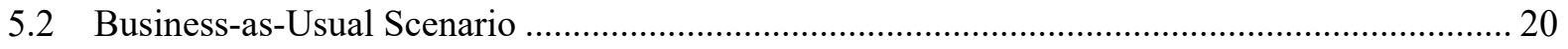

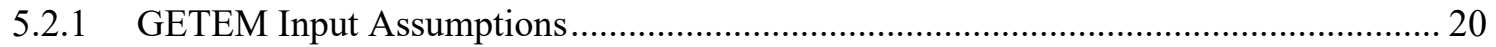

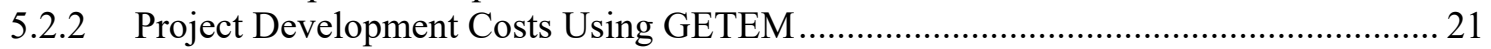

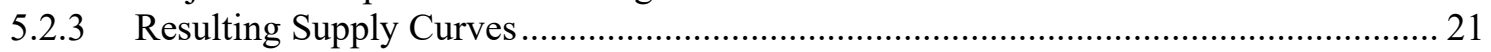

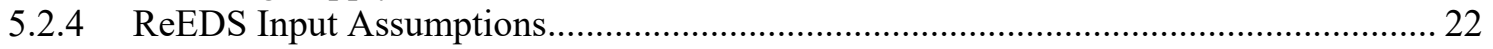

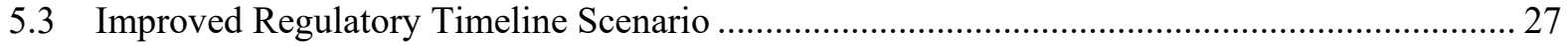

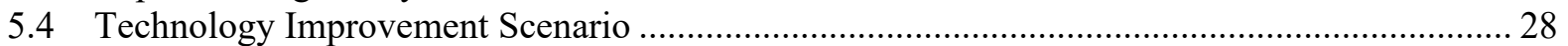

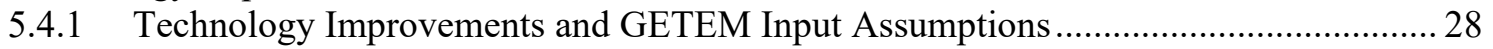

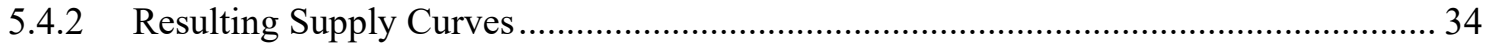

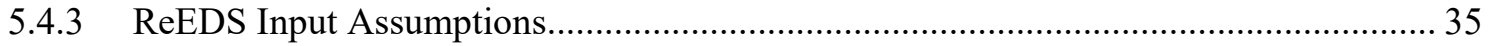

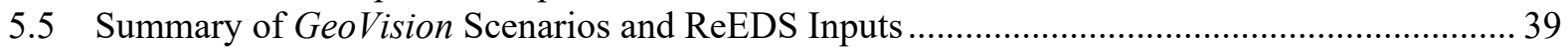

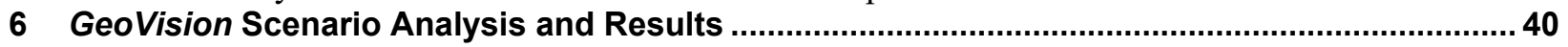

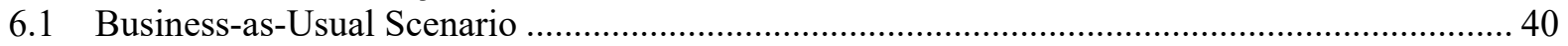

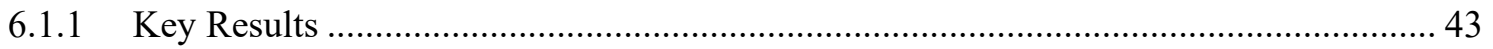

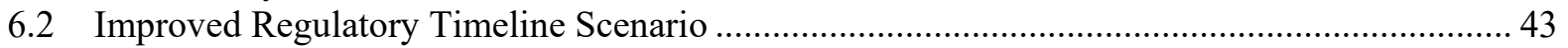

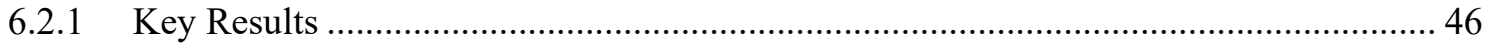

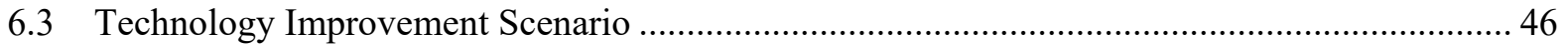

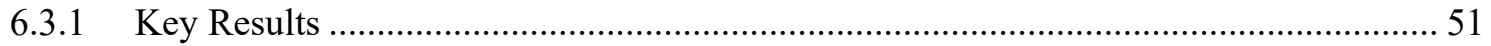

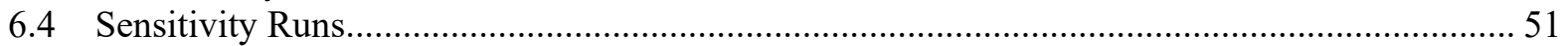

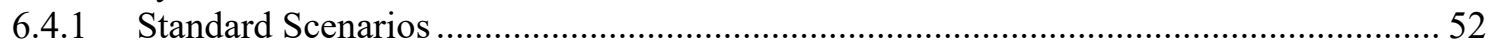

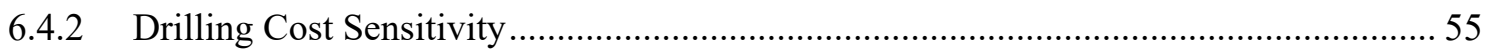

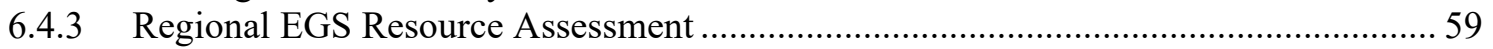

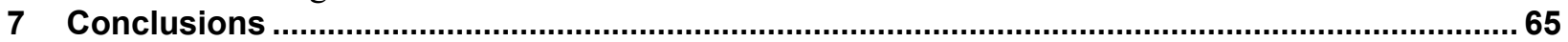

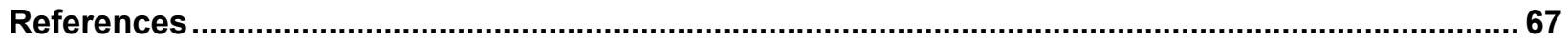

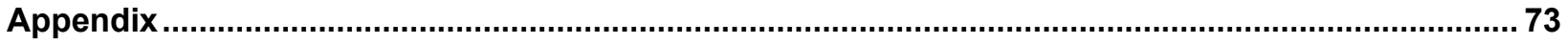




\section{List of Figures}

Figure ES-1. Installed geothermal capacity by year for GeoVision scenarios ..........................................vii

Figure 1. Historic annual electricity generation $(\mathrm{GWh})$ and installed net summer capacity (MW) for

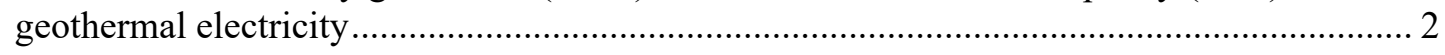

Figure 2. Current and planned U.S. geothermal nameplate capacity by state......................................... 3

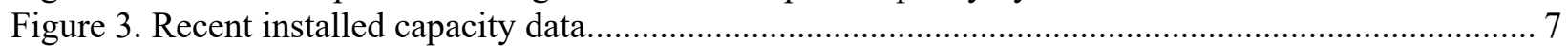

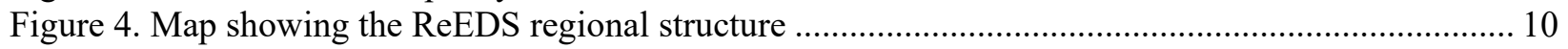

Figure 5. Schematic of GeoVision workflow for modeling electricity generation ................................. 13

Figure 6. Geothermal supply curve for the GeoVision BAU scenario................................................... 22

Figure 7. Diagram of perceived geothermal project risk and cumulative investment costs over time ....... 24

Figure 8. Cost curves used in the GeoVision study (Lowry et al. 2017a) relative to previous well cost

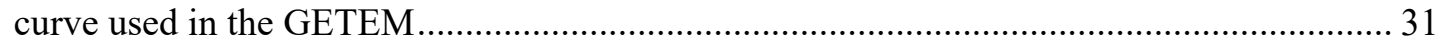

Figure 9. Geothermal supply curve for the GeoVision TI scenario ....................................................... 35

Figure 10. Installed geothermal capacity by year for the BAU scenario ............................................. 40

Figure 11. Cumulative installed capacity by year for all technologies in ReEDS for the BAU scenario ... 41

Figure 12. Annual electricity generation by year for all technologies in ReEDS for the BAU scenario .... 42

Figure 13. Map of installed geothermal capacity by ReEDS BAA in 2050 for the BAU scenario ............ 42

Figure 14. Installed geothermal capacity by year for the IRT scenario ................................................ 44

Figure 15. Cumulative installed capacity by year for all technologies in ReEDS for the IRT scenario..... 44

Figure 16. Annual electricity generation by year for all technologies in ReEDS for the IRT scenario...... 45

Figure 17. Map of installed geothermal capacity by ReEDS BAA in 2050 for the IRT scenario ..............46

Figure 18. Installed geothermal capacity by year for the TI scenario .................................................... 47

Figure 19. Cumulative installed capacity by year for all technologies in ReEDS for the TI scenario........ 48

Figure 20. Annual electricity generation by year for all technologies in ReEDS for the TI scenario ........ 48

Figure 21. Annual generation (MWh) from equivalent 100-MW solar photovolatic, wind, and geothermal power plants based on average capacity factors.................................................................... 49

Figure 22. Generation by year for renewable energy technologies in the DOE Office of Energy Efficiency and Renewable Energy portfolio under the GeoVision TI scenario ..................................... 50

Figure 23. Map of installed geothermal capacity by ReEDS BAA in 2050 for the TI scenario................ 51

Figure 24. Total installed geothermal capacity for the ReEDS Standard Scenarios assuming the GeoVision TI case

Figure 25. Standard scenarios using the GeoVision TI scenario with highest geothermal electricity generation capacity deployment compared to the Mid-case scenario using all the GeoVision

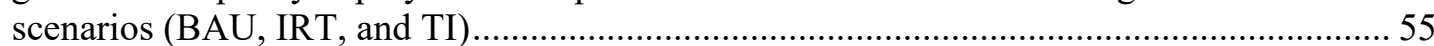

Figure 26. TI scenario deep EGS supply curves using drilling cost curves that assume different levels of

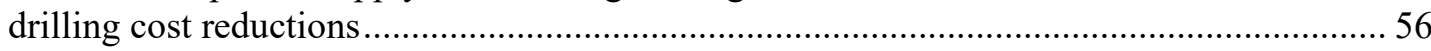

Figure 27. Total installed geothermal capacity for the TI scenario assuming different drilling cost curves

Figure 28. Installed deep EGS geothermal capacity for the TI scenario assuming different drilling cost

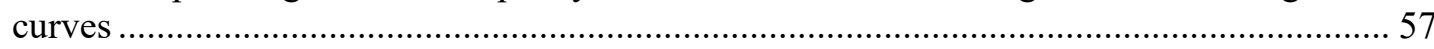

Figure 29. Total installed geothermal capacity for the TI scenario assuming an improved construction timeline that reduces the project development times by 1 year ............................................ 59

Figure 30. Comparison of SMU temperature estimates at a depth of $3.5 \mathrm{~km}$ (left) and temperature estimates at $3 \mathrm{~km}$ from a detailed regional study of the Cascades region.

Figure 31 . Temperature estimates at a depth of $3 \mathrm{~km}$ from a regional study of the Great Basin..............

Figure 32. Supply curves for deep EGS resources using the TI scenario and the impact of using regional EGS resource potential data. Costs use both the Ideal and Intermediate 1 drilling cost curves. 
Figure 33. Comparison of total installed geothermal capacity projections showing the impact of using EGS resource potential values from regional maps in the Cascades and Great Bain vs. national maps

\section{List of Tables}

Table F-1. Guide to Technical Research Documents Providing the Basis of the GeoVision Analysis ......... i Table ES-1. Summary of Geothermal Resources Available (in $\mathrm{MW}_{\mathrm{e}}$ ) in ReEDS for Different GeoVision Scenarios

Table ES-2. Summary of GeoVision Analysis Electric-Sector Scenarios Assumptions..............................vi

Table 1. List of Currently Installed Geothermal Power Plants ${ }^{\mathrm{a}}$ (as of 2015) and Names of Corresponding Identified Hydrothermal Sites from USGS 2008 Geothermal Resource Assessment (Williams et al. 2008)...

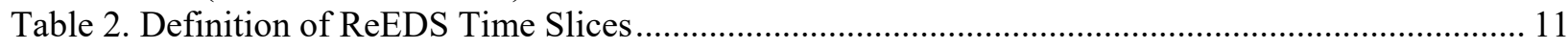

Table 3. Updated Deep EGS Electricity Generation Potential $\left(\mathrm{MW}_{\mathrm{e}}\right)$ for the Continental United States

Binned by Temperature and Depth Intervals .................................................................... 18

Table 4. Summary of Geothermal Resources Available (in $\mathrm{MW}_{\mathrm{e}}$ ) in ReEDS for Different GeoVision

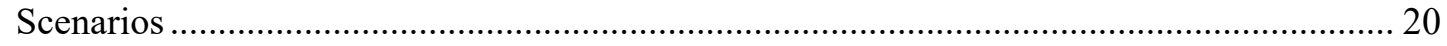

Table 5. Summary of Financing Costs and Percentage Spending by Phase for Hydrothermal and EGS projects and Resulting Overall Project WACC.................................................................. 25

Table 6. Breakdown of Project Capital Expenditures by Year for BAU Hydrothermal and EGS Scenarios

Table 7. Breakdown of Project Capital Expenditures by Year for IRT Scenario: Hydrothermal and EGS

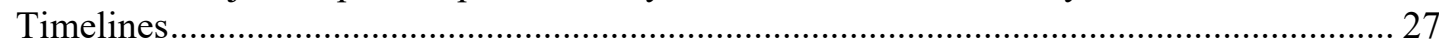

Table 8. Summary of Changes to BAU GETEM Inputs for TI Scenario ................................................2 29

Table 9. List of Installed Hydrothermal Power Plants Using Binary Plant Technology with High-

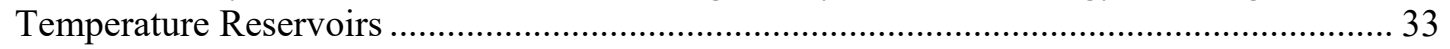

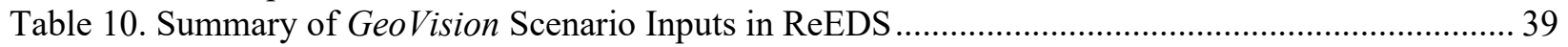

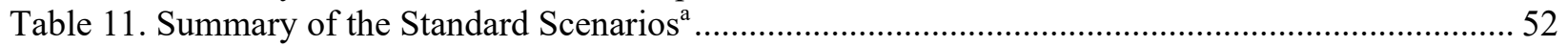

Table 12. Comparison of EGS Resource Potential Estimates for the Great Basin from GeoVision Deep EGS Resource Potential at $3.5 \mathrm{~km}$ vs. from Analysis of Regional Great Basin Temperature Map (Coolbaugh 2005) at $3 \mathrm{~km}$ 62

Table A-1. GETEM Inputs for BAU and IRT GeoVision Scenarios ${ }^{\mathrm{a}}$.................................................. 73

Table A-2. Summary of GETEM Input Changes for TI Scenario ${ }^{\mathrm{a}}$.......................................................... 80 


\section{Introduction}

This report describes the research conducted by the Potential to Penetration Task Force in support of the U.S. Department of Energy (DOE) Geothermal Vision Study (GeoVision: Harnessing the Heat Beneath Our Feet [DOE 2019]). The Potential to Penetration Task Force, as the name implies, was responsible for determining the potential amount of geothermal electricity generation capacity that could be deployed under future scenarios considered in the GeoVision study. The GeoVision study considers two types of geothermal resources for electricity generation: conventional hydrothermal resources and enhanced geothermal systems (EGS). The GeoVision study looks at three primary scenarios for evaluating the future potential of geothermal electricity generation in the United States:

- Business-as-Usual (BAU): assumes that the geothermal industry continues on its current trajectory

- Improved Regulatory Timeline (IRT): assumes an improved regulatory environment leading to accelerated geothermal permitting processes and development timeline

- Technology Improvement (TI): assumes a future where technology advances, cost reductions, and favorable financing options reduce the cost of geothermal technologies; includes IRT assumptions.

Like other DOE vision studies, this study uses the Regional Energy Deployment System (ReEDS) model to simulate electricity generation capacity deployment for each scenario through the year 2050 .

The report begins with a summary of the current U.S. geothermal electricity generation market and its likely future trajectory. Next, the models and methodology used by the task force are described. The electricity generation resource potential of hydrothermal and EGS resources and the data sources and assumptions used to develop them is discussed. The inputs and assumptions used for the GeoVision scenarios are presented, along with the resulting electricity generation supply curves that serve as inputs for the ReEDS model. Finally, the model results for each scenario are shown and discussed. Additional sensitivity runs not included in the main GeoVision report are included here. The report ends with a conclusion section that summarizes the main results and insights from the study. 


\section{U.S. Geothermal Electric Power Industry}

\subsection{Current Geothermal U.S. Market Status}

The current geothermal U.S. market status and industry trends were determined by looking at the historical growth rates for installed capacity and generation for geothermal electricity. Historical installed capacity and generation from geothermal installations are shown in Figure 1. Data for Figure 1 are exclusively from the U.S. Energy Information Administration (EIA), although multiple EIA publications were used to compile the information. Geothermal electricity generation is a relatively mature industry, especially compared to some other renewable energy (RE) industries. The first geothermal power plant in the United States was installed at the Geysers, California, in 1960. Growth has been steady since then, and as of 2016, 3,812 MW of installed nameplate geothermal capacity provide an average of 2,542 $\mathrm{MW}$ of net summer capacity to the grid $^{1}$ and produce $15,920 \mathrm{GWh}$ of electricity annually (Figure 1). Geothermal net summer capacity is projected to exceed 2,900 MW by 2022 .

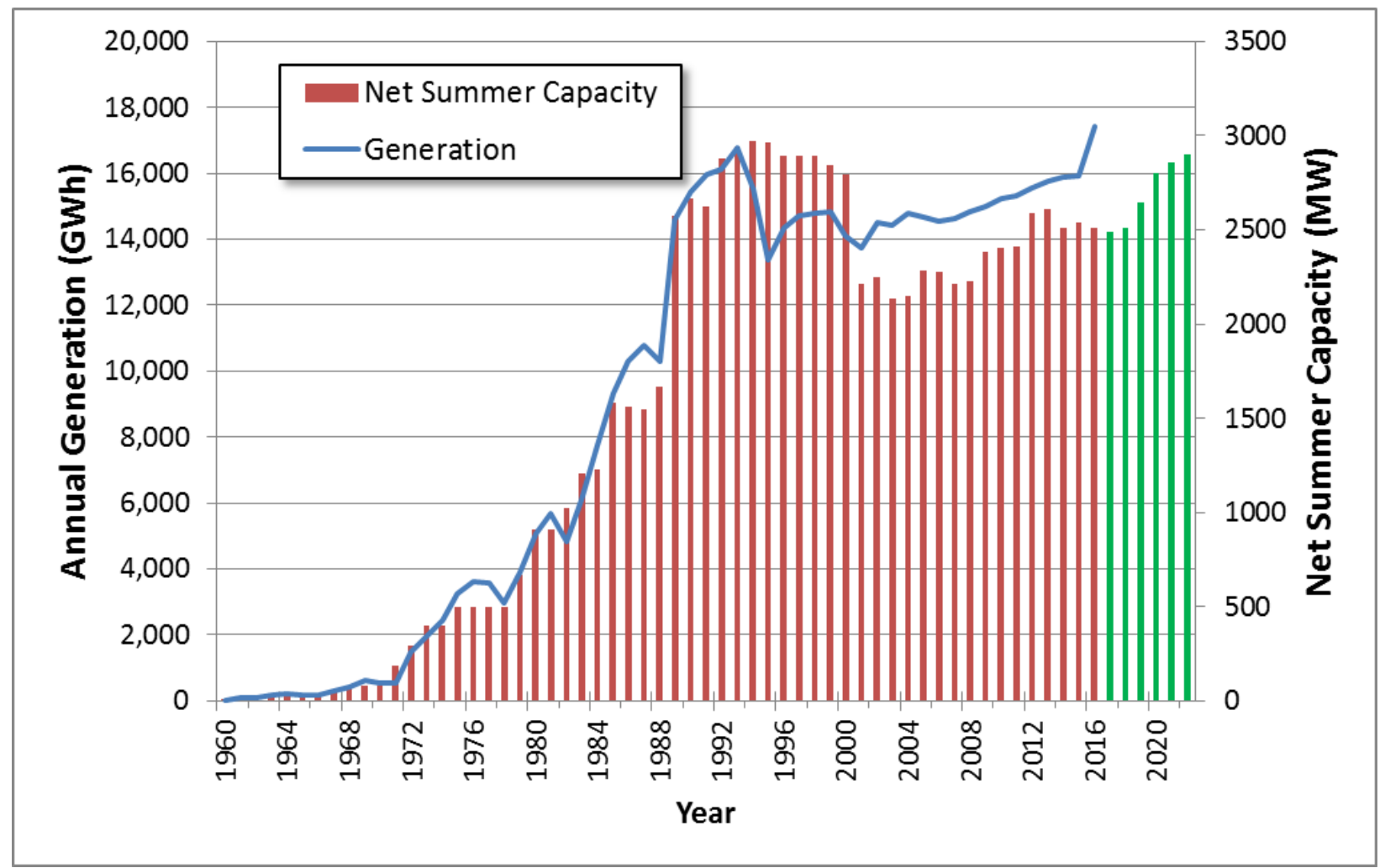

Figure Note: The decrease in net summer capacity from 2000 to 2001 reflects a combination of retirements and de-rating of some power plants at The Geysers geothermal field.

Figure 1. Historic annual electricity generation (GWh) and installed net summer capacity (MW) for geothermal electricity (EIA 2017a, Table 7.2b; EIA 2011, Table 8.11b; EIA 2016a; EIA 2017b, Table 6.2.B and Table 6.5). The green bars show projected growth.

\footnotetext{
${ }^{1}$ The nameplate and net capacities differ greatly because geothermal power plants provide their own power for operating the plant, which includes power to operate pumps that produce and inject geothermal brines from the subsurface. Additionally, the net capacity in summer is less than the optimal net capacity because plants that use air cooling do not operate as efficiently at high ambient temperatures
} 
The United States is the largest generator of geothermal electricity in the world. Current and planned nameplate capacities for geothermal power generation by state are shown in Figure 2, and the names and installed capacities of individual current geothermal power plants are listed in Table 1. Geothermal electric power plants are concentrated in the western United States, with the vast majority residing in California and Nevada. California alone has more installed geothermal capacity than any other country in the world (Bertani 2015). Because of this, geothermal plays a larger-than-typical role in electric grids in the West. Although geothermal energy accounts for only $0.4 \%$ of total electricity generation nationwide, it makes up $6 \%$ of total generation in California and $8 \%$ in Nevada (EIA 2016b).

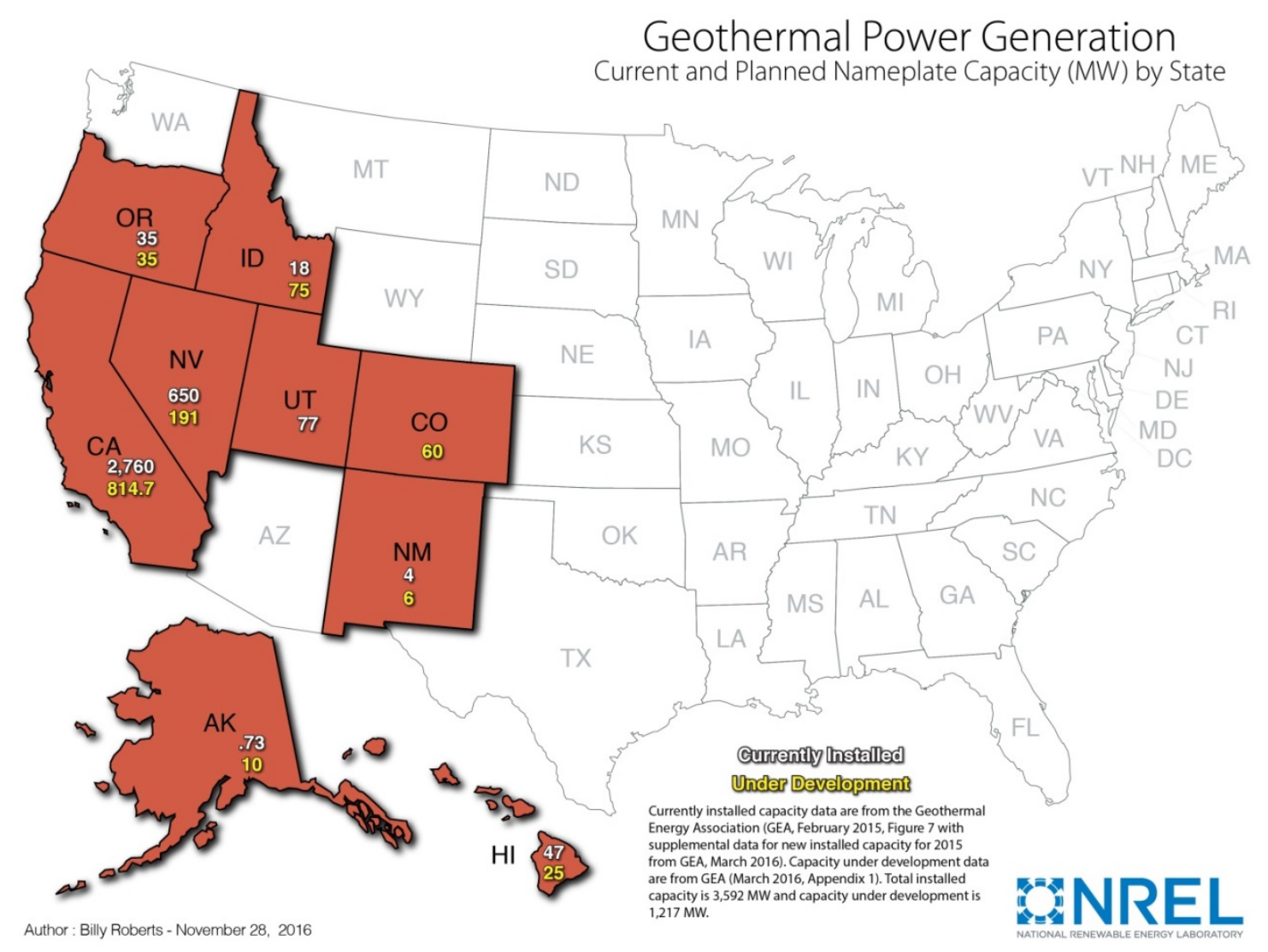

Source: Graphic from NREL; data from GEA 2016

Figure 2. Current and planned U.S. geothermal nameplate capacity by state 
Table 1. List of Currently Installed Geothermal Power Plants ${ }^{a}$ (as of 2015) and Names of Corresponding Identified Hydrothermal Sites from USGS 2008 Geothermal Resource Assessment

(Williams et al. 2008)

\begin{tabular}{|c|c|c|c|}
\hline Plant Name & $\begin{array}{l}\text { Corresponding USGS } 2008 \\
\text { Identified Hydrothermal Site }\end{array}$ & State & $\begin{array}{l}\text { Installed } \\
\text { Summer } \\
\text { Capacity (MW) }\end{array}$ \\
\hline Aidlin Geothermal Power Plant & Geysers & CA & 18 \\
\hline Amedee Geothermal Venture I & Amedee & CA & 2.2 \\
\hline Beowawe Power & Beowawe HS & NV & 14.1 \\
\hline Blundell & Roosevelt HS & UT & 34 \\
\hline Bottle Rock Power & Geysers & $\mathrm{CA}$ & 10 \\
\hline Brady & Brady HS & NV & 26.8 \\
\hline Calistoga Power Plant & Geysers & CA & 100 \\
\hline CE Leathers & Salton Sea Area & CA & 42 \\
\hline CE Turbo LLC & Salton Sea Area & CA & 10.9 \\
\hline Chena & Chena & AK & 0.5 \\
\hline Coso Energy Developers & Coso Area & $\mathrm{CA}$ & 67.8 \\
\hline Coso Finance Partners & Coso Area & $\mathrm{CA}$ & 81.2 \\
\hline Coso Power Developers & Coso Area & CA & 80.3 \\
\hline Del Ranch Company & Salton Sea Area & CA & 42 \\
\hline Desert Peak Power Plant & Desert Peak & NV & 17.5 \\
\hline Don A Campbell 1 Geothermal & Not Included & NV & 11.5 \\
\hline Don A Campbell 2 Geothermal & Not Included & NV & 16.2 \\
\hline Elmore Company & Salton Sea Area & $\mathrm{CA}$ & 42 \\
\hline Enel Cove Fort & $\begin{array}{l}\text { Cove Fort - Sulphurdale - } \\
\text { Liquid }\end{array}$ & UT & 25 \\
\hline ENEL Salt Wells LLC & Not Included & NV & 20.2 \\
\hline Galena 2 Geothermal Power Plant & Steamboat Hills & NV & 9.2 \\
\hline Galena 3 Geothermal Power Plant & Steamboat Hills & NV & 15.8 \\
\hline Geo East Mesa II & East Mesa (Shallow) & CA & 13.5 \\
\hline Geo East Mesa III & East Mesa (Shallow) & CA & 16.7 \\
\hline Geothermal 1 & Geysers & $\mathrm{CA}$ & 52 \\
\hline Geothermal 2 & Geysers & CA & 78.1 \\
\hline Geysers Unit 5-20 & Geysers & CA & 704 \\
\hline Heber Geothermal & Heber Shallow & CA & 45.5 \\
\hline Jersey Valley Geothermal Power Plant & Not Included & NV & 12.5 \\
\hline John L. Featherstone Plant & Salton Sea Area & CA & 49.9 \\
\hline Lightning Dock Geothermal HI-01, LLC & Lightning Dock & NM & 1.6 \\
\hline
\end{tabular}




\begin{tabular}{|c|c|c|c|}
\hline Plant Name & $\begin{array}{l}\text { Corresponding USGS } 2008 \\
\text { Identified Hydrothermal Site }\end{array}$ & State & $\begin{array}{l}\text { Installed } \\
\text { Summer } \\
\text { Capacity (MW) }\end{array}$ \\
\hline Mammoth Pacific I & Long Valley Shallow & $\mathrm{CA}$ & 6.4 \\
\hline Mammoth Pacific II & Long Valley Shallow & $\mathrm{CA}$ & 21.6 \\
\hline McGinness Hills & Not Included & NV & 60 \\
\hline Neal Hot Springs Geothermal Project & Neal HS & OR & 17.7 \\
\hline NGP Blue Mountain I LLC & Blue Mountain & NV & 39 \\
\hline North Brawley Geothermal Plant & North Brawley & $\mathrm{CA}$ & 64 \\
\hline Ormesa I & East Mesa (Shallow) & $\mathrm{CA}$ & 21.4 \\
\hline Ormesa IH & East Mesa (Shallow) & CA & 4.8 \\
\hline Ormesa II & East Mesa (Shallow) & CA & 20 \\
\hline Paisley Geothermal Generating Plant & Summer Lake Hot Springs & OR & 1.8 \\
\hline Patua Geothermal Project Phase 1A & $\begin{array}{l}\text { Fernley area (Patua } \\
\text { HS/Hazen) }\end{array}$ & NV & 30 \\
\hline Ples I & Long Valley Shallow & CA & 12 \\
\hline Puna Geothermal Venture I & Puna Geothermal Venture & $\mathrm{HI}$ & 43 \\
\hline Raft River Geothermal Power Plant & Raft River & ID & 10 \\
\hline Richard Burdett Geothermal & Steamboat Hills & NV & 15.6 \\
\hline Salton Sea Power Gen Co - Unit 1 & Salton Sea Area & CA & 10 \\
\hline Salton Sea Power Gen Co - Unit 2 & Salton Sea Area & CA & 16.1 \\
\hline Salton Sea Power Gen Co - Unit 3 & Salton Sea Area & CA & 47.5 \\
\hline Salton Sea Power Gen Co - Unit 4 & Salton Sea Area & CA & 44 \\
\hline Salton Sea Power LLC - Unit 5 & Salton Sea Area & CA & 46 \\
\hline San Emidio & San Emidio Desert area & NV & 6.3 \\
\hline Second Imperial Geothermal & Heber Shallow & CA & 54.8 \\
\hline Soda Lake Geothermal No I II & Soda Lake Area & NV & 11.3 \\
\hline Sonoma California Geothermal & Geysers & $\mathrm{CA}$ & 50 \\
\hline Steamboat 1 & Steamboat Hills & NV & 6.3 \\
\hline Steamboat 1A Power Plant & Steamboat Hills & NV & 1.8 \\
\hline Steamboat Hills LP & Steamboat Hills & NV & 7.6 \\
\hline Steamboat II & Steamboat Springs & NV & 10.8 \\
\hline Steamboat III & Steamboat Springs & NV & 10.8 \\
\hline Stillwater Facility & Stillwater Area & NV & 40.4 \\
\hline Terra-Gen Dixie Valley & Dixie Valley Geothermal Field & NV & 56 \\
\hline Thermo No 1 & Thermo Hot Springs & UT & 14 \\
\hline Tuscarora Geothermal Power Plant & $\begin{array}{l}\text { Hot Sulphur Springs - } \\
\text { Tuscarora }\end{array}$ & NV & 18 \\
\hline
\end{tabular}




\begin{tabular}{llll}
\hline Plant Name & $\begin{array}{l}\text { Corresponding USGS 2008 } \\
\text { Identified Hydrothermal Site }\end{array}$ & State & $\begin{array}{l}\text { Installed } \\
\text { Summer } \\
\text { Capacity (MW) }\end{array}$ \\
\hline Vulcan-BN Geothermal Power Company & Salton Sea Area & CA & 29.5 \\
\hline Wabuska & Wabuska Hot Springs & NV & 2.5 \\
West Ford Flat Power Plant & Geysers & CA & 30 \\
\hline Grand Total & & & $\mathbf{2 , 5 4 2}$ \\
\hline
\end{tabular}

a Data from EIA 2016c

Figure 2 shows that there are 1,217 MW of geothermal projects under development, but many of these projects are stuck in early phases awaiting financing or power purchase agreements, according to the Geothermal Energy Administration (GEA 2016). Further, a study by the National Renewable Energy Laboratory (NREL) found that approximately $1.7 \mathrm{GW}$ of geothermal projects are stalled because of various barriers such as financing, permitting, transmission, and acquisition of power purchase agreements (Wall and Young 2016).

\subsection{U.S. Geothermal Market Trajectory}

As Figure 1 shows, the geothermal industry grew rapidly during the 1970s and 1980s, but it leveled off somewhat during the 1990s. After a decrease in net summer capacity from 2000 to 2001 from a combination of retirements and de-rating of some power plants at The Geysers geothermal field, the geothermal industry has grown steadily at a rate of about $2 \%$ per year. This current growth rate was determined via a "best fit" calculation to historical production capacity and current projections. Data from 2001 to the present were used because they are recent and relatively stable.

The best fit to annual growth varies depending on the time frame and reference year chosen. For example, a calculation of moving averages during time frames from 1-10 years from 2001-2022 shows that the percentage growth rate can vary greatly from one year to another. A least-squares best fit for percentage growth rate also varied significantly depending on the time frames chosen. For GeoVision, a 2\% annual growth rate was chosen based on input from industry and Visionary Team $^{2}$ members as representative of what the industry could achieve during the next 30 years. Figure 3 shows the fit of an assumed $2 \%$ annual growth rate to recent installed capacity data and near future projections. This rate corresponds to about $50 \mathrm{MW}$ per year of new installed net summer capacity and would result in approximately 5,120 MW of new installed geothermal capacity by 2050 .

\footnotetext{
2 The GeoVision Visionary Team is a set of 21 industry peers that advised the GeoVision task forces and reviewed analysis inputs, assumptions, and results over the course of the GeoVision process.
} 


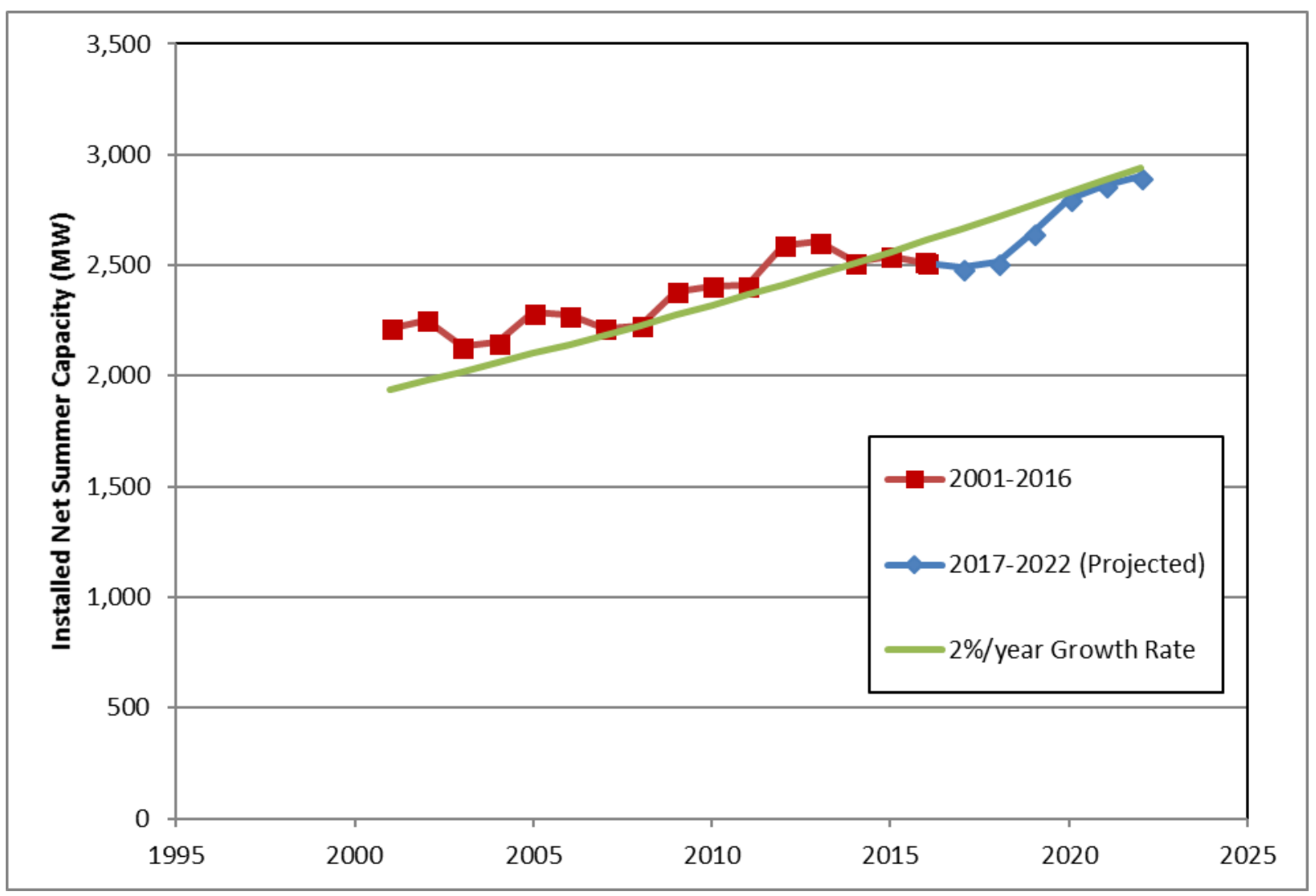

Figure 3. Recent installed capacity data.The green line shows a growth rate of $2 \%$ per year. 


\section{GeoVision Model Summaries and Assessment Methods}

The GeoVision study made use of existing models in assessing the potential future deployment and impact of electricity generating geothermal technologies. The Geothermal Electricity Technology Evaluation Model (GETEM) was used to estimate the costs of developing geothermal resources for electric power generation under various technology scenarios including capital costs and operation and maintenance (O\&M) costs. Other cost details and impacts, such as financing and project timelines, were implemented in the Regional Energy Deployment System (ReEDS) model. ReEDS modeled the capacity deployment of geothermal technologies on the U.S. electric grid.

\subsection{Geothermal Electricity Technology Evaluation Model (GETEM)}

GETEM is a Microsoft Excel-based tool that estimates the cost of geothermal electricity generation from hydrothermal and EGS resources using either a flash-steam or air-cooled binary power plant based on specified resource parameters. GETEM is a deterministic model that uses a bottom-up analysis to calculate the levelized cost of energy (LCOE) and capital costs of hydrothermal and EGS projects based on a set of user-specified variables. The user defines the resource characteristics (e.g., hydrothermal or EGS, temperature, depth), project details (e.g., plant type and size, pump types, well productivity), and other required parameters. GETEM then calculates the individual component costs associated with each phase of the project - such as exploration, well field development, power plant construction, and O\&M costs - based on userdefined cost inputs, embedded cost and system performance correlations, and cost indices to account for the year the project is developed. All costs are in U.S. dollars. The inputs and calculated costs used to determine the LCOE are "overnight" 3 values. GETEM's primary output is the LCOE for the project, but it also provides the total capital costs and a breakdown of capital costs and LCOE contributions from the project phases. GETEM was designed to examine the impact of technology improvements and cost reductions on geothermal power costs. The user can specify technology or cost improvements in the model input parameters, and GETEM quantifies the changes in project costs in a side-by-side comparison of the two cases.

GETEM was used to estimate costs for all geothermal electricity generation resources considered in this study. For this study, the 2016 GETEM version (DOE 2016) was used and modified as needed. A baseline year of 2015 (the most current available in GETEM at the time) was assumed. Given the large number of sites that were evaluated for this study, the GETEM inputs for each site were limited to the resource temperature, depth, technology type (hydrothermal or EGS), plant type (binary or flash), and plant size. With these specified, a set of defined inputs for the scenario being evaluated were applied. The resulting overnight capital costs and O\&M costs were recorded and used as inputs to the ReEDS capacity deployment model. A detailed description of GETEM and how to use it is provided in the GETEM User Manual (Mines 2016).

\footnotetext{
3 "Overnight" capital costs is a term used to describe the cost of building a power plant if it were built overnight, i.e., if no interest was incurred during the construction period. It is often used when comparing the economic feasibility of building various plants.
} 


\subsection{ReEDS Model}

\subsubsection{Description}

The ReEDS model (NREL 2018b) is a capacity expansion and dispatch model for the contiguous U.S. electric power sector that relies on system-wide, least-cost optimization to estimate the type and location of future generation and transmission capacity. To represent the competition among the many electricity generation, storage, and transmission options throughout the contiguous United States, ReEDS identifies the cost-optimal mix of technologies that meet regional electric power demand requirements based on grid reliability (reserve) requirements, technology resource constraints, and policy constraints. This cost minimization routine is performed for each of 21 2-year periods from 2010-2050. Some of the major outputs of ReEDS include the amount and location of generator capacity and annual generation from each technology, storage capacity expansion, transmission capacity expansion, total electric sector costs, electricity price, fuel demand and prices, and carbon dioxide $\left(\mathrm{CO}_{2}\right)$ emissions.

Within ReEDS, load is served and power plants are constructed in 134 model balancing authority areas (BAAs) that overlay the contiguous United States, shown in Figure 4. The model BAAs are not designed to represent or align perfectly with real BAAs; instead, they represent model nodes where electricity supply and demand is balanced. The model's transmission network connects those BAAs and comprises roughly 300 representative lines across the three asynchronous interconnections: the Western Interconnection, the Eastern Interconnection, and the Electric Reliability Council of Texas. The BAAs also respect state boundaries, allowing the model to represent individual state regulations and incentives. The BAAs are further subdivided into 356 resource regions to describe wind and solar resource supply and quantity with more spatial granularity than the BAA regions alone allow. Additional geographical layers include 3 electricity interconnects, 18 model regional transmission operators designed after existing regional transmission operators, 19 North American Electric Reliability Corporation reliability subregions, and 9 census divisions as defined by the U.S. Census Bureau.

In the ReEDS model, load is served and operational reliability is maintained over 17 time slices in each model year, as defined in Table 2. Each of the four seasons is modeled as a representative day of four time slices: overnight, morning, afternoon, and evening. The 17th time slice is a summer "superpeak" representing the top 40 hours of summer load. Although this schedule allows the model to capture seasonal and diurnal variations in demand, wind, and solar profiles, it is insufficient to address some of the shorter timescale challenges associated with unit commitment and economic dispatch, especially under scenarios with high penetration levels of variable generation (e.g., wind and solar). To more accurately represent how renewable generation grid integration might affect investment and dispatch decisions, the ReEDS model includes statistical parameters designed to address intra-time-slice variability and uncertainty of wind and some other renewable resources. The major conventional thermal generating technologies represented in ReEDS include simple and combined-cycle natural gas, several varieties of coal, oil/gas steam, and nuclear. In addition to representing these technologies, ReEDS includes many renewable technologies using several kinds of resources, including geothermal, hydropower, biopower, wind, and solar. Electricity storage technologies include pumped hydropower storage, compressed-air energy storage, batteries, and concentrating solar power with thermal storage. 


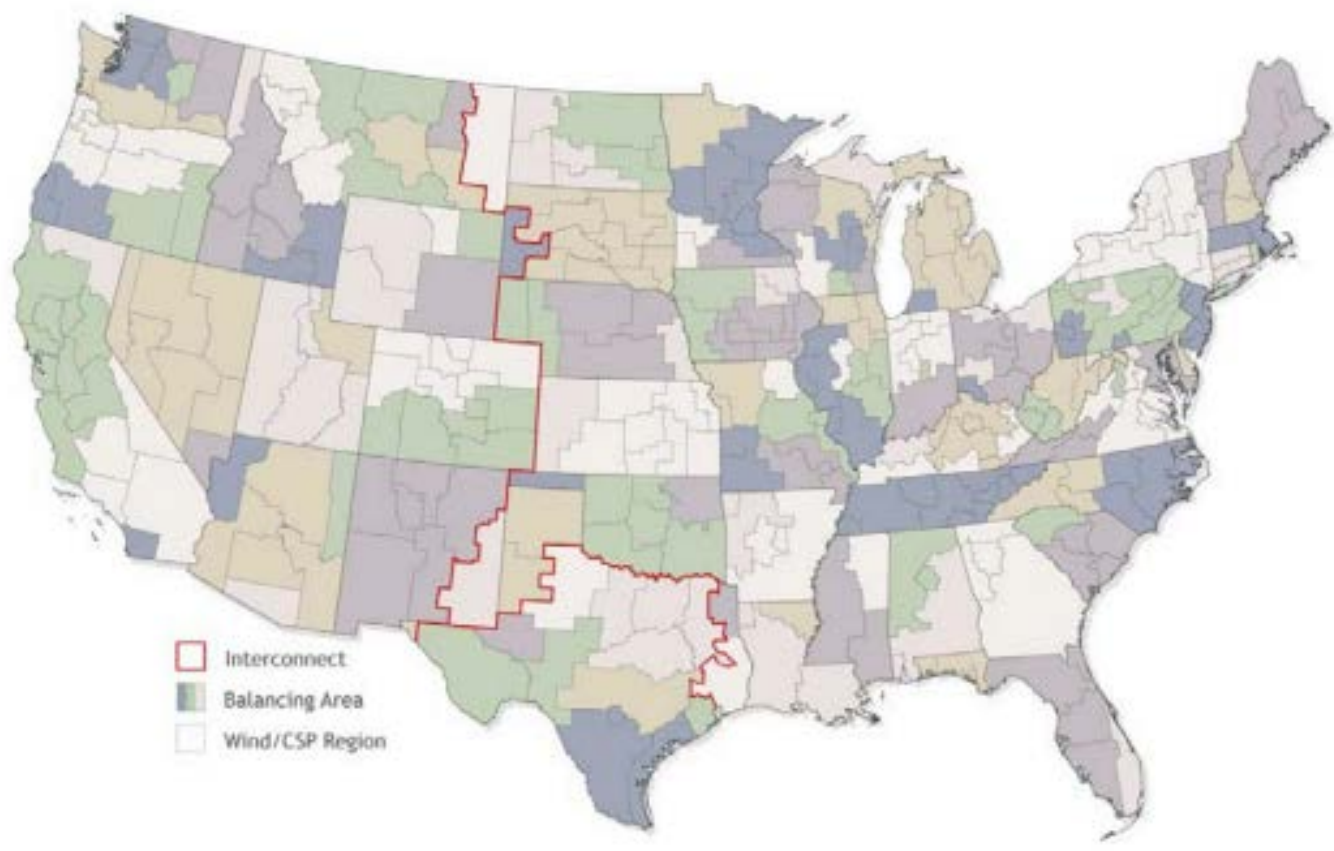

Figure 4. Map showing the ReEDS regional structure. ReEDS includes 3 interconnections, 134 model BAAs, and 356 wind and concentrating solar power resource regions.

ReEDS is structured as a sequence of 21 individual but interacting optimization problems, each representing a 2-year period from 2010-2050. Each ReEDS scenario launches with an infrastructure base representing installed generation and transmission capacity as of December 31, 2010. New infrastructure that came online from 2011 through the present is prescribed into the ReEDS system in the proper model year, and recently decommissioned units are removed in the same way. Similarly, high-likelihood, pending generators are included as prescribed builds in near-term future years, and scheduled retirements are set to be removed from the fleet as appropriate. Additionally, ReEDS inputs include an equipment lifetime for each technology that is used to retire capacity as it ages. In certain types of scenarios, some existing stock might be underused because of, for example, high fuel prices or emissions standards. ReEDS facilitates "economic" retirements of underused coal capacity if usage (i.e., capacity factor) falls below a certain threshold. Economic coal retirement in ReEDS is applied starting in 2022 with an increasingly stringent threshold of underuse through 2040.

ReEDS tracks emissions of $\mathrm{CO}_{2}$, sulfur dioxide $\left(\mathrm{SO}_{2}\right)$, nitrogen oxides ( $\mathrm{NOx}$ ), and mercury from both generators and storage technologies. Caps can be imposed at the national level on any of these emissions, and constraints can be applied to impose caps at state or regional levels.

Annual electric loads and fuel price supply curves are exogenously specified to define the system boundaries for each period of the optimization. The source for most load and fuel inputs is the most recent Annual Energy Outlook (AEO) from the EIA. Coal and uranium fuels are assumed to be price-inelastic; ReEDS can demand as much of those fuels as it likes at the AEO-specified price. However, natural gas prices are defined by regional supply curves so that the prices respond to changes in electric sector demand for gas. 
Table 2. Definition of ReEDS Time Slices

\begin{tabular}{lllll}
\hline Time-Slice & $\begin{array}{l}\text { Number of } \\
\text { Hours per Year }\end{array}$ & Season & Time of Day & Period \\
\hline H1 & 736 & Summer & Overnight & 10 p.m. to 6 a.m. \\
H2 & 644 & Summer & Morning & 6 a.m. to 1 p.m. \\
H3 & 328 & Summer & Afternoon & 1 p.m. to 5 p.m. \\
H4 & 460 & Summer & Evening & 5 p.m. to 10 p.m. \\
H5 & 488 & Fall & Overnight & 10 p.m. to 6 a.m. \\
H6 & 427 & Fall & Morning & 6 a.m. to 1 p.m. \\
H7 & 244 & Fall & Afternoon & 1 p.m. to 5 p.m. \\
H8 & 305 & Fall & Evening & 5 p.m. to 10 p.m. \\
H9 & 960 & Winter & Overnight & 10 p.m. to 6 a.m. \\
H10 & 840 & Winter & Morning & 6 a.m. to 1 p.m. \\
H11 & 480 & Winter & Afternoon & 1 p.m. to 5 p.m. \\
H12 & 600 & Winter & Evening & 5 p.m. to 10 p.m. \\
H13 & 736 & Spring & Overnight & 10 p.m. to 6 a.m. \\
H14 & 644 & Spring & Morning & 6 a.m. to 1 p.m. \\
H15 & 368 & Spring & Afternoon & 1 p.m. to 5 p.m. \\
H16 & 460 & Spring & Evening & 5 p.m. to 10 p.m. \\
H17 & 40 & Summer & Peak & 40 highest demand \\
& & & & hours of H3 \\
\hline
\end{tabular}

\subsubsection{General Inputs and Assumptions}

ReEDS models future capacity installations on grids for the contiguous United States based on projections of electricity demand and the cost of developing new generation capacity within and among regions. ReEDS is an optimization routine, and it selects capacity additions among the available electricity generating technologies that minimize system costs within the model constraints and requirements based on the technology and fuel costs that are provided by the user. For GeoVision, the Annual Technology Baseline (ATB [NREL 2018a]) was used to provide detailed cost and performance data (both current and projected) for non-geothermal renewable and conventional technologies. The ATB is a set of input assumptions updated annually by NREL to support and inform electric sector analysis in the United States. The products of this work include assessments of current and projected technology cost and performance through 2050 for renewable and conventional electricity generation technologies. The ATB includes Low, Mid, and High technology cost projections for renewable energy technology costs and performance based on values reported in public literature. GeoVision used 
the $2016^{4}$ version of the ATB (Cole, Kurup et al. 2016; NREL 2016) and assumes the Mid-case technology cost projections.

ReEDS also requires projections of electricity demand and fuel prices. NREL annually documents a diverse set of potential futures of the U.S. electricity sector that includes technology cost and performance assumptions from the ATB called the Standard Scenarios. The Standard Scenarios consist of a range of power sector scenarios that provide a quantitative examination of how ranges of values of specific inputs impact the development of the power sector (NREL 2018a). GeoVision used the 2016 version of the Standard Scenarios (Cole, Mai et al. 2016). The GeoVision study assumes the NREL Mid-case scenario for all modeling runs, unless otherwise noted. The Mid-case scenario is used in the Standard Scenario analysis as a reference case reflecting business-as-usual conditions. The default assumptions used in the Mid-case scenario reflect median or midline expectations for model inputs (e.g., reference case fuel prices and midcase technology costs) based on current information. It is used in this study for the same purpose to represent present and future costs of nongeothermal technologies. The Mid-case scenario uses the following assumptions:

- Electricity demand growth ${ }^{5}$ : AEO 2016 reference (EIA 2016d)

- Fuel prices: AEO 2016 reference (EIA 2016d)

- Electricity generation technology costs: 2016 ATB Mid-case projections

- Existing fleet retirement: lifetime retirements based on ABB Velocity Suite database (ABB 2016)

- Policy/regulatory environment: includes policies as of April 1, 2016, with the exception of the Clean Power Plan: the Clean Power Plant was not assumed to be in effect in the GeoVision ReEDS runs.

- Earth system feedbacks: no feedback because of changes in the climate.

The other Standard Scenarios are discussed and modeled in detail in Section 6.4.1.

\subsection{Model Relationships and Workflow}

Figure 5 illustrates the workflow and relationships among models and data flow used to model the electricity generation market. The methodology used for the GeoVision study closely follows the one described in Augustine (2011).

\footnotetext{
${ }^{4}$ The 2016 versions of the ATB and Standard Scenarios were the most recent data available at the time this analysis was performed. The 2018 ATB, published shortly before this report was written, use lower cost projections for some technologies (notably wind and solar technologies) that the 2016 ATB. Using the updated cost projections would make wind and solar technologies, and perhaps others, more competitive and likely result in lower geothermal deployment projections than those presented in this report. Geothermal cost projections will be incorporated into the ATB after publication of the GeoVision report and will likely be used in the 2019 Standard Scenarios, and can then be used to assess the impact of changes in non-geothermal technology cost projections on GeoVision results.

${ }^{5}$ The GeoVision study includes analysis and projections of geothermal heat pump deployment, which if realized simultaneously as the scenarios in this report could alter future electricity demand. Preliminary analysis found that the results from the geothermal heat pump model had negligible impact on ReEDS results, so the geothermal heat pump results were not incorporated into the ReEDS model in the final analysis.
} 


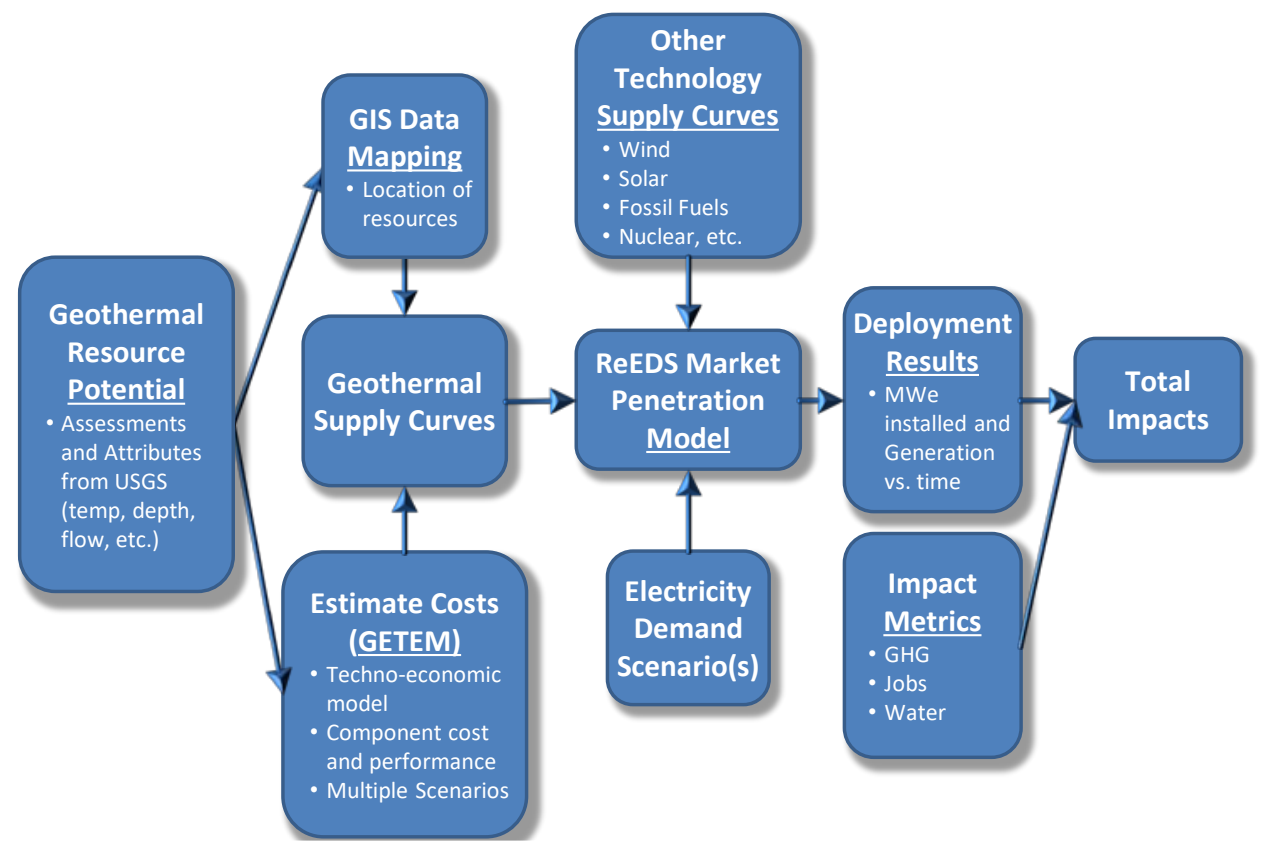

Figure 5. Schematic of GeoVision workflow for modeling electricity generation

The first step is developing the geothermal electricity generation supply curves. A supply curve is the combination of the technology resource potential and the cost to develop the resource. It shows how much of a resource is available and the cost of a given technology to develop that resource into a power plant to deliver electricity to the grid. When graphed as electricity generation capacity versus cost, it is a visual representation of the amount of resource available for development as a function of cost.

To develop the supply curves, first, the geothermal resource potential estimates are developed. A resource potential consists of estimates of the electricity generation capacity (in megawatts) of geothermal resources, includes the location of the resources - identified using geographic information system mapping - and provides at least the minimum amount of information about the resource attributes (nature and quality) needed to calculate the cost of developing the resource. For this study, supply curves for four types of geothermal resources were included: identified hydrothermal, undiscovered hydrothermal, near-hydrothermal field EGS (NF-EGS), and deep EGS. The selection of these four types of geothermal resources was based on available data and the techniques and technologies used to develop those resources. Resource potential development is discussed in detail in Section 4.

Next, the cost of developing these resources is estimated. The cost of developing each category of geothermal resource was estimated based on the resource characteristics, the technology components required to develop the resource, and any factors or assumptions included in the scenario under which the resource would be developed. This estimation requires a technoeconomic model of the cost of developing a power plant based on the cost and performance of a given technology. For the GeoVision study, this was performed using the GETEM. For the GETEM, the minimum resource attributes required to estimate the cost of development are resource temperature, depth, technology type (hydrothermal or EGS), plant type (binary or flash), and plant size. The cost and performance of the components depends on the scenario 
being evaluated. The outputs from GETEM used for capacity expansion modeling in ReEDS were overnight capital costs and O\&M costs. The inputs to GETEM for these scenarios are discussed in detail in Section 5.

Next, the resource potential and cost estimates are combined to create supply curves. These are then used as inputs to the ReEDS market penetration model. ReEDS uses overnight capital costs and O\&M costs values from GETEM. Other geothermal technology assumptions and values such as financing, construction time, and plant attributes are input directly into ReEDS.

ReEDS requires the same degree of knowledge about the cost and availability of all the electricity generation technologies included in the model as it does geothermal technologies. In other words, ReEDS also needs supply curves for all these technologies. Finally, ReEDS requires projections of electricity demand and fuel prices. For GeoVision, the 2016 ATB was used to provide other technology costs and fuel inputs and the 2016 NREL Standard Scenarios was used to provide electricity demand (see Section 3.2.2).

The result of the ReEDS modeling is a projection of installed capacity and annual electricity generation for all technologies by balancing authority. These data are used to generate the impacts of the GeoVision future scenarios on jobs, air quality emissions, and water use. More details on the impacts from the GeoVision scenarios can be found in Millstein et al. (2019). 


\section{Electricity Generation Resource Potential}

For this study, two types of geothermal resources were considered for electricity generation: hydrothermal and EGS. The hydrothermal resource consists of the naturally occurring geothermal sites used conventionally to produce electricity. The hydrothermal resource potential is based on the recently completed geothermal resource assessment of the United States performed by the U.S. Geological Survey (USGS) (Williams et al. 2008). The assessment divides the resources into identified sites and "undiscovered" resources. EGS are geothermal reservoirs that have been engineered to extract economic amounts of heat from geothermal resources that have low permeability and/or lack natural in-situ fluids for heat extraction. EGS technologies are still being developed and are not yet commercially available. At its most basic, EGS consists of pumping fluids into wells in a way that increases their ability to produce or circulate fluids. EGS offers the opportunity to access enormous amounts of thermal energy in the Earth by drilling wells and connecting them through a fracture network so that fluid can be circulated to harvest heat and produce electricity. EGS technologies are likely to be developed and deployed in stages, expanding from existing hydrothermal sites to greenfield sites. For this study, the EGS potential resource is divided into two groups: the NF-EGS resource and the deep EGS resource.

\subsection{Identified Hydrothermal Resources}

The USGS 2008 geothermal assessment (Williams et al. 2008) identified 241 moderate- and high-temperature $\left(>90^{\circ} \mathrm{C}\right)$ sites on private or accessible public land in the United States. The sites are concentrated entirely within 13 states in the western United States, Alaska, and Hawaii. The methodology used to estimate the recoverable energy from each site identified in the 2008 USGS assessment is similar to that used in the previous USGS Circular 790 assessment (Muffler 1979), and it is described in Williams, Reed, and Mariner (2008). Based on this analysis, the USGS 2008 resource assessment predicts a mean total of $9,057 \mathrm{MW}_{\mathrm{e}}$ of power generation potential from identified hydrothermal systems on private or accessible public lands, with a $95 \%$ probability of at least $3,675 \mathrm{MW}$ and a $5 \%$ probability of up to $16,457 \mathrm{MW}_{\mathrm{e}}$ of geothermal power generation potential.

The total mean value of 9,057 $\mathrm{MW}_{\mathrm{e}}$ for the recoverable electric power generation potential from the USGS 2008 assessment was adopted as the starting point for the identified hydrothermal resources. The site-specific data for the identified hydrothermal resources were obtained from the USGS (DeAngelo and Williams, 2010). A cutoff temperature of $110^{\circ} \mathrm{C}$ was adopted because cost estimates for resources at these low temperatures are prohibitively expensive. This results in the removal of 106 identified hydrothermal sites representing $460 \mathrm{MW}$ of power-producing potential. Because of the low temperature of these resources, they are not likely to be commercially viable, and their exclusion should not impact the results of the ReEDS modeling. The USGS 2008 assessment does not exclude currently installed generating capacity at identified hydrothermal sites. Data on installed geothermal capacity from EIA Form 860 (EIA 2016c) were used to remove existing capacity at USGS identified hydrothermal sites. As Table 1 shows, there were 2,542 $\mathrm{MW}_{\mathrm{e}}$ of installed geothermal net summer capacity at the end of 2015; however, only $2,421 \mathrm{MW}_{\mathrm{e}}$ of this installed capacity is at USGS identified hydrothermal sites. According to the installed capacity, some sites, such as the Geysers in California, have more existing production capacity than potential capacity, so their potential was completely removed from the assessment. When current capacity and sites with temperatures $<110^{\circ} \mathrm{C}$ are removed from the USGS 2008 
mean power producing potential, the subsequent remaining mean potential capacity for identified hydrothermal sites in the United States is $6,370 \mathrm{MW}_{\mathrm{e}}$. Because ReEDS models only the contiguous United States, sites in Alaska and Hawaii were removed as well. The result is that the remaining hydrothermal resource potential used as input for the ReEDS models in this study is $5,657 \mathrm{MW}$.

\subsection{Undiscovered Hydrothermal Resources}

In addition to identified hydrothermal resources, the USGS 2008 geothermal resource assessment estimated the power production potential from undiscovered geothermal resources. The undiscovered resources for each state in the western United States was estimated by USGS using geographic information system-based statistical methods to analyze the correlation between spatial data sets and existing geothermal resources to derive the probability of the existence of geothermal resources in unexplored regions. The undiscovered geothermal resource power generation potential from the study has a mean value of $30,033 \mathrm{MW}_{\mathrm{e}}$, with a $95 \%$ probability of at least 7,917 $\mathrm{MW}_{\mathrm{e}}$ and a $5 \%$ probability of up to $73,286 \mathrm{MW}_{\mathrm{e}}$. For this study, the mean value of $30,033 \mathrm{MW}_{\mathrm{e}}$ was used. Of this, 25,810 $\mathrm{MW}_{\mathrm{e}}$ occurs in the contiguous United States and is included in the ReEDS modeling.

The estimation of the LCOE in GETEM requires characterization of the geothermal resource; however, the actual resource characteristics of the undiscovered hydrothermal resource, such as reservoir depth and temperature, are unknown. In the absence of actual data, it was assumed that the undiscovered resources would be similar in nature to identified hydrothermal sites in the same region. To characterize the undiscovered hydrothermal resource, identified hydrothermal sites were first divided into ReEDS BAAs. The identified sites were further divided into three subgroups by temperature: sites with reservoir temperatures $<140^{\circ} \mathrm{C}$, likely not commercially viable; sites with temperatures $\geq 140^{\circ} \mathrm{C}$ and $<200^{\circ} \mathrm{C}$, likely binary plants; and sites with temperatures $\geq 200^{\circ} \mathrm{C}$, likely flash plants.

The mean potential capacity from identified hydrothermal resources in each subgroup for a BAA was totaled. The undiscovered hydrothermal resource in each state was first apportioned among BAAs based on the percentage of identified hydrothermal resource in each BAA in a state and then apportioned among the designated temperature ranges based on the percentage of identified hydrothermal resource in each subgroup. For several states, such as Colorado, the entire undiscovered resource was assumed to have a temperature $<140^{\circ} \mathrm{C}$ because all the identified hydrothermal sites in those states have estimated reservoir temperatures of $<140^{\circ} \mathrm{C}$.

Within each BAA, a single reservoir temperature, depth, and production well flow rate was assumed for the undiscovered resource in each temperature subgroup. The temperature, depth, and flow rate of the undiscovered hydrothermal resource in each subgroup was determined by calculating the mean capacity-weighted average of each of these parameters from the identified hydrothermal sites in each subgroup. Because the reservoir characteristics were determined using the potential power capacity-weighted average, the undiscovered resource is assumed to be more similar to the large identified hydrothermal sites in each state that have large power producing potential. This means, for example, that the high-temperature undiscovered resource characteristics in California are heavily influenced by the characteristics of large sites such as the Geysers and the Salton Sea. 


\subsection{NF-EGS Resources}

The NF-EGS resources consist of the areas around existing hydrothermal sites that lack sufficient permeability and/or in-situ fluids to be economically produced as a conventional hydrothermal resource. These resources require the application of EGS reservoir engineering techniques to become economic producers of electricity. Because these resources are around existing hydrothermal sites, they tend to be relatively hot and shallow, and they are likely to be the least expensive and first EGS resources to be commercially developed. Estimates of nearfield and deep-field EGS potential around a selection of existing sites were developed as part of USGS 2008 geothermal resource assessment. Via personal communication on May 2, 2013, the USGS supplied a list of these sites, including estimates of the resource potential, temperature, depth, and location. For areas around 21 existing, producing hydrothermal fields considered in this study, the NF-EGS potential was 1,493 MWe.

\subsection{Deep EGS Resources}

The deep EGS resources consist of all the thermal energy stored deep in the Earth's crust at depths accessible using existing drilling technology. The cost of electricity from an EGS site depends heavily on the depth and temperature of the reservoir to be developed. The U.S. deep EGS resource potential is defined here as the thermal energy stored in rock at depths greater than $3 \mathrm{~km}$ below the Earth's surface and at temperatures exceeding $150^{\circ} \mathrm{C}$ in the continental United States. The deep EGS resource potential estimate is based on temperature-at-depth maps developed by the Southern Methodist University (SMU) Geothermal Laboratory. Both the methodology and the underlying temperature-at-depth maps of the United States used to develop the deep EGS resource potential estimate for the United States in this study originated in the Future of Geothermal Energy report (Tester et al. 2006). The methodology was adopted by NREL and used to develop supply curves for EGS in Petty and Porro (2007) and in Augustine (2011), which made improvements to the methods used to account for land exclusions and corrected some errors in the resource potential calculations. The deep EGS electricity generation resource potential estimate was recently updated for the GeoVision study (Augustine 2016) using the most recent temperature-at-depth maps available from SMU (Blackwell et al. 2011) and the same methodology used to develop the resource potential estimate in the previous estimates.

The methodology used to generate the resource potential estimate is as follows. First, the subsurface is divided into intervals 1-km thick, similar to the SMU maps. Then, the amount of thermal energy in place in a given volume of rock is calculated assuming an overall average reservoir temperature decline of $10^{\circ} \mathrm{C}$. Next, the amount of this thermal energy that can be recovered is calculated, assuming a recovery factor of $20 \%$. The recovered thermal energy is then converted to electric energy potential on a $\mathrm{MW} / \mathrm{km}^{3}$ basis by a power plant at the surface, assuming a plant lifetime of 20 years and a power plant conversion efficiency (DiPippo 2004) based on the temperature intervals from the SMU maps. Finally, the electric energy potential values are used to estimate the electricity generation potential at a location based on the temperature values from the SMU maps.

The updated deep EGS resource potential estimate was calculated for rock at depths between 3$7 \mathrm{~km}$ with estimated temperatures exceeding $150^{\circ} \mathrm{C}$. The updated deep EGS electricity generation resource potential estimate was calculated to be 5,157 GWe. A summary of the EGS 
electricity generation potential for the contiguous United States as a function of temperature and depth is shown in Table 3.

Table 3. Updated Deep EGS Electricity Generation Potential ( $\mathbf{M W}_{\mathrm{e}}$ ) for the Continental United States Binned by Temperature and Depth Intervals

\begin{tabular}{|c|c|c|c|c|c|c|c|c|c|c|}
\hline \multicolumn{11}{|c|}{ Deep EGS Electricity Generation Potential (MWe) } \\
\hline & & \multicolumn{9}{|c|}{ Resource Temperature $\left({ }^{\circ} \mathrm{C}\right)$} \\
\hline & & $150-175$ & $175-200$ & $200-225$ & $225-250$ & $250-275$ & $275-300$ & $300-325$ & $325-350$ & $>350$ \\
\hline \multirow{4}{*}{ 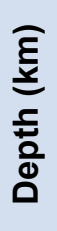 } & $3-4$ & 74,217 & 2,592 & 100 & - & - & - & - & & \\
\hline & $4-5$ & 740,466 & 233,228 & 11,886 & 325 & 84 & 32 & - & & \\
\hline & $5-6$ & 517,601 & 724,689 & 373,680 & 57,281 & 4,654 & 195 & 128 & & \\
\hline & $6-7$ & 635,384 & 491,641 & 700,330 & 453,610 & 120,677 & 12,116 & 1,883 & 0 & 157 \\
\hline
\end{tabular}




\section{GeoVision Scenarios and Supply Curves}

The total cost of developing geothermal resources depends on the assumptions made about present and future component costs and the performance of the project. Advances in technology, reductions in component costs, or changes to project financing, such as the cost of capital or project timelines, can reduce the cost of geothermal technology development. As mentioned previously, the GeoVision study looks at three primary scenarios for evaluating the future potential of geothermal electricity generation in the United States:

- Business-as-Usual (BAU): assumes that the geothermal industry continues on its current trajectory

- Improved Regulatory Timeline (IRT): assumes an improved regulatory environment leading to accelerated geothermal permitting processes and development timeline

- Technology Improvement (TI): assumes a future where technology advances, cost reductions, and favorable financing options reduce the cost of geothermal technologies; includes IRT assumptions.

The GeoVision scenarios and supply curve development are described in detail in the following sections. First the resource potential used in each scenario is described. Next, each scenario is described in detail. The scenario assumptions and values are used to develop the cost and performance inputs for the GETEM. The GETEM is run for each geothermal site or resource class and the resulting project development cost outputs from GETEM are used to develop the supply curves that serve as inputs to the ReEDS model.

\subsection{Geothermal Resource Potential Used in GeoVision Scenarios}

The resource potential values calculated in the USGS 2008 geothermal resource assessment and in Table 3 exclude federally protected and U.S. Department of Defense lands on which development is highly restricted. Additional barriers that prevent or inhibit the development of geothermal projects, without absolutely forbidding it, were identified as part of the GeoVision study. These barriers include environmentally sensitive areas, tribal concerns, the presence of threatened or endangered species, and proximity to military bases, among others. Because of these barriers, the amount of land that is practically available for development is less than the estimates above.

The results of the additional barriers analysis were incorporated into the resource potential estimates for the GeoVision scenarios. The amount of land available under the GeoVision scenarios is summarized in Table 4. The BAU and IRT scenarios assume that areas where development is currently identified as unallowed or having significant barriers are not included in the resource potential estimate. The TI scenario assumes a disruptive improvement to land access that includes mitigation measures that allow access to additional areas with significant barriers. Unless otherwise stated, the "Business-as-Usual" land access values are used to develop the supply curves for use in the ReEDS model. Details on these additional barriers, their impacts on geothermal resource availability, and the disruptive improvement land access assumptions are discussed in the GeoVision report and Young et al. (2019). 
Table 4. Summary of Geothermal Resources Available (in $\mathrm{MW}_{\mathrm{e}}$ ) in ReEDS for Different GeoVision Scenarios

\begin{tabular}{lllll}
\hline GeoVision Scenario & $\begin{array}{l}\text { Identified } \\
\text { Hydrothermal }\end{array}$ & $\begin{array}{l}\text { Undiscovered } \\
\text { Hydrothermal }\end{array}$ & $\begin{array}{l}\text { NF- } \\
\text { EGS }\end{array}$ & $\begin{array}{l}\text { Deep } \\
\text { EGS }\end{array}$ \\
\hline $\begin{array}{l}\text { Land Access Assumptions Used in } \\
\begin{array}{l}\text { USGS (2008) and Augustine (2016) } \\
\text { (Minimal barriers: only federally } \\
\text { protected lands excluded) }\end{array}\end{array}$ & 5,657 & 25,807 & 1,493 & $5,156,956$ \\
\hline BAU & 5,078 & 18,830 & 1,382 & $3,375,275$ \\
IRT & 5,128 & 23,038 & 1,443 & $4,248,879$ \\
\hline TI & & & & \\
\hline
\end{tabular}

\subsection{Business-as-Usual Scenario}

The purpose of the BAU scenario is to project the future growth of the geothermal industry based on current industry trends. It assumes that the industry continues along the current path, absent any major technology advances being implemented-e.g., EGS reaching commercial maturity. This scenario serves as a basis upon which the other scenarios and their improvements are built and compared.

\subsubsection{GETEM Input Assumptions}

The BAU scenario assumes cost and performance inputs for GETEM representative of today's technology and costs. Different inputs are applied depending on the technology type (hydrothermal or EGS) and whether the site is considered a greenfield or brownfield. Sites that are considered brownfields have inputs that lead to reduced costs during the exploration phase because it is assumed that these sites have already been characterized to some extent. Geothermal resource types are matched to input assumptions as follows:

- Identified hydrothermal: hydrothermal brownfield

- Undiscovered hydrothermal: hydrothermal greenfield

- NF-EGS: EGS brownfield

- Deep EGS: EGS greenfield.

GETEM inputs are based on the default inputs in GETEM described in the GETEM User Manual (Mines 2016). These default inputs were developed by an LCOE analysis team from 2011-2013 through a series of interviews with industry subject area experts to validate both the approaches used in the GETEM and the reasonableness of costs that were estimated for the different aspects of the project development.

The default inputs were additionally reviewed by the GeoVision task forces for accuracy and reasonableness. The most significant change was the decision to use an updated set of drilling cost curves developed by the Reservoir Maintenance and Development Task Force (Lowry et al. 
2017a) in place of the default GETEM drilling cost curves. ${ }^{6}$ A full list of default assumptions used in the GETEM for the BAU scenario is provided in the appendix of this report.

Note that because of the large number of geothermal sites, detailed site information was not considered when estimating costs in the GETEM. All sites used the same drilling costs curves, even though drilling costs can vary considerably by location.

\subsubsection{Project Development Costs Using GETEM}

The capital and O\&M costs for all geothermal resources were estimated using the GETEM on a site-by-site basis. First, site-specific resource definitions were input into the GETEM, including resource temperature, depth to reservoir (i.e., drilling depth), technology type, plant type, and plant size. As in previous supply curve reports, a reservoir depth of 1,524 km (5,000 ft) was used when site-specific estimates were not available and was mostly applied to identified hydrothermal sites. The technology options include hydrothermal or flash steam, with the plant types being either binary with temperatures less than $200^{\circ} \mathrm{C}$ or flash with temperatures equal to or greater than $200^{\circ} \mathrm{C}$. Identified hydrothermal and NF-EGS plant sizes were based on resource potential and were limited to a maximum size of $60 \mathrm{MW}$. If the resource targeted was larger than this, it was assumed that multiple plants would be developed at the site. For undiscovered hydrothermal and deep EGS, plant sizes of 25-40 MWe were used.

With all inputs defined, the GETEM was run to estimate project development costs. For binary plants, the GETEM estimates the cost of the power plant based on its "brine effectiveness," or the amount of electricity that the plant can generate from a given volume of geofluid. More efficient plants have a higher cost on a $\$ / \mathrm{kW}$ basis. Plant efficiency was optimized to minimize capital costs using Excel SOLVER. For flash plants, the GETEM uses a correlation to calculate efficiency and estimate flash plant costs based on inlet temperature. Once these estimates are complete, overnight capital cost $(\$ / \mathrm{kW})$ and fixed O\&M cost $(\$ / \mathrm{kW} / \mathrm{yr})$ results were recorded and used to generate supply curves and as inputs to the ReEDS model.

\subsubsection{Resulting Supply Curves}

The resulting supply curves for the BAU scenario are shown in Figure 6. The axes for the capital costs and available capacity have been truncated to make the figure readable. The capacity for the deep EGS resources extends beyond 3,000,000 $\mathrm{MW}_{\mathrm{e}}$, and the overnight capital costs extend beyond $\$ 100,000 / \mathrm{kW}_{\mathrm{e}}$; however, both of these values are irrelevant in practice because that much resource or resources at those costs would be unlikely to be deployed in a BAU scenario.

\footnotetext{
${ }^{6}$ Additional details are available in the GETEM User Manual (Mines 2016) Appendix A6, page 66, and production
} well flow rates and productivity/injectivity index values and their basis are in Appendix B. 


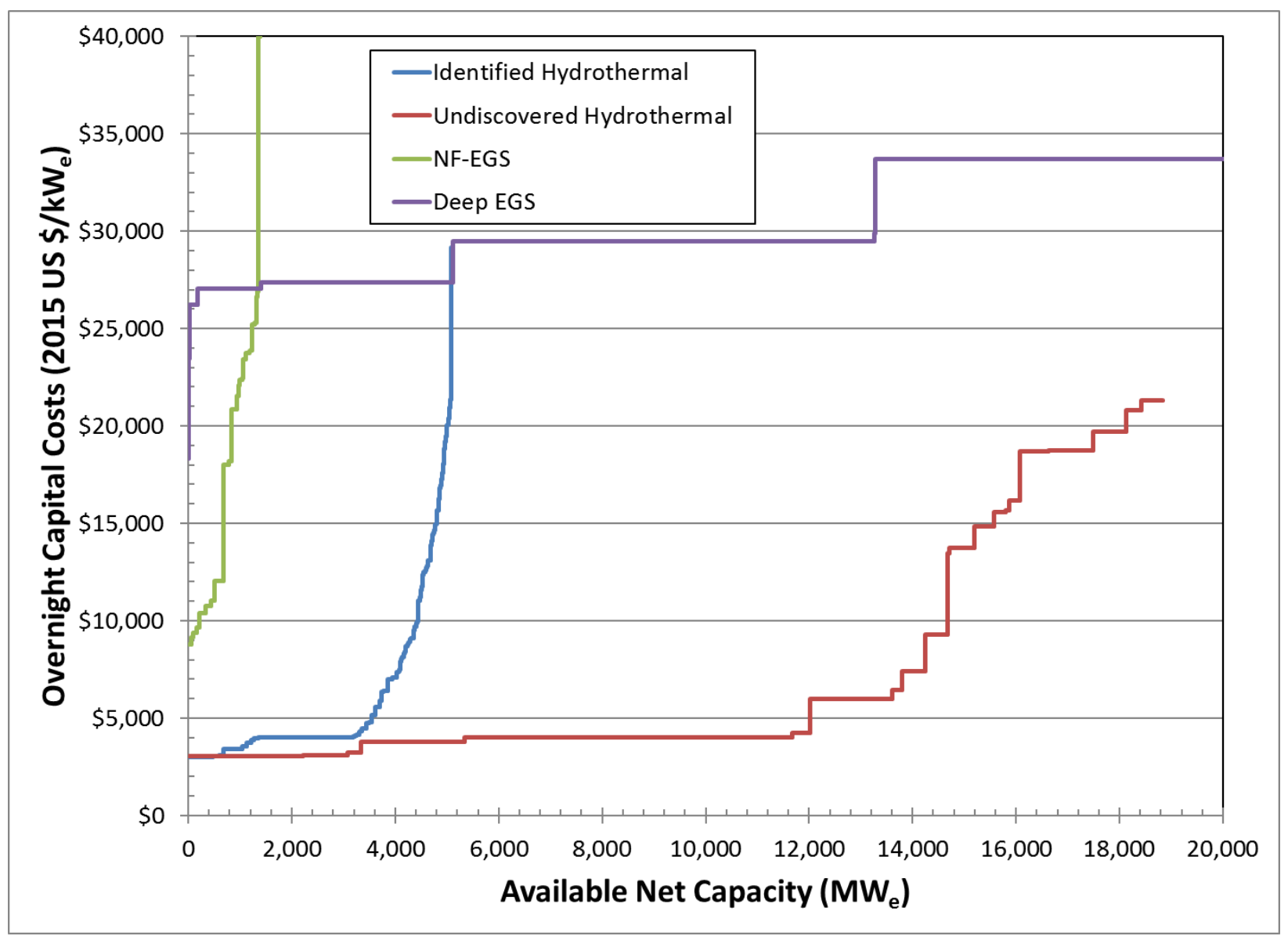

Figure 6. Geothermal supply curve for the GeoVision BAU scenario. The net capacity and capital cost axes are truncated for readability.

The following observations were made from the resulting supply curves for the BAU scenario. Identified hydrothermal capital costs are competitive for high-temperature resources, but they increase quickly as the resource temperature drops. The reason for the "hockey stick" shape of the identified hydrothermal resource is the abundance of small, low-temperature resources at the tail of the curve. The low temperatures lead to reduced power generation potential and increased drilling costs relative to the amount of power generated per well. The undiscovered hydrothermal resource is much larger than the identified hydrothermal resource. It is likely to dominate deployed geothermal resources in the BAU scenario. Both NF-EGS and deep EGS resources are likely too expensive to be deployed in the BAU scenario. This is primarily because of the relatively low production well flow rates and drilling success rates assumed for EGS in the BAU scenario. These make drilling costs expensive relative to the amount of power generated from the resulting geofluids. Essentially, the BAU scenario reflects that EGS technologies are not currently commercially viable on a broad scale.

\subsubsection{ReEDS Input Assumptions}

The supply curves used as input into the ReEDS model contain the site name, resource potential $(\mathrm{MW})$, location (ReEDS BAA the site is in), technology type (hydrothermal or EGS), plant type (binary or flash), overnight capital costs $\left(\$ / \mathrm{kW}_{\mathrm{e}}\right)$ and O\&M costs $(\$ / \mathrm{kW} / \mathrm{yr})$. All remaining inputs and calculations required to model the cost of geothermal projects are handled within the 
ReEDS model. The additional inputs required include financing assumptions such as the weighted average cost of capital (WACC), the project construction time frame including percentage of project expenditures by year, the plant capacity factor $(80 \%$ for binary plants, $90 \%$ for flash plants), a 20-year economic lifetime, and assumptions about when resources and technologies become available for deployment. Inputs that require additional discussion are described in the following sections.

\subsubsection{Financing Assumptions}

The ReEDS model uses a discounted cash flow analysis to calculate the net present value of electricity generation projects. It then selects projects to meet electricity generation capacity requirements based on their net present value to minimize the system cost while simultaneously meeting any modeling constraints or requirements, such as renewable portfolio standards and Federal Energy Regulatory Commission grid stability requirements. To calculate the net present value of projects, ReEDS uses a WACC to determine the financing costs. WACC combines investments in debt and equity in the following proportions:

$$
\mathrm{WACC}=\mathrm{rD}(1-\mathrm{Tc}) *(\mathrm{D} / \mathrm{V})+\mathrm{rE} *(\mathrm{E} / \mathrm{V})
$$

where $r D$ is the pretax cost of debt, $r E$ is the cost of equity, $T c$ is the marginal corporate tax rate, $D$ is the dollar amount of debt, $E$ is the dollar amount of equity, and $V$ is the company's book value $(D+E)$.

Geothermal projects have higher financing costs than most other electricity generation projects because of the high risk of the early exploration and drilling phases. Debt financing is typically not available during the earliest stages, and the project relies on equity financing. The perceived risk of the project drops significantly as production drilling proceeds and the resource is proven to have commercial potential (Figure 7). Debt financing becomes available at reduced rates in the later drilling and plant construction phases of the project.

The type of financing available (equity or debt) and the hurdle rates demanded to invest are heavily tied to the stage of project feasibility. Therefore, the WACC for geothermal projects was determined by analyzing the proportion and cost of debt and equity as a function of geothermal project phase. The WACC for the BAU scenario was determined from a compilation of costs and capital for geothermal projects and analysis performed by Wall, Dobson, and Thomas (2017). 


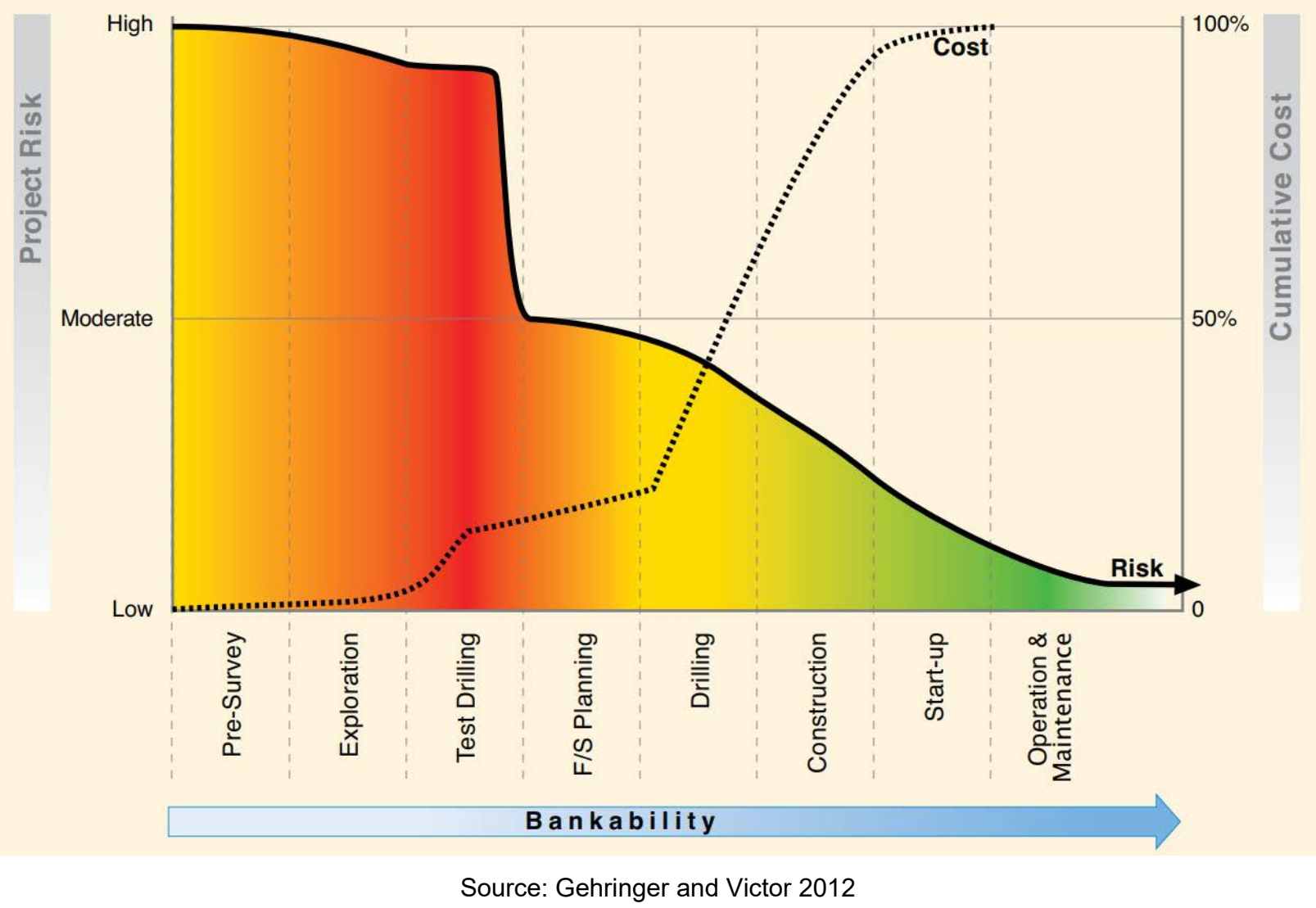

Figure 7. Diagram of perceived geothermal project risk and cumulative investment costs over time

The GeoVision study uses the balance sheet (internal) funding analysis from the study to develop the WACC for hydrothermal projects. The following details are sourced from Wall, Dobson, and Thomas (2017):

- During the early stages of exploration, projects have been able to receive only equity financing, either in the form of corporate balance sheet funding or private equity. Balance sheet financing, i.e., the use of internal funding such as retained earnings, has required a minimum hurdle rate of 12\%-13\% (Glacier Partners 2009; Solomon et al. 2011).

- During drilling, mezzanine financing offers the ability to obtain both equity and debt as a bridge between commercial lending and private equity. The costs of mezzanine debt are approximately $12.5 \%$ more than Libor, with $15 \%$ in total preferred (Glacier Partners 2009; Solomon et al. 2011). The lower range of balance sheet rates are assumed for equity financing in this phase.

- Construction loans on the order of 10-year U.S. Treasuries, plus 325 to 375 basis points for projects with a signed power purchase agreement were reported by Solomon et al. (2011). Using the mid-range value, this currently translates to a construction period cost of debt of 5.32\% (Wall, Dobson, and Thomas 2017). 
- Glacier Partner's 2009 financial model and accompanying report and GETEM overnight construction costs for a typical hydrothermal project were used to determine the proportion of project spending by phase.

The GeoVision study uses the private equity (external) funding analysis from the study to develop the WACC for EGS projects. The following details are sourced from Wall, Dobson, and Thomas (2017):

- Private equity is used for the exploration phase, and funding has required a cost of equity at minimum $30 \%$, with $35 \%$ being preferred.

- During drilling and field development, because balance sheet financing is not available, equity comes from mezzanine financing at a cost of 30\%. The cost of debt from mezzanine financing is assumed to be $15 \%$.

- As with hydrothermal, construction loans on the order of 10-year U.S. Treasuries plus 325 to 375 basis points for projects with a signed power purchase agreement were reported by Solomon et al. (2011). Using the mid-range value, this currently translates to a construction period cost of debt of 5.32\% (Wall, Dobson, and Thomas 2017).

- A modified version of Glacier Partner's 2009 financial model and accompanying report and GETEM overnight construction costs for a typical hydrothermal project were used to determine the proportion of project spending by phase.

The resulting WACC values are summarized in Table 5.

Table 5. Summary of Financing Costs and Percentage Spending by Phase for Hydrothermal and EGS projects and Resulting Overall Project WACC

\begin{tabular}{|c|c|c|c|c|c|c|c|c|c|c|}
\hline \multirow[b]{2}{*}{$\begin{array}{l}\text { Project } \\
\text { Stage }\end{array}$} & \multicolumn{5}{|c|}{ Hydrothermal } & \multicolumn{5}{|c|}{ EGS } \\
\hline & $\begin{array}{c}\text { Cost } \\
\text { of } \\
\text { Equity } \\
(\%)\end{array}$ & $\begin{array}{c}\text { Cost } \\
\text { of } \\
\text { Debt } \\
(\%)\end{array}$ & $\begin{array}{c}\% \\
\text { Equity }\end{array}$ & $\begin{array}{c}\% \\
\text { Debt }\end{array}$ & $\begin{array}{c}\% \text { of } \\
\text { Spending }\end{array}$ & $\begin{array}{c}\text { Cost } \\
\text { of } \\
\text { Equity } \\
(\%)\end{array}$ & $\begin{array}{c}\text { Cost } \\
\text { of } \\
\text { Debt } \\
(\%)\end{array}$ & $\begin{array}{c}\% \\
\text { Equity }\end{array}$ & $\begin{array}{c}\% \\
\text { Debt }\end{array}$ & $\begin{array}{c}\% \text { of } \\
\text { Spending }\end{array}$ \\
\hline $\begin{array}{l}\text { Exploration: } \\
\text { Feasibility }\end{array}$ & $13 \%$ & $\mathrm{n} / \mathrm{a}$ & $100 \%$ & $0 \%$ & $12 \%$ & $35 \%$ & $\mathrm{n} / \mathrm{a}$ & $100 \%$ & $0 \%$ & $3 \%$ \\
\hline $\begin{array}{l}\text { Drilling/Well } \\
\text { Field } \\
\text { Development }\end{array}$ & $12 \%$ & $15 \%$ & $60 \%$ & $40 \%$ & $58 \%$ & $30 \%$ & $15 \%$ & $60 \%$ & $40 \%$ & $66 \%$ \\
\hline $\begin{array}{l}\text { Plant } \\
\text { Construction } \\
\text { and Startup }\end{array}$ & $\mathrm{n} / \mathrm{a}$ & $5.3 \%$ & $0 \%$ & $100 \%$ & $30 \%$ & $\mathrm{n} / \mathrm{a}$ & $5.3 \%$ & $0 \%$ & $100 \%$ & $31 \%$ \\
\hline WACC & \multicolumn{5}{|c|}{$14.0 \%$} & \multicolumn{5}{|c|}{$16.3 \%$} \\
\hline
\end{tabular}

\subsubsection{Construction Timelines}

ReEDS uses the WACC to determine the cost of capital during project construction in determining the net present value of the project. ReEDS also requires the project construction timeline and a breakdown of project spending by year. Longer project construction timelines result in increased costs of capital because of the time value of money and interest on 
construction capital. Geothermal projects tend to have long construction timelines with relatively small expenditures in the early exploration phases and the bulk of capital required in the later drilling and plant construction phases.

For the BAU scenario, GeoVision assumes that hydrothermal resources have 8-year project construction periods and that EGS resources have 10-year project construction periods. Table 6 shows the breakdown of capital expenditures by year. Expenditures are small during the exploration phase in the early years and sometimes zero if the project needs to wait a long time for necessary permits. The majority of expenditures come near the end of the project to cover drilling and power plant costs.

Table 6. Breakdown of Project Capital Expenditures by Year for BAU Hydrothermal and EGS Scenarios

\begin{tabular}{lllllllllll}
\hline Year & 1 & 2 & 3 & 4 & 5 & 6 & 7 & 8 & 9 & 10 \\
\hline Hydrothermal & $10 \%$ & $2 \%$ & $11 \%$ & $0 \%$ & $0 \%$ & $22 \%$ & $23 \%$ & $32 \%$ & & \\
EGS & $2 \%$ & $1 \%$ & $0 \%$ & $6 \%$ & $0 \%$ & $0 \%$ & $35 \%$ & $12 \%$ & $28 \%$ & $16 \%$ \\
\hline
\end{tabular}

\subsection{Undiscovered Hydrothermal Resource Availability vs. Time}

The majority of the hydrothermal resource is "undiscovered." The rate of deployment of geothermal resources in the ReEDS model will depend heavily on the assumption of when the undiscovered hydrothermal resource is available for development. To prevent ReEDS from assuming that all the undiscovered resource is currently available for development and attempting to deploy it at an unrealistic pace, an assumption about how quickly the geothermal industry explores for and discovers these resources must be made. In the BAU case, it reflects both the ability of current industry to carry out exploration and current industry deployment trends.

To implement this in ReEDS, a "discovery rate" is used. This is the amount of the undiscovered hydrothermal resource (from USGS 2008) that is assumed to be found and become available for development in ReEDS, expressed as a percentage per year of the total undiscovered hydrothermal resource. GeoVision assumes that the distribution of where undiscovered hydrothermal resources are found each year is uniform across the resource. The BAU case assumes that all identified barriers are included — see Section 4 and Young et al. (2019) for details.

ReEDS was run using the BAU inputs for the geothermal resources for a range of discovery rates. The results and reasoning are discussed in detail in the results section, but based on modeling results, a discovery rate of $1 \%$ per year, with the first undiscovered hydrothermal resources available for deployment in 2020, was assumed for the BAU scenario. This assumes that a "discovery rate" of $1 \%$ per year corresponds to $188.3 \mathrm{MW}$ of undiscovered hydrothermal becoming discovered and available for development each year.

It is difficult to quantify annual geothermal discoveries because these are not reported in any standard way. Developers tend to keep exploration details secret because knowledge of potential sites is a competitive advantage. Wall and Dobson (2016) calculated a geothermal exploration project success rate of $21 \%$ versus an industry feedback value of $25 \%$. This implies that one out 
of every four or five sites that are "discovered" and explored result in a successful project. The annual growth rate of about $50 \mathrm{MW} / \mathrm{yr}$ from the historic data (see Section 2.2) would correspond with about 200-250 MW/yr of sites that are explored according to this success rate. Given this, the assumption of about $200 \mathrm{MW} / \mathrm{yr}$ of newly discovered hydrothermal resource matches well with observations and seems reasonable.

\subsection{Improved Regulatory Timeline Scenario}

The IRT scenario explores the impact of an improved regulatory environment leading to accelerated geothermal permitting processes and development timelines. The IRT scenario was based on the GeoVision analysis of non-technical barriers to geothermal deployment (Young et al. 2019), which considered a number of pathways and potential combinations of approaches to streamline and reduce project development timelines. Potential regulatory-related scenarios for shortened regulatory time frames include centralized permitting offices to facilitate regulatory requirements, an updated Programmatic Environmental Impact Statement, expanded use of preleasing environmental assessments, and a categorical exclusion from having to complete an environmental assessment or environmental impact statement under the National Environmental Policy Act of 1969, which would allow drilling and testing of confirmation wells - consistent with the general parameters established for oil and gas in Section 390 of the Energy Policy Act of 2005 and as proposed for the geothermal industry in Section 3012 of S. 1460, the Energy and Natural Resources Act of 2017 (115th Congress). Exploring the details of such a categorical exclusion was outside of the scope of the GeoVision study.

The net impact of the IRT scenario is twofold. First, it decreases the construction timeline. The hydrothermal construction timeline is shortened from 8 years in the BAU scenario to 4 years in the IRT, and the EGS construction timeline is shortened from 10 years in the BAU scenario to 5 years in the IRT. Assumed project capital expenditures are shown in Table 8.

Table 7. Breakdown of Project Capital Expenditures by Year for IRT Scenario: Hydrothermal and EGS Timelines

\begin{tabular}{llllll}
\hline Year & 1 & 2 & 3 & 4 & 5 \\
\hline Hydrothermal & $10 \%$ & $35 \%$ & $23 \%$ & $32 \%$ & \\
\hline EGS & $2 \%$ & $34 \%$ & $24 \%$ & $35 \%$ & $5 \%$ \\
\hline
\end{tabular}

The second impact is an increase in resource exploration and an increase in the discovery rate for undiscovered geothermal resources from $1 \%$ per year to $3 \%$ per year. ${ }^{7}$ This assumption is based on the reasoning that because of the decreased time it takes to get exploration permits, projects can greatly increase the amount of exploration that is performed, resulting in more resource discoveries. The assumption was reviewed by members of the GeoVision Visionary Team, including geothermal developers, and deemed reasonable.

\footnotetext{
7 The 3\% per year discovery rate is based on interviews with geothermal developers as part of the GeoVision study on the impact that decreased permitting times for activities associated with exploration would have on the amount of exploration they could achieve in a given amount of time.
} 
All remaining assumptions in the IRT scenario are identical to the BAU scenario. Because the GETEM inputs are identical, the supply curves for the IRT scenario are the same as those for the BAU scenario shown in Figure 6. The financing assumptions and WACC values used in ReEDS are also identical to the BAU scenario. The result is that the IRT scenario shows the impacts on geothermal deployment if soft costs and barriers are reduced, even with current technology.

\subsection{Technology Improvement Scenario}

The TI scenario looks at the impacts of aggressive technology advances and cost reductions developed amongst the GeoVision task forces for use as GETEM inputs on the potential for geothermal deployment. These improvements greatly benefit EGS, reducing its costs to the point where it is commercially competitive, and they are also beneficial for hydrothermal technologies. The TI scenario also incorporates the IRT scenario assumptions that lead to both a threefold increase in the discovery rate of hydrothermal resources (from $1 \%$ per year to $3 \%$ per year) and a decrease in the project construction timeline. Additionally, technology improvements in exploration and drilling lead to a decrease in project risk, which translates into reduced financing costs. The TI scenario assumes that geothermal projects are able to obtain financing at rates (WACC) similar to other power generation technologies. Finally, disruptive improvements to land access enable development in areas that previously had significant barriers, increasing the total geothermal resource potential in ReEDS (see Section 5.1).

\subsubsection{Technology Improvements and GETEM Input Assumptions}

In the TI scenario, it is assumed that large utility-scale plants continue to be the predominate goal of project developers and that geothermal providers have advanced significant technology breakthroughs from a confluence of technology improvements. The improvements were developed by GeoVision task forces in their respective areas based on analysis of current and future technologies and incorporated as GETEM inputs as part of the bottoms-up analysis framework of the GeoVision. These improvements include the availability of big data to optimize exploration and drilling, advanced exploration drilling techniques such as microhole drilling, reductions in costs and improvements in the success rate of drilling overall, and the development of EGS techniques such as multistage stimulation of horizontal wells that increase the productivity and longevity of EGS reservoirs. Changes to the GETEM inputs from the BAU scenario are summarized in Table 8 and discussed in detail in the following sections. The TI scenario assumes the BAU values for all other GETEM inputs.

\subsubsection{Pre-Exploration}

The TI scenario assumes that pre-exploration activities and costs will be heavily oriented toward big data analytics of regional and site-specific information and that all other predrilling exploration methods (geochemical and/or geophysical) will address gaps identified from this initial screening, such as 3-D seismic methods for EGS. This assumes that operators are able to access these data or collect initial data that can be used for multiple sites (e.g., improved drone and/or remote sensing over large areas) (Doughty et al., 2018). 
Table 8. Summary of Changes to BAU GETEM Inputs for TI Scenario

\begin{tabular}{|c|c|c|c|c|c|}
\hline \multirow{2}{*}{\multicolumn{2}{|c|}{ GETEM Input }} & \multicolumn{2}{|c|}{ BAU } & \multicolumn{2}{|c|}{$\mathrm{TI}$} \\
\hline & & Hydro & EGS & Hydro & EGS \\
\hline \multirow{5}{*}{$\begin{array}{l}\text { Resource } \\
\text { Exploration }\end{array}$} & Exploration: predrilling costs & $\$ 600 \mathrm{k}-\$ 1.2 \mathrm{M}$ & $\$ 250 k$ & \multicolumn{2}{|c|}{ About the same } \\
\hline & Exploration: drilling costs & $\$ 3.3 \mathrm{M}-\$ 5.4 \mathrm{M}$ & $\$ 1.5 \mathrm{M}-\$ 5 \mathrm{M}$ & \multicolumn{2}{|c|}{$2 / 3$ of $B A U$} \\
\hline & $\begin{array}{l}\text { Multiplier for confirmation } \\
\text { well costs }\end{array}$ & 1.2 & 1.5 & \multicolumn{2}{|c|}{1} \\
\hline & $\begin{array}{l}\text { Full-sized confirmation well } \\
\text { success rate }\end{array}$ & $50 \%$ & $50 \%$ & \multicolumn{2}{|c|}{$75 \%$ (with stimulation) } \\
\hline & $\begin{array}{l}\text { \# Full-sized confirmation } \\
\text { wells (well cost multiplier }>1 \text { ) }\end{array}$ & 3 & 9 & \multicolumn{2}{|c|}{3} \\
\hline \multirow{2}{*}{ Drilling } & Drilling success rate & \multicolumn{2}{|c|}{$75 \%$} & \multicolumn{2}{|c|}{$90 \%$} \\
\hline & Drilling costs & \multicolumn{2}{|c|}{ Base } & \multicolumn{2}{|c|}{ Ideal } \\
\hline \multicolumn{2}{|c|}{ Geofluid Gathering System and Pumping } & \multicolumn{4}{|c|}{ No changes } \\
\hline \multirow{3}{*}{$\begin{array}{l}\text { Reservoir } \\
\text { Definition }\end{array}$} & Stimulate wells? & No & Yes & \multicolumn{2}{|c|}{ Yes } \\
\hline & Well flow rate & $\begin{array}{l}\text { Binary: } 110 \mathrm{~kg} / \mathrm{s} \\
\text { Flash: } 80 \mathrm{~kg} / \mathrm{s}\end{array}$ & $40 \mathrm{~kg} / \mathrm{s}$ & \multicolumn{2}{|c|}{$\begin{array}{c}\text { Binary: } 110 \mathrm{~kg} / \mathrm{s} \\
\text { Flash: } 80 \mathrm{~kg} / \mathrm{s}\end{array}$} \\
\hline & Well productivity & $\begin{array}{l}4.6 \mathrm{~kg} / \mathrm{s} / \mathrm{bar} \\
5.8 \mathrm{gpm} / \mathrm{psi}\end{array}$ & $\begin{array}{l}0.46 \mathrm{~kg} / \mathrm{s} / \mathrm{bar} \\
0.58 \mathrm{gpm} / \mathrm{psi}\end{array}$ & \multicolumn{2}{|c|}{$\begin{array}{l}4.6 \mathrm{~kg} / \mathrm{s} / \mathrm{bar} \\
5.8 \mathrm{gpm} / \mathrm{psi}\end{array}$} \\
\hline \multicolumn{2}{|l|}{ O\&M } & \multicolumn{4}{|c|}{ No changes } \\
\hline \multicolumn{2}{|l|}{ Power Plant } & \multicolumn{4}{|c|}{ No changes } \\
\hline
\end{tabular}

Based on the research and recommendations of the GeoVision Exploration \& Confirmation Task Force, the result of using big data and these exploration technology advances is that preexploration drilling costs for the TI scenario are only slightly different from those for the BAU scenario but result in a high success rate for projects that move beyond predrilling into the drilling phase, reducing overall project risk. This translates into increased drilling success rates and decreased financing costs. 


\subsubsection{Exploration Drilling}

In exploratory drilling practices, microdrilling applications are an example of a technology that could potentially be modified to great benefit for the geothermal industry. The TI scenario assumes that all slim wells will be preceded by microdrilling, at minimum, to reduce costs and improve the success rate of finding full-sized production wells. Microdrilling has been developed primarily for oil and gas applications; thus, it could work well even today for shallow EGS systems. A 2016 study estimates that even with extending the depths to traditional hydrothermal systems, microdrilling achieves an expected $33.5 \%$ cost savings after 1,000 completed microdrilled wells compared to the application of production-sized wells and some $\$ 6.7$ million (29\%) cost reduction when drilling a slim hole (RWTH Aachen University 2016). Therefore, in the TI scenario, exploration drilling costs are reduced by 33.5\% (except the EGS brownfield). Additionally, high exploration drilling success rates further increase the overall exploration success rate and reduce project risk.

\subsubsection{Full-Sized Confirmation Wells}

The first full-sized wells drilled at geothermal sites, sometimes referred to as confirmation wells, typically cost more and have reduced success rates than wells drilled later during field development. The TI scenario assumes reductions in cost and improvements in success rate for these first full-sized confirmation wells compared to the BAU scenario.

Several technology and industry improvements work together to realize these reductions. One example is that a large increase in the deployment of geothermal would lead to significant growth of the geothermal drilling industry, leading to drilling teams with more experience in geothermal settings. Real-time data collection during exploration and drilling has become commonplace in the oil and gas industry, but recent studies have shown that very little of this information is leveraged in the final decision-making for development (e.g., DiChristopher [2015]). Further, less than $10 \%$ of current projects use fully automated drilling systems (Wang 2016). The TI scenario assumes that the geothermal industry will use these available data and analytics to its advantage for every project. Additionally, the exploration technologies discussed in the pre-exploration section translate to improvements in identifying drilling targets and increases in drilling success rates. It is also assumed that both hydrothermal and EGS systems will advance the use of stimulation for production wells and that well stimulation technologies will be advanced and are employed in hydrothermal wells in cases of "dry" holes.

Based on research and recommendations from the GeoVision Exploration \& Confirmation Task Force, the results of these technology advances for the TI scenario include the more experienced drilling team workforce and real-time data collection, contributing to a reduction of the cost multiplier for confirmation wells to 1 -i.e., the confirmation wells will cost the same as wells drilled later during field development. Confirmation well drilling success rates also improve because of exploration technologies that better identify drilling targets and through the use of stimulation technologies in hydrothermal fields that increase the effective permeability of dry holes and make them useful wells.

For hydrothermal resources, in the BAU scenario, it was assumed that there would be a $50 \%$ confirmation well success rate and that two confirmation wells were needed-i.e., of the four wells drilled, two were dry. In the TI scenario, EGS technologies can be applied so that both dry wells are stimulated but only one successfully. This results in four confirmation wells drilled, 
with two successful conventional wells, and two dry holes that are stimulated. One is successfully stimulated to flow at commercial levels.

For EGS resources, in the BAU scenario, it was assumed that there would be a $50 \%$ confirmation well success rate and that nine confirmation wells would be needed (for a total of 18 wells drilled). In the TI scenario, out of every four wells drilled, one is an unsuccessful stimulated injection well (and could be considered a "learning" well for the site). One well is successfully stimulated and used as an injection well, and the remaining two are successful, unstimulated production wells hydraulically connected to the injection well.

\subsubsection{Drilling and Well Completion Costs}

In the TI scenario, advances in drilling technology lead to significant reductions in drilling and well completion costs for both hydrothermal and EGS. Based on research and analysis performed by the GeoVision Reservoir Maintenance and Development Task Force, several well cost curves were developed for GeoVision (Figure 8). The Ideal well cost curve was used for the TI scenario. Lowry et al. (2017a and 2017b) contains the full details of the well cost curves.

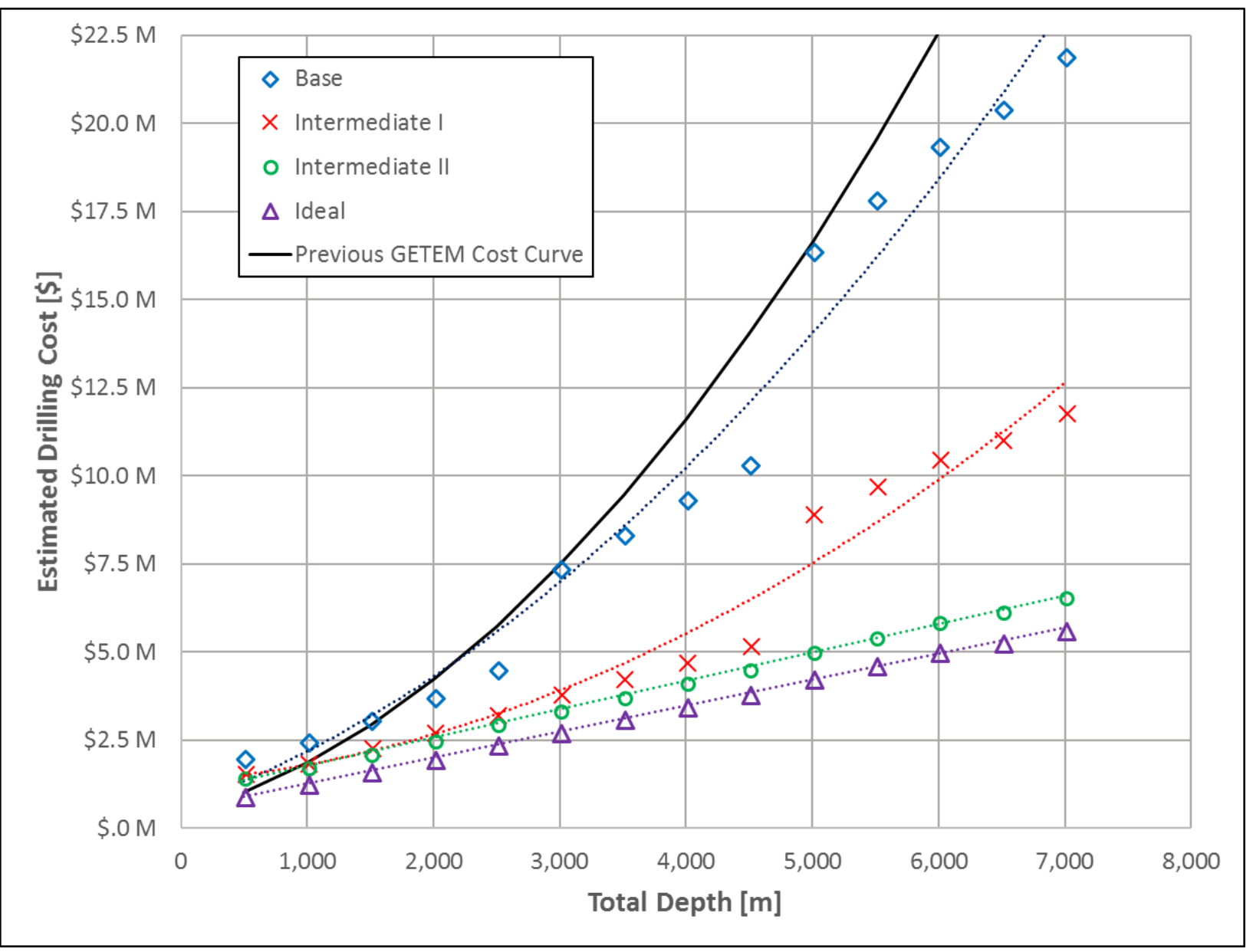

Figure 8. Cost curves used in the GeoVision study (Lowry et al. 2017a) relative to previous well cost curve used in the GETEM. Curves shown are for large-diameter vertical wells with an open hole. The TI scenario uses the Ideal cost curve. 


\subsection{EGS Technologies}

The TI scenario assumes that improvements in EGS technologies will allow for the multistage stimulation of deviated wells in the creation of EGS reservoirs. The geothermal industry is assumed to be able to adapt directional drilling and multizonal isolation techniques from the oil and gas industry and develop reservoir stimulation technologies in order to create EGS reservoirs with volumes and surface areas large enough to support commercial production well flow rates for decades. The result is that EGS reservoirs are assumed to have flow and productivity characteristics similar to hydrothermal reservoirs: production well flow rates of $80 \mathrm{~kg} / \mathrm{s}$ for flash plants, and $110 \mathrm{~kg} / \mathrm{s}$ for binary plants ${ }^{8}$; well injectivity/productivity index of $4.6 \mathrm{~kg} / \mathrm{s} / \mathrm{bar}$.

The application of EGS technologies also enables the replication of the high success rates seen in the unconventional shale industry. Based on task force recommendations and reviews by GeoVision Visionary Team members, a 90\% drilling success rate and a 90\% stimulation success rate for EGS applications was assumed.

Hydrothermal resources are also able to take advantage of EGS technologies for well stimulation to increase the effective well success rate, resulting in a $90 \%$ success rate with EGS techniques used on dry holes. With a 90\% success rate, the GETEM assumes that only dry holes (in drilling phase) are stimulated.

\subsubsection{Power Plant}

The TI scenario does not make any assumptions about improvements to power plant costs or performance or about improvements to O\&M costs; it assumes the same values as in the BAU scenario. However, the GeoVision study assumes that all EGS plants use binary power plant technology when evaluating water usage impacts. It was assumed that EGS plants would always be binary plants because flash plants generally use condensate from the steam turbine as cooling water in a cooling tower. This requires makeup water to maintain the fluid level in the reservoir. There is concern that this practice will cause dissolved solids to build up in the reservoir fluid and create scaling or corrosion problems. Using binary plants, which reinject all the water that is produced from the reservoir, should alleviate this scaling issue. This assumption differs from the GETEM, which assumes that EGS uses flash plants at temperatures higher than $200^{\circ} \mathrm{C}$, as it does for conventional hydrothermal plants.

The assumption of using EGS binary plants for all EGS resources raises the following questions:

- Can binary plants operate effectively at high temperatures?

- What are the costs of these high-temperature binary systems relative to flash plants?

Many high-temperature $\left(>200^{\circ} \mathrm{C}\right)$ conventional hydrothermal resources that use binary plants and/or complete reservoir fluid injection are operating worldwide today. A partial list of hightemperature binary plants or plants using binary bottoming cycles to achieve complete reservoir

\footnotetext{
${ }^{8}$ Binary plants generally have higher production well flow rates than flash plants because the wells can be pumped to increase flow rates. Geothermal brine temperatures at flash plants are usually above the maximum operating temperature for downhole pumps or have two-phase (liquid and gas) flow in the well that would cause cavitation in the pump, and therefore must be self-flowing.
} 
fluid reinjection is shown in Table 9. All the plants in the list were designed by Ormat. The list consists of two types of plants:

- Binary or organic Rankine cycle plants: geothermal fluid, often two-phase, is used to vaporize an organic fluid that drives a turbine in a closed loop. Plants that use two-phase flow use a steam separator to generate both steam and liquid brine. The organic fluid is heated by a preheater with liquid brine and condensate and an evaporator heated by geothermal steam from a steam separator.

- Geothermal combined-cycle units (GCCU): consists of a back-pressure steam turbine and one or more organic Rankine cycle bottoming cycles that run on the turbine outlet fluid and/or geothermal brine.

Table 9. List of Installed Hydrothermal Power Plants Using Binary Plant Technology with HighTemperature Reservoirs

\begin{tabular}{|c|c|c|c|c|c|c|}
\hline Plant & Location & $\begin{array}{l}\text { Plant } \\
\text { Type }\end{array}$ & $\begin{array}{l}\text { Reservoir } \\
\text { Temperature } \\
\left({ }^{\circ} \mathrm{C}\right)\end{array}$ & $\begin{array}{l}\text { Steam Inlet } \\
\text { Temperature } \\
\left({ }^{\circ} \mathrm{C}\right)\end{array}$ & $\begin{array}{l}\text { Size } \\
\left(\mathrm{MW}_{\mathrm{e}}\right)\end{array}$ & Sources \\
\hline Rotokawa & $\begin{array}{l}\text { New } \\
\text { Zealand }\end{array}$ & GCCU & 330 & 226 & 33 & $\begin{array}{l}\text { Legmann and } \\
\text { Sullivan (2003) }\end{array}$ \\
\hline TOPP1 & $\begin{array}{l}\text { New } \\
\text { Zealand }\end{array}$ & Binary & 290 & NA & 20 & $\begin{array}{l}\text { McPherson, and } \\
\text { Koorey (2013) }\end{array}$ \\
\hline Mokai & $\begin{array}{l}\text { New } \\
\text { Zealand }\end{array}$ & GCCU & 324 & 208 & 60 & Legmann (2000) \\
\hline Ngatamariki & $\begin{array}{l}\text { New } \\
\text { Zealand }\end{array}$ & Binary & 290 & 192 & 100 & Legmann (2015) \\
\hline Ngawha & $\begin{array}{l}\text { New } \\
\text { Zealand }\end{array}$ & Binary & 320 & 230 & 33 & Koorey (2008) \\
\hline Sarullo, SIL & Indonesia & GCCU & 275-310 & 213 & 118 & $\begin{array}{l}\text { Wolf and Gabbay } \\
(2015)\end{array}$ \\
\hline $\begin{array}{l}\text { Aluto } \\
\text { Langano }\end{array}$ & Ethiopia & $\begin{array}{l}1 \text { GCCU } \\
\text { and } 1 \\
\text { Binary }\end{array}$ & $\mathrm{Na}$ & 180 & 8.5 & Tassew (2010) \\
\hline $\begin{array}{l}\text { Puna } \\
\text { (Expansion) }\end{array}$ & Hawaii & GCCU & $\sim 315$ & $\sim 200$ & 38 & $\begin{array}{l}\text { Kaleikini, } \\
\text { Spielman, and } \\
\text { Buchanan } \\
\text { (2011); Richard } \\
\text { (1990) }\end{array}$ \\
\hline $\begin{array}{l}\text { Upper } \\
\text { Mahiao }\end{array}$ & Phillipines & GCCU & 324 & 184 & 125 & $\begin{array}{l}\text { Forte (1996); } \\
\text { Dobbie, and } \\
\text { Menzies. (1979) }\end{array}$ \\
\hline
\end{tabular}

The list shows that organic Rankine cycle plants and GCCUs that use organic Rankine cycle bottoming cycles are capable of handling fluids from reservoirs with temperatures well above $300^{\circ} \mathrm{C}$ while completely condensing and reinjecting all the fluid produced from the reservoir.

Although many papers describe the operation of high-temperature binary plants, little publicly available data details their cost. A conversation with representatives from Ormat on April 26, 
2017, revealed that these high-temperature binary systems and GCCUs are comparable in terms of costs on a dollar per $\mathrm{kW}$ basis to a double flash plant, as assumed in the GETEM, and generally have less O\&M costs than flash plants. Therefore, it seems a safe assumption that using cost estimates for flash plants from the GETEM while assuming water use impacts similar to those of binary plants is justified for the GeoVision study.

\subsubsection{Resulting Supply Curves}

The improved scenario assumes that there will be improved land access and that the barriers that currently limit the areas where geothermal projects can be practically developed will be removed, resulting in more land available for development. Table 4 and Young et al. (2019) have more details on these barriers and the resulting geothermal resources available for development. The result is that the resource potential of developable geothermal resources increases.

The resulting supply curves for the TI scenario are shown in Figure 9. The axis for available capacity has been truncated to make the figure readable. The capacity for deep EGS resources extends beyond 4,200,000 $\mathrm{MW}_{\mathrm{e}}$ while the overnight capital costs remain below $\$ 10,000 / \mathrm{kW}_{\mathrm{e}}$ for the entire deep EGS supply curve. 


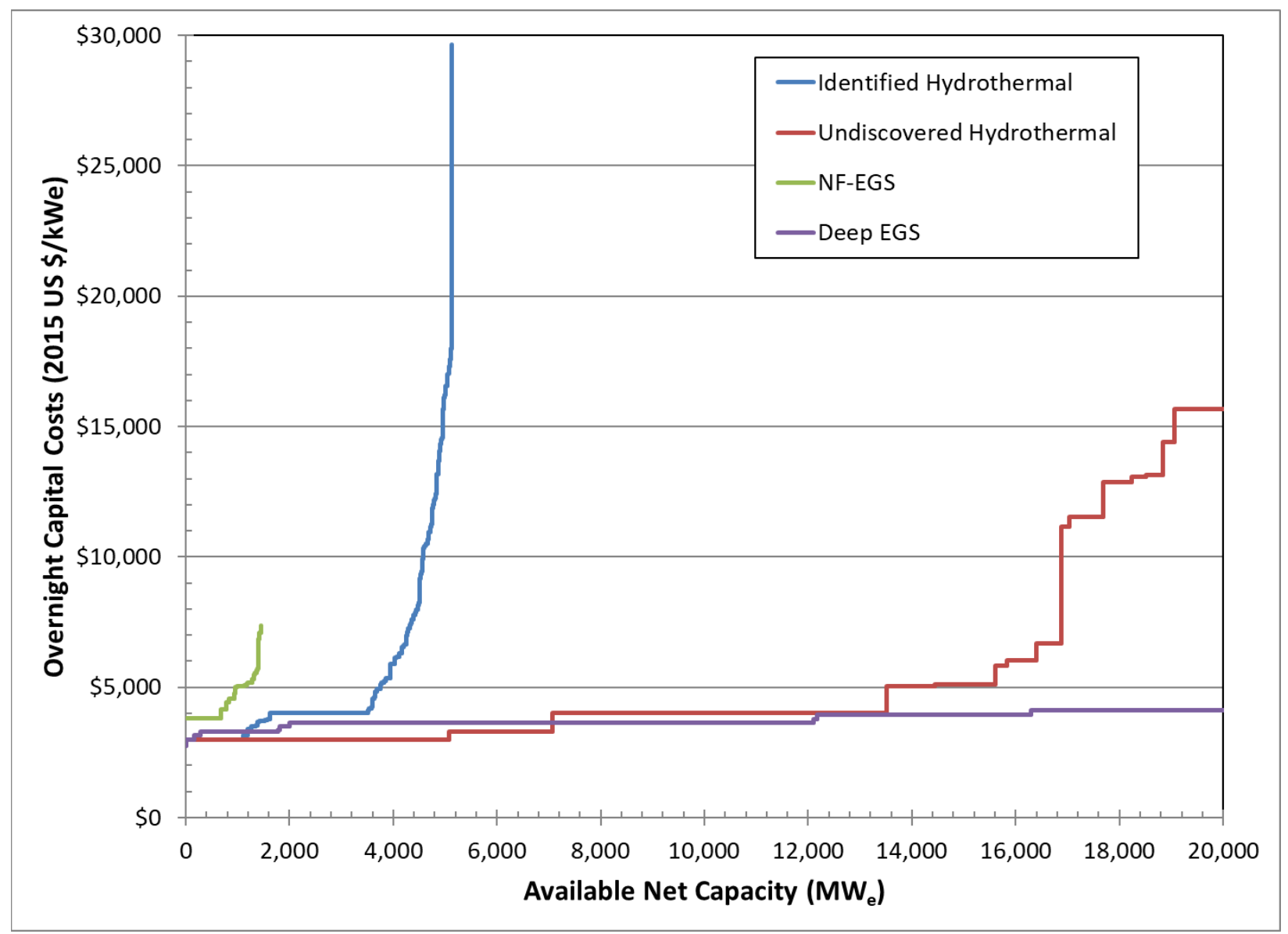

Figure 9. Geothermal supply curve for the GeoVision TI scenario. The capacity and capital cost axes are truncated for readability.

A number of observations can be made from the resulting supply curves for the TI scenario. First, the TI scenario has a noticeable impact on the overnight capital costs of hydrothermal technologies relative to the BAU scenario, especially for lower temperature, higher cost resources farther out on the supply curve. Although some resources will likely become commercially competitive, many of the lower temperature resources are still too expensive to be deployed in most circumstances. Second, the undiscovered hydrothermal resource continues to dominate the hydrothermal supply curves, as in the BAU scenario. Third, EGS capital costs are decreased significantly compared to the BAU scenario because of technology improvements and cost reductions. A large amount of EGS, especially deep EGS, should be cost-competitive. When compared to the other geothermal supply curves, it appears that deep EGS should make up the majority of geothermal deployment in the TI scenario.

\subsubsection{ReEDS Input Assumptions}

\subsubsection{Financing Assumptions}

As stated in the BAU scenario, geothermal projects currently have higher financing costs than most other electricity generation projects because of the high risk of the early exploration and drilling phases. Debt financing is typically not available during the earliest stages, and the project relies on equity financing. 
The TI scenario includes technology advances that greatly decrease the risk of geothermal projects. Predrilling exploration uses big data analytics and exploration technology advances to achieve high success rates for projects that move beyond predrilling into the drilling phase, reducing overall project risk. High exploration drilling success rates further increase overall exploration success rates, reducing project risk. EGS stimulation technologies, based on technologies and best practices from the unconventional shale industry, are advanced and employed in both hydrothermal and EGS settings. This leads to higher drilling success rates and reduced overall risk.

These technology advances and reduced risks decrease the cost of financing in the TI scenario. Wall, Dobson, and Thomas (2017) studied the impact of these technologies in analogous resource-focused industries that incorporate these technologies, such as the petroleum industry. The report outlines the potential for alternative capital structures and financing rates under a set of possible scenarios. The High Technology scenario in particular is very similar to the TI scenario for GeoVision and was used as a basis with some modifications.

For the TI scenario, which borrows technologies from the petroleum industry, the GeoVision study assumes that equity financing for the exploration and development phase of the geothermal project is the same as the cost of equity from a leading major oil and gas operator using similar technology, such as Exxon Mobil and Chevron. The GeoVision study assumes debt and equity costs from current geothermal developers during plant construction and operation. Current and historical data from Bloomberg LP were collected for major public companies in these industries (e.g., Exxon and Ormat) to determine the numerical values assumed as representative for the GeoVision (Bloomberg LP 2016a, 2016b, 2016c, 2016d).

The results of this analysis are WACC values that range from $4.29 \%-5.01 \%$ for the scenarios evaluated. These WACC values are significantly less than the standard ReEDS assumption of $8 \%$ WACC used for all other electricity generation technologies in the ReEDS model. It did not seem reasonable that geothermal technologies would be able to obtain financing at rates less than that of other electricity generating technologies. Therefore, GeoVision assumed the ReEDS standard 8\% WACC for all geothermal technologies including hydrothermal and EGS. This basically assumes that geothermal has a risk profile similar to other electricity generation technologies and can obtain financing on the same terms as other energy technologies. Because geothermal tends to have longer construction periods than most other electricity generation technologies, the resulting total cost of financing for geothermal projects is still generally more than competitors.

\subsubsection{Construction Timelines}

The TI scenario incorporates the improved permitting process from the IRT scenario, and therefore uses the same assumptions for construction timelines. The ability to use IRT's reduced regulatory burdens and streamlined regulations results in a decrease in the construction timeline for geothermal. The hydrothermal construction timeline is shortened from 8 years in the BAU scenario to 4 years in the TI scenario. The EGS construction timeline is shortened from 10 years in the BAU scenario to 5 years in the TI scenario. The TI scenario also assumes the same increased discovery rate for undiscovered geothermal resources from $1 \%$ per year to $3 \%$ per year. 


\subsubsection{Implementation of Technology Improvement Scenario in ReEDS}

As mentioned previously, EGS technologies are still being developed and are currently not commercially available for widespread deployment. The DOE Geothermal Technologies Office is developing a dedicated site called the Frontier Observatory for Research in Geothermal Energy (FORGE) where scientists and engineers will be able to develop, test, and accelerate breakthroughs in EGS technologies and techniques (DOE 2018b). FORGE's mission is to enable cutting-edge research and drilling and technology testing as well as to allow scientists to identify a replicable, commercial pathway to EGS. The TI scenario assumes EGS technology progression moving from in-field or hydrothermal-only application, to NF-EGS (using techniques, technologies, and lessons learned at FORGE), to large-scale deep EGS deployment.

The first EGS technologies likely to be used are at existing conventional hydrothermal fields. These in-field EGS techniques will be used to increase the productivity and injectivity of dry or noncommercial hydrothermal wells - wells that would otherwise be stranded capital. The overall costs and risks associated with drilling hydrothermal wells would be decreased if well sites could be made usable for injection or production by connecting them with the existing reservoir or creating new reservoirs via EGS.

In-field EGS is already being used at existing hydrothermal sites. For example, the Geysers has been reinjecting treated municipal wastewater since 1997 to sustain steam production, resulting in $155 \mathrm{MW}_{\mathrm{e}}$ of additional capacity (Khan 2010). More recently, three DOE-funded EGS demonstration projects in the United States have shown success using in-field EGS techniques (DOE 2018a). In the first, at the Desert Peak power plant in Nevada, the injectivity of a well was increased 175 -fold using various stimulation techniques, enabling the plant to increase its power output by $1.7 \mathrm{MW}_{\mathrm{e}}$ (Chabora and Zemak 2013). Similarly, stimulation techniques were used on a subcommercial injection well at Raft River, Idaho, to increase its injectivity to commercial rates of roughly 1,000 gpm (Informatics 2018). And at the Geysers field in California, stimulation of an abandoned geothermal well resulted in the creation of a new reservoir yielding enough steam to generate 5 MWe of electricity (Walters 2013).

As the experience at the Geysers suggests, the next stage is likely to be EGS in the areas around existing or known hydrothermal resources, or NF-EGS. The areas around or under existing hydrothermal systems have elevated temperatures from the nearby thermal anomaly but lack permeability and a connected fracture network. Because of their proximity to existing sites, these areas are usually well characterized and close to existing infrastructure, and they are likely to be low-hanging fruit for next-stage EGS development.

As EGS techniques are refined, applications will expand to create stand-alone, greenfield (and typically deep) EGS. These will be reservoirs created in areas with high temperatures but no existing conventional hydrothermal system. EGS reservoirs will be created by drilling wells and connecting them by creating a commercial fracture network via well stimulation and will be available for harvesting thermal energy and the production of hot fluids for electricity generation. Lessons learned by creating these initial greenfield EGS reservoirs could be used to develop additional reservoirs in the area at less cost, resulting in EGS farms with large aggregate capacity. 
The TI scenario requires significant technology advances, and these take time to develop. Therefore, the ReEDS model does not assume that they are available instantly. Likewise, if ReEDS does predict large increases in geothermal deployment, it will take some time for the geothermal industry to ramp up; however, ReEDS does not take industry growth rates into direct consideration, so additional assumptions were made to address this issue. For hydrothermal resources, technology improvements are implemented using a linear cost reduction curve to take project costs from BAU values to the TI values. Costs decrease linearly from the BAU values in 2015 to TI scenario values in 2030. EGS technology improvements also assume a linear cost reduction from BAU values to TI values, but the schedule differs. Early EGS deployment is most likely to come from NF-EGS because areas around existing hydrothermal fields are known and have existing infrastructure. NF-EGS should also be able to take advantage of FORGE reservoir development technologies in the years after its completion, around the 2022-2024 time frame.

The TI scenario was implemented in ReEDS by assuming that NF-EGS achieves its cost reductions before deep EGS. This effectively makes it so that NF-EGS is commercially viable before deep EGS. For GeoVision, it was assumed that NF-EGS takes advantage of research-anddevelopment and other lessons resulting from FORGE and achieves its cost reductions by 2024 (after completion of the FORGE initiative) so that NF-EGS reaches full improved technology costs in ReEDS in 2024. Deep EGS costs decrease linearly from BAU scenario values in 2015 to TI scenario values in 2030, the same as the hydrothermal technologies.

ReEDS does not model industry ramp-up by default. To recognize that it will take some time for the EGS industry to become established, it was assumed that there were limits on how much NFEGS can be deployed initially. NF-EGS deployments were limited to $50 \mathrm{MW} / \mathrm{yr}$ in 2024 and increased to $100 \mathrm{MW} / \mathrm{yr}$ in 2026 and $200 \mathrm{MW} / \mathrm{yr}$ in 2028. No limits were imposed in and after 2030. These growth rates are small compared to the overall size of the geothermal industry at any given point, but they are comparable to annual capacity additions that have occurred in recent years. This scenario prevents EGS from being deployed at unrealistic rates early in its lifetime, but it allows the ReEDS model to determine if any NF-EGS is deployed at all based on its cost relative to demand and competition

The identified hydrothermal resources are available for immediate deployment, as in the BAU scenario. Undiscovered hydrothermal resources first become available for deployment in 2020, with the assumption that the amount of undiscovered hydrothermal resource increases annually at a rate of $3 \%$ of the total available undiscovered hydrothermal resource. This $3 \%$ per year discovery rate reflects that the undiscovered hydrothermal resource is currently hidden and that the geothermal industry discovers it over time. Other ReEDS inputs, such as capacity factor, are the same as assumed in the BAU scenario. 


\subsection{Summary of GeoVision Scenarios and ReEDS Inputs}

A summary of the GeoVision scenarios and the inputs and assumptions used to model them in ReEDS is shown in Table 10.

Table 10. Summary of GeoVision Scenario Inputs in ReEDS

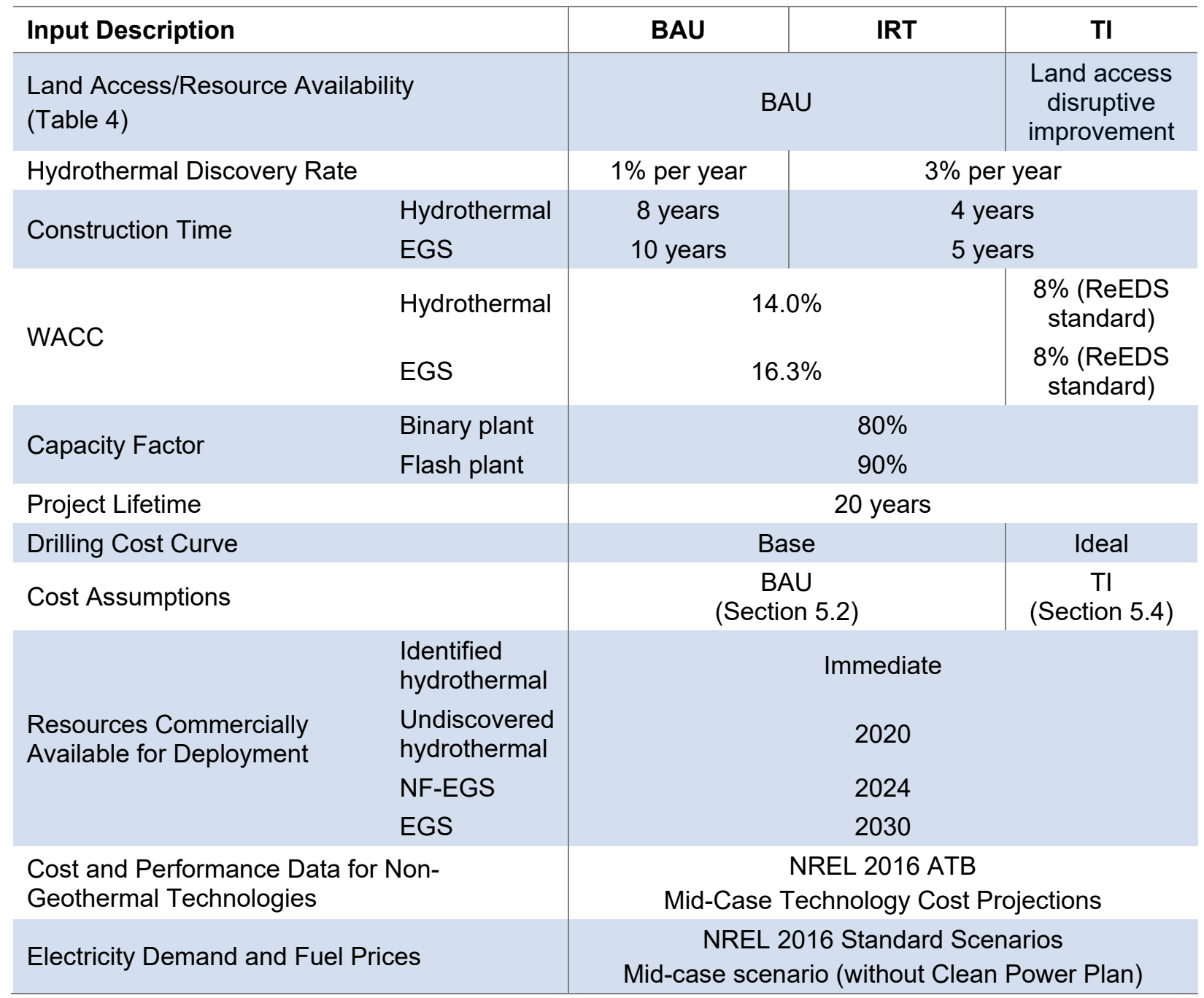




\section{GeoVision Scenario Analysis and Results}

\subsection{Business-as-Usual Scenario}

For the BAU scenario, the ReEDS model was run using the BAU supply curves for geothermal described in Section 5.2 and the Mid-case scenario from NREL's Standard Scenarios. The resulting cumulative installed geothermal capacity by year is shown in Figure 10.

The total installed geothermal capacity in 2050 for the BAU scenario ReEDS run is $5,924 \mathrm{MW}_{\mathrm{e}}$. This matches well with the $2 \%$ industry growth rate discussed in Section 2.2, which projects about $5.1 \mathrm{GW}_{\mathrm{e}}$ of installed geothermal capacity by 2050 . This agreement indicates that the assumed $1 \%$ per year discovery rate is appropriate and that the BAU scenario reflects current industry trends. The vast majority of new geothermal capacity deployed in the BAU scenario is undiscovered hydrothermal. This implies that exploration technologies and the amount of exploration that the geothermal industry does are important factors for the growth of the geothermal industry. EGS technologies are not deployed in the BAU scenario; with BAU technology and performance assumptions, their overnight capital costs are too high for them to be commercially competitive in the ReEDS model.

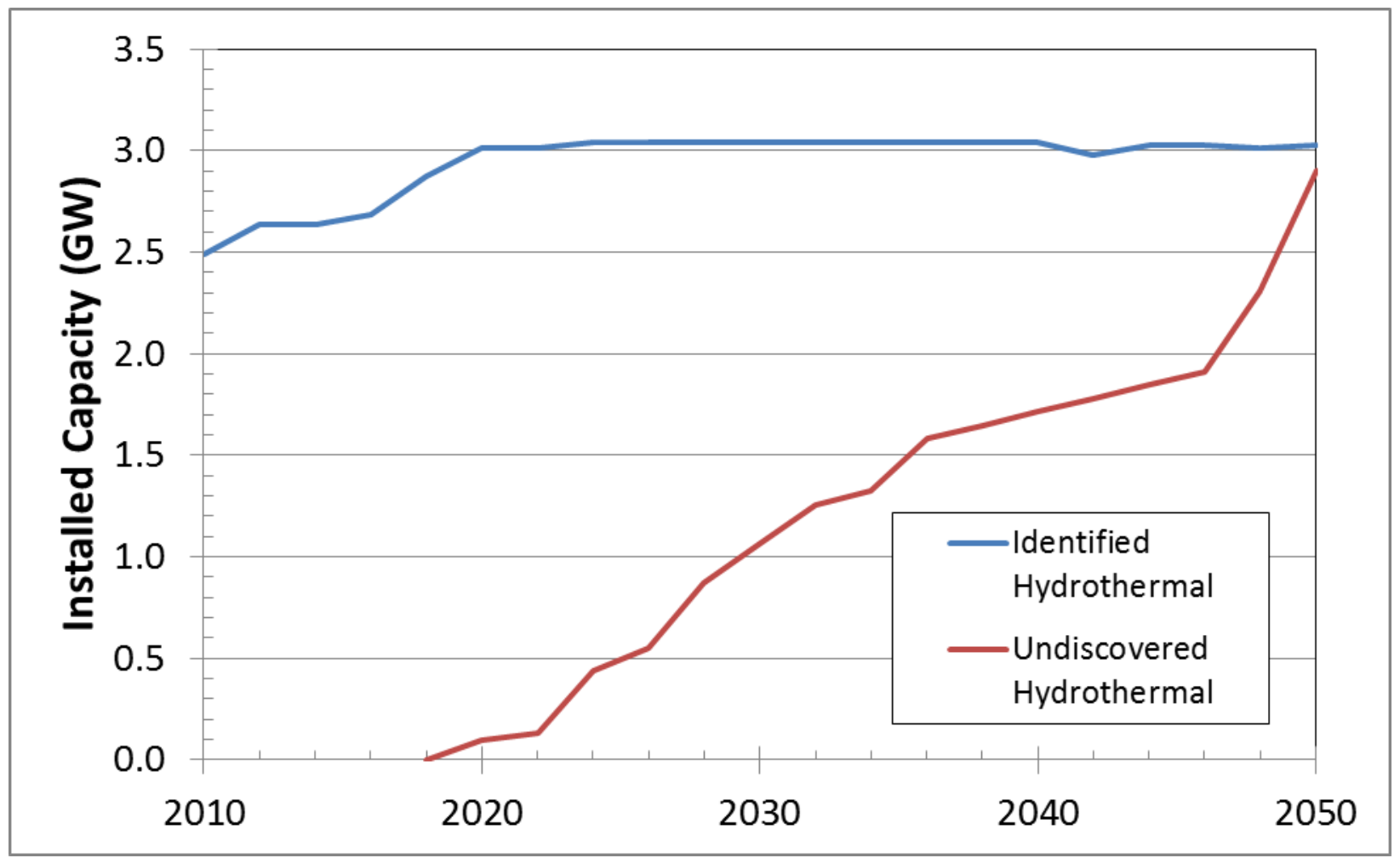

Figure 10. Installed geothermal capacity by year for the BAU scenario

The cumulative installed capacity by year for all technologies in ReEDS for the BAU scenario is shown in Figure 11. Geothermal installed capacity is barely visible at the bottom of the figure and makes up only $0.34 \%$ of total installed capacity in 2050 , which is comparable to the $0.3 \%$ of total installed capacity now. 


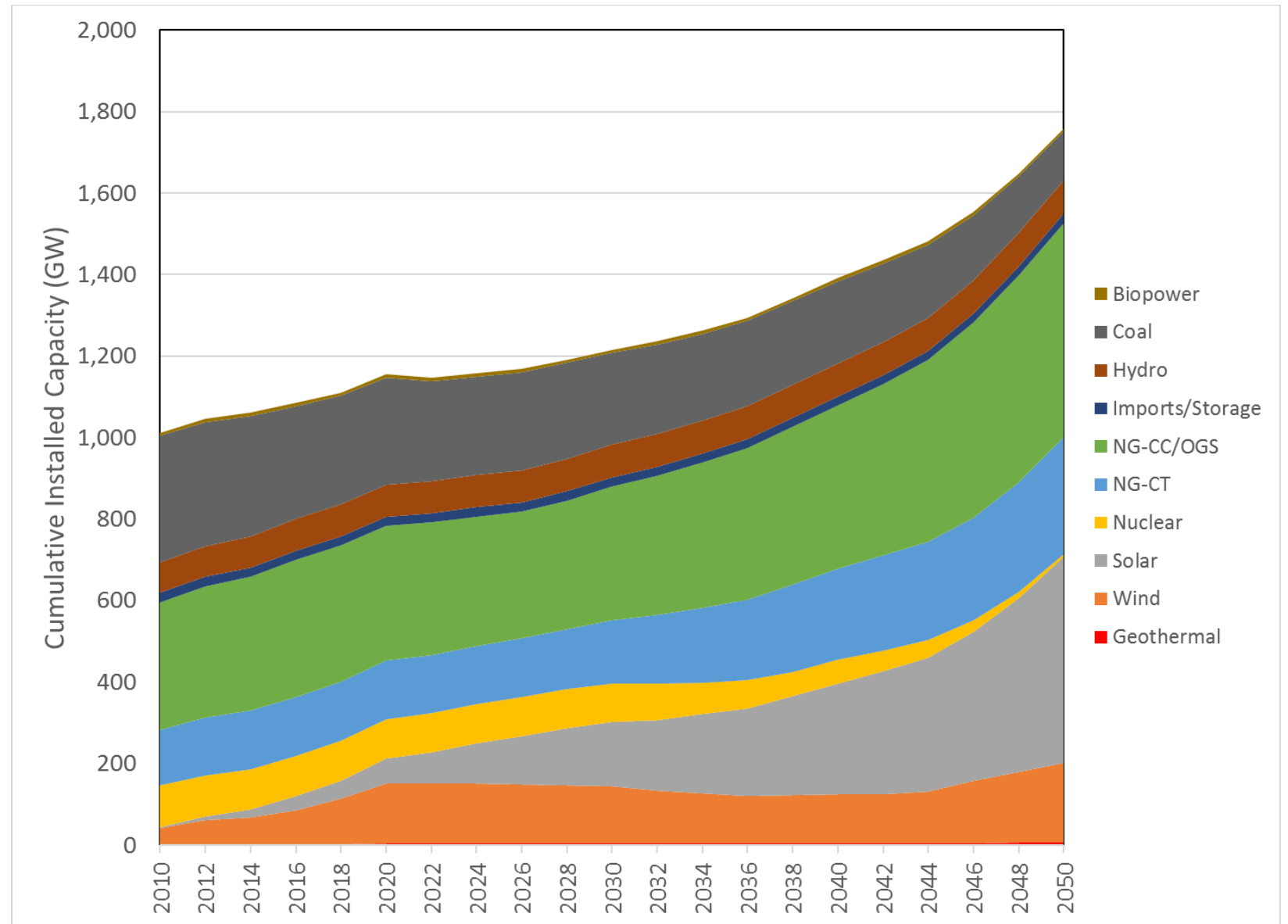

Note: NG-CC = Natural Gas Combined Cycle; OGS = Oil/Gas Steam Turbine; NG-CT = Natural Gas Combustion Turbine

Figure 11. Cumulative installed capacity by year for all technologies in ReEDS for the BAU scenario

The annual electricity generation by year for all technologies in ReEDS for the BAU scenario is shown in Figure 12. Geothermal generates 44.09 TWh of electricity in 2050, which is about $0.84 \%$ of overall generation, compared to $17.4 \mathrm{TWh}$ of electricity in 2016 , or about $0.3 \%$ of overall generation. Both values suggest that in the BAU scenario, geothermal remains a niche player in the electricity generation market. A map of geothermal capacity by ReEDS BAA is shown in Figure 13. It shows that as is currently the case, geothermal installations are limited to the western United States in the BAU scenario, with the majority of installed capacity in California. 


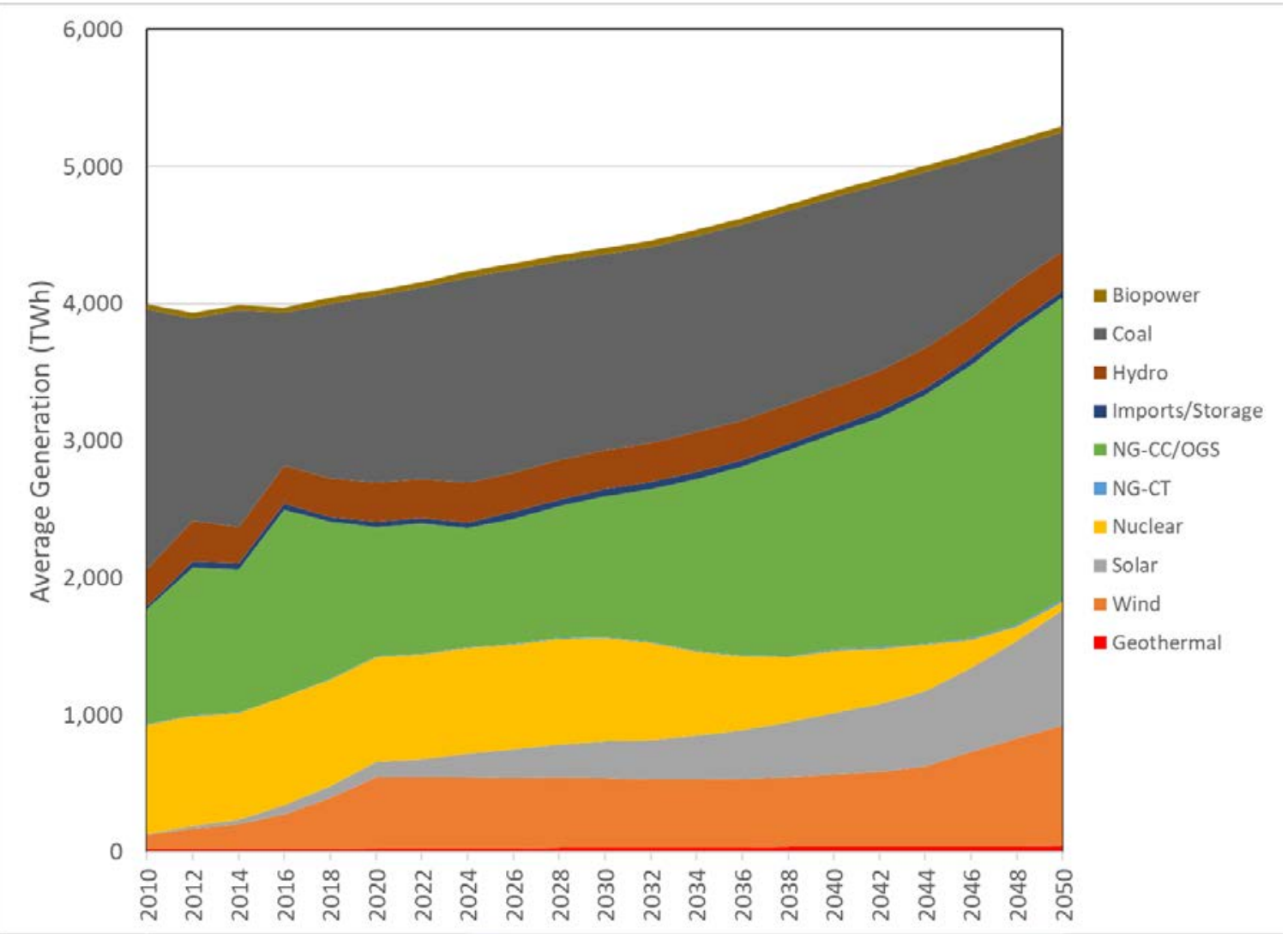

Figure 12. Annual electricity generation by year for all technologies in ReEDS for the BAU scenario

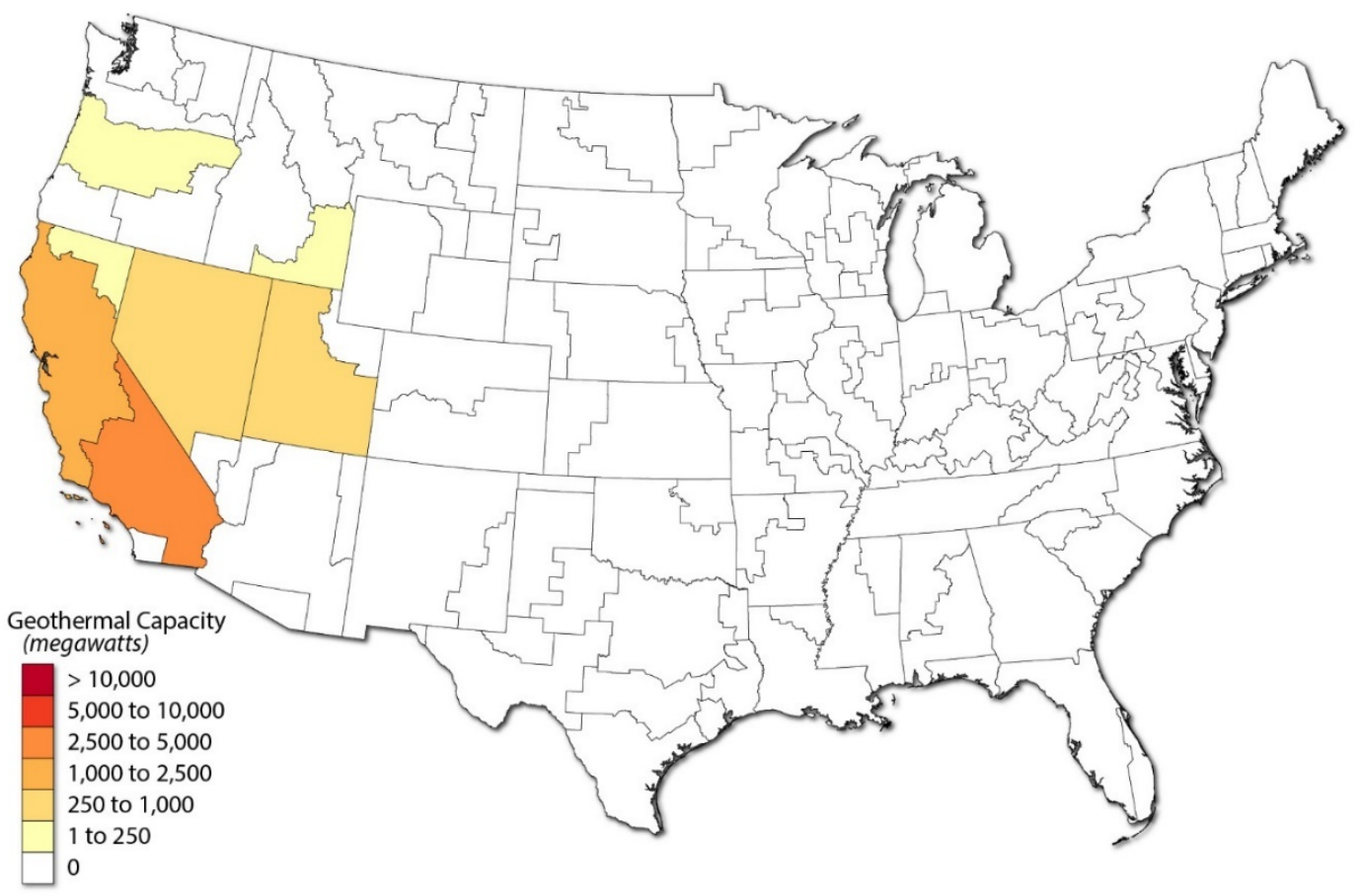

Figure 13. Map of installed geothermal capacity by ReEDS BAA in 2050 for the BAU scenario 


\subsubsection{Key Results}

The results of the GeoVision BAU scenario show that absent any substantial changes to the industry, geothermal will continue to be a niche player in the electricity generation market, with capacity additions confined to the western United States. Most new geothermal capacity additions come from undiscovered hydrothermal resources, indicating that the exploration and discovery of new geothermal resources is key to additional conventional hydrothermal deployment. EGS technologies are too costly to be competitive in the BAU scenario, and none are deployed within the ReEDS model.

\subsection{Improved Regulatory Timeline Scenario}

For the IRT scenario, the ReEDS model was run using the BAU supply curves for geothermal described in Section 5.3 and the Mid-case scenario from NREL's Standard Scenarios. But it assumes that an improved permitting process and access to categorical exclusions shorten the project construction time from 8 years to 4 years for hydrothermal and from 10 years to 5 years for EGS. It also assumes that easier and faster access to sites for exploration triples the rate of discovery of hydrothermal resources to $3 \%$ per year.

The resulting cumulative installed geothermal capacity by year is shown in Figure 14. The total installed geothermal capacity in 2050 is $12,891 \mathrm{MW}_{\mathrm{e}}$. This is more than double the value in the BAU scenario. As in the BAU scenario, the vast majority of geothermal deployed in the IRT scenario is undiscovered hydrothermal resources. This supports the observation from the BAU scenario that exploration technologies and the amount of exploration that the geothermal industry performs are important factors for the growth of the geothermal industry. EGS technologies are not deployed in the IRT scenario. This is not surprising because the IRT scenario uses the same geothermal supply curve as the BAU scenario. Even with the reductions in construction time, the EGS overnight capital costs are too high for them to be commercially competitive in the ReEDS model.

The cumulative installed capacity by year for all technologies in ReEDS for the IRT scenario is shown in Figure 15, and the annual electricity generation by year for all technologies in ReEDS for the IRT scenario is shown in Figure 16. Geothermal makes up 0.75\% of total installed capacity in 2050, and it generates 95.9 TWh of electricity, or $1.8 \%$ of all electricity generation. 


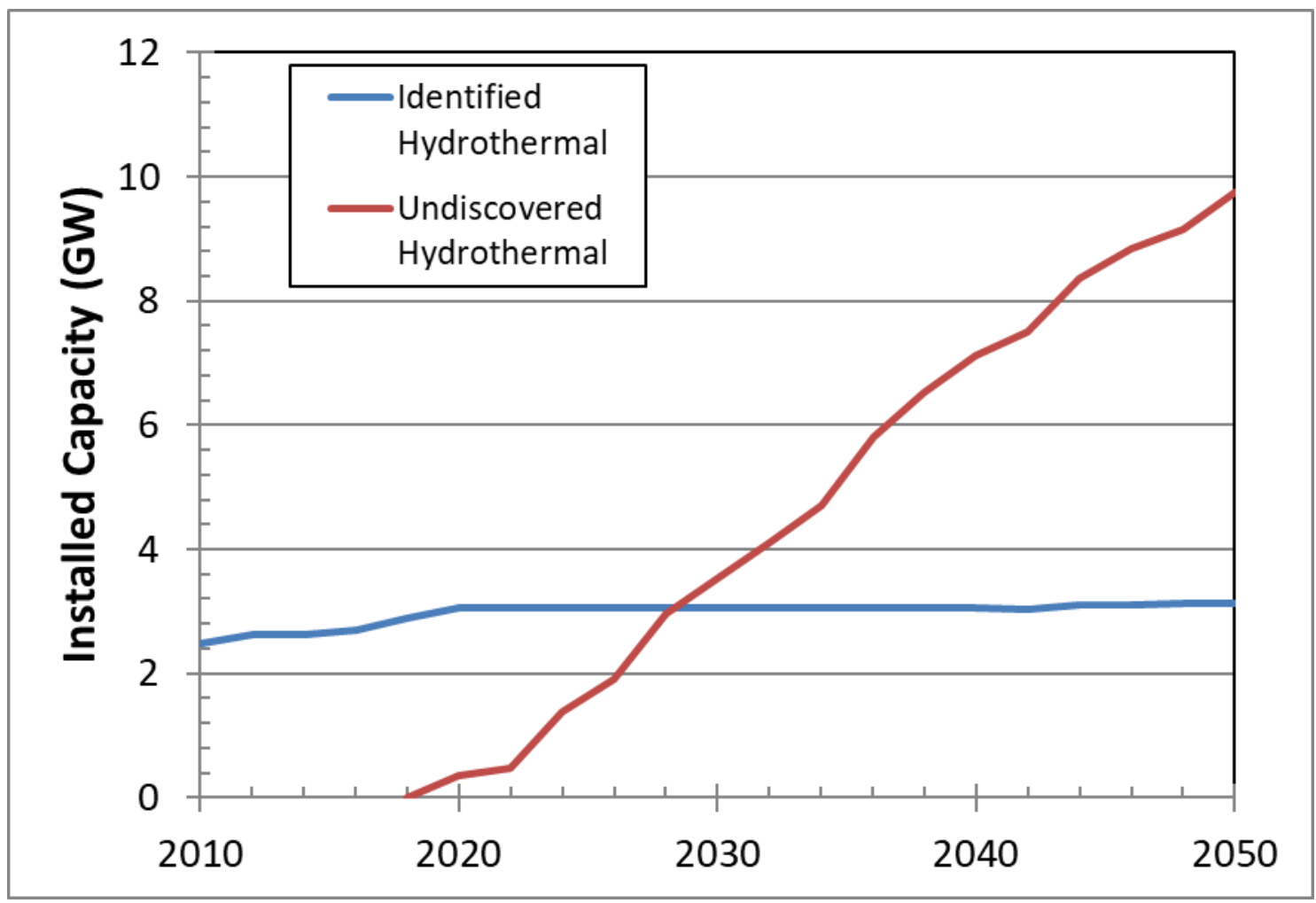

Figure 14. Installed geothermal capacity by year for the IRT scenario

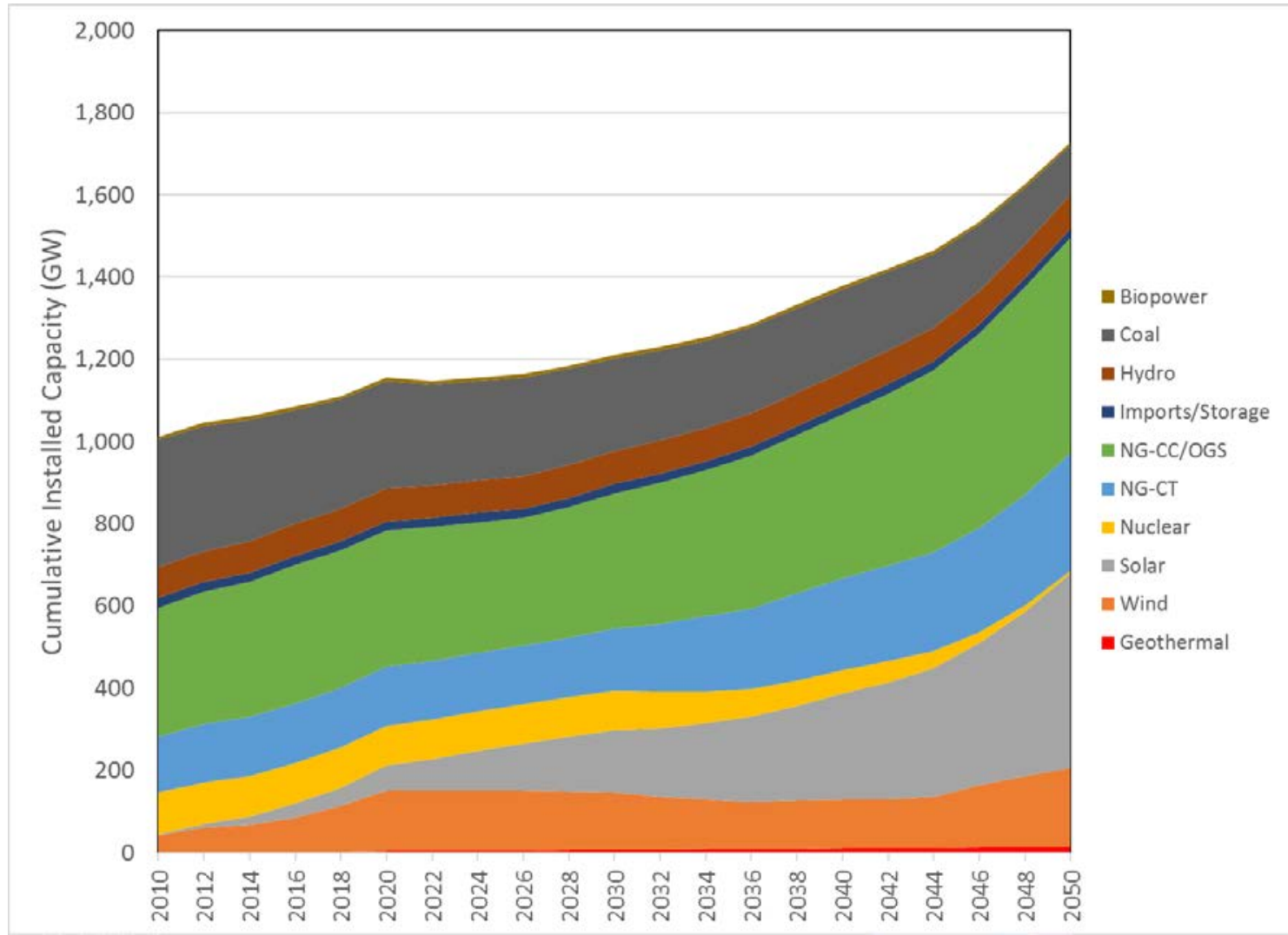

Figure 15. Cumulative installed capacity by year for all technologies in ReEDS for the IRT scenario 


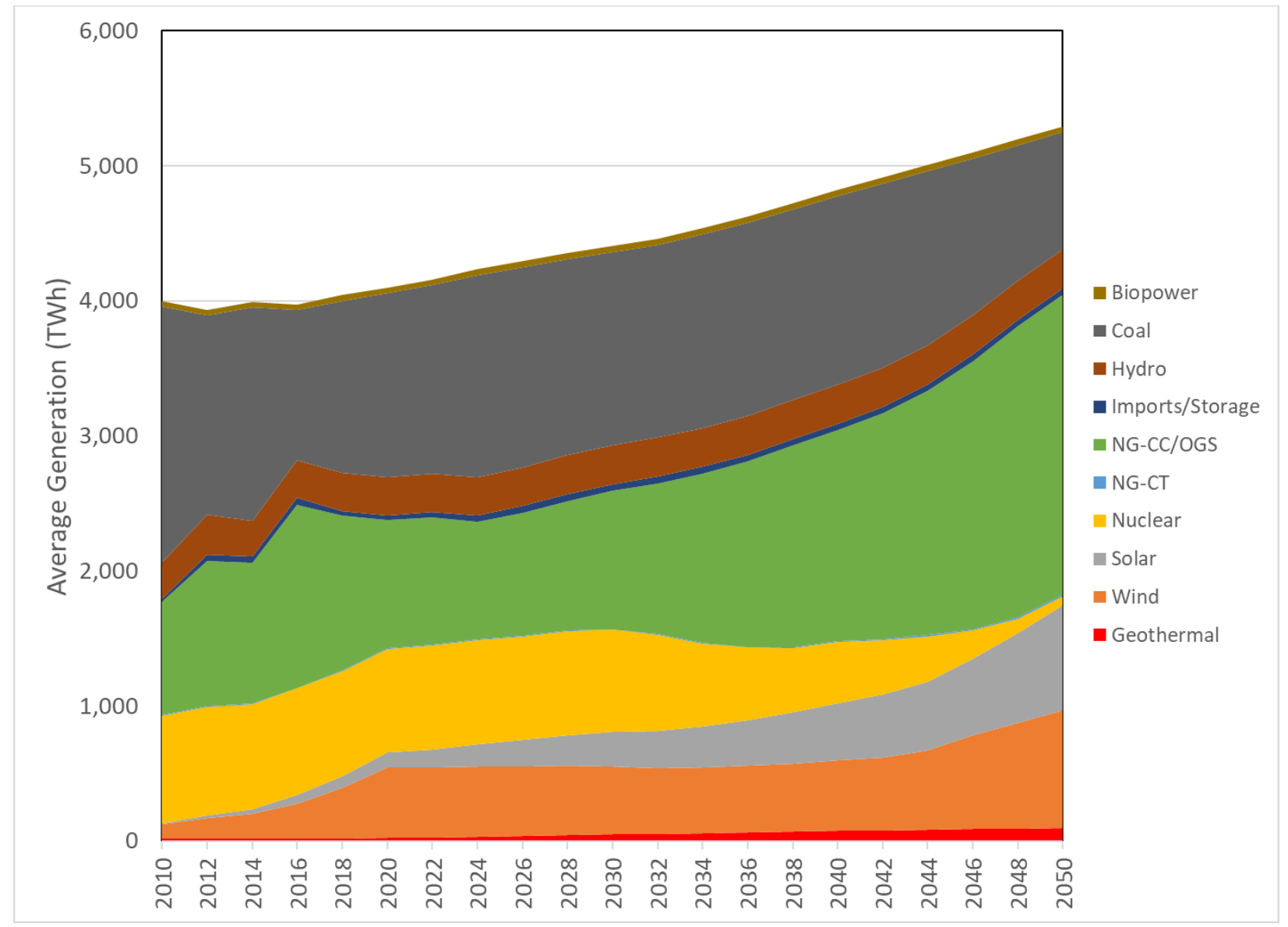

Figure 16. Annual electricity generation by year for all technologies in ReEDS for the IRT scenario

A map of the installed geothermal capacity in 2050 for the IRT scenario is shown in Figure 17. As in the BAU scenario, geothermal electricity generation deployments remain confined to the western United States. In fact, the ReEDS BAAs where there is installed geothermal capacity in the IRT scenario are identical to those in the BAU scenario (Figure 13). In the IRT scenario, no EGS resources are deployed, so geothermal installations are confined to areas with good conventional hydrothermal resources. By comparison, analysis of geothermal heat pumps in the full GeoVision report (DOE, 2019) shows that they are deployed over a much broader geographic region. Geothermal heat pumps use the earth as a heat sink and source and can be deployed almost anywhere where a subsurface heat loop can be installed. Like wind turbines and solar photovoltaics, their performance will depend on the conditions at a given location, but technically they can be installed and will function. Conventional hydrothermal resources, on the other hand, are geologic anomalies. If a hydrothermal reservoir does not exist at a site, then a hydrothermal power plant is simply not a possibility. This inherent trait restricts conventional hydrothermal deployment to specific locations in limited regions and results in a severe siting limitation. The promise of EGS technologies for the geothermal industry is that the requirements for site suitability are much more relaxed since the reservoir is created, not found. As the next section shows, this greatly expands the geographic extent for geothermal electricity generation potential. 


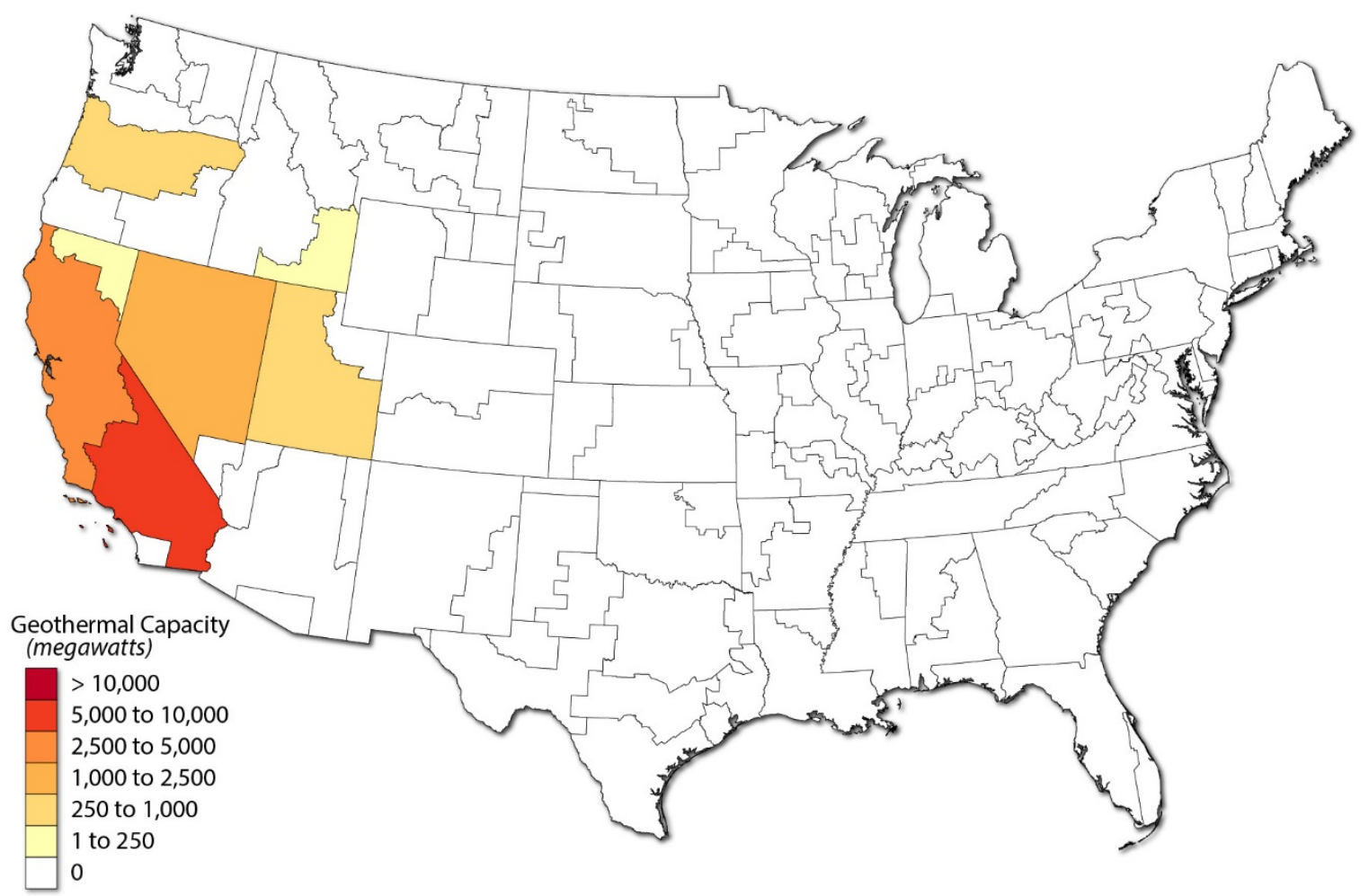

Figure 17. Map of installed geothermal capacity by ReEDS BAA in 2050 for the IRT scenario

\subsubsection{Key Results}

The IRT scenario results indicate that the geothermal industry could double in size by regulation reform alone. Reducing construction timelines can have big impacts on overall project costs and subsequent deployment absent any technology advances, meaning that hydrothermal resources could show significantly more deployment even with current technology if soft costs and barriers are reduced. As in the BAU scenario, most of the new geothermal capacity additions come from undiscovered hydrothermal resources, illustrating that the exploration and discovery of new geothermal resources remain key to additional conventional hydrothermal deployment. EGS technologies remain too costly to be deployed in the IRT scenario, despite the shorter assumed construction timeline.

\subsection{Technology Improvement Scenario}

For the TI scenario, the ReEDS model was run using the TI supply curves for geothermal described in Section 5.4 and the Mid-case scenario assumptions from NREL's Standard Scenarios. It includes the IRT scenario assumptions of an improved permitting process and access to categorical exclusions that shorten the project construction time and assume a rate of discovery of hydrothermal resources of 3\% per year. It also assumes that geothermal projects can obtain financing at the ReEDS standard WACC, the same as all other electricity generation technologies in the ReEDS model.

The resulting cumulative installed geothermal capacity by year is shown in Figure 18. The total installed geothermal capacity in 2050 is $60,701 \mathrm{MW}$. Most of the installed capacity is deep EGS resource, with $43.6 \mathrm{GW}_{\mathrm{e}}$ of installed capacity by 2050 . About $580 \mathrm{MW}_{\mathrm{e}}$ of NF-EGS is installed 
by 2030. To simulate the amount of time it will take for the geothermal industry to ramp up EGS deployments, hard limits were put on the amount of NF-EGS that could be deployed each year (see Section 5.4.3.3 for full details). The ReEDS modeling reaches these hard limits in 2024 and 2026 (ReEDS makes capacity addition decisions in 2-year increments), but it fails to reach the limit in 2028 because the best NF-EGS resources have already been developed.

Hydrothermal resources are deployed consistently throughout the modeled time frame. As in the BAU and IRT scenarios, the majority of the hydrothermal capacity additions come from undiscovered hydrothermal resources. The model assumes that these resources are discovered, i.e., become available for development, at a rate of $3 \%$ per year of the total undiscovered resource. These resources are developed continually as they become available.

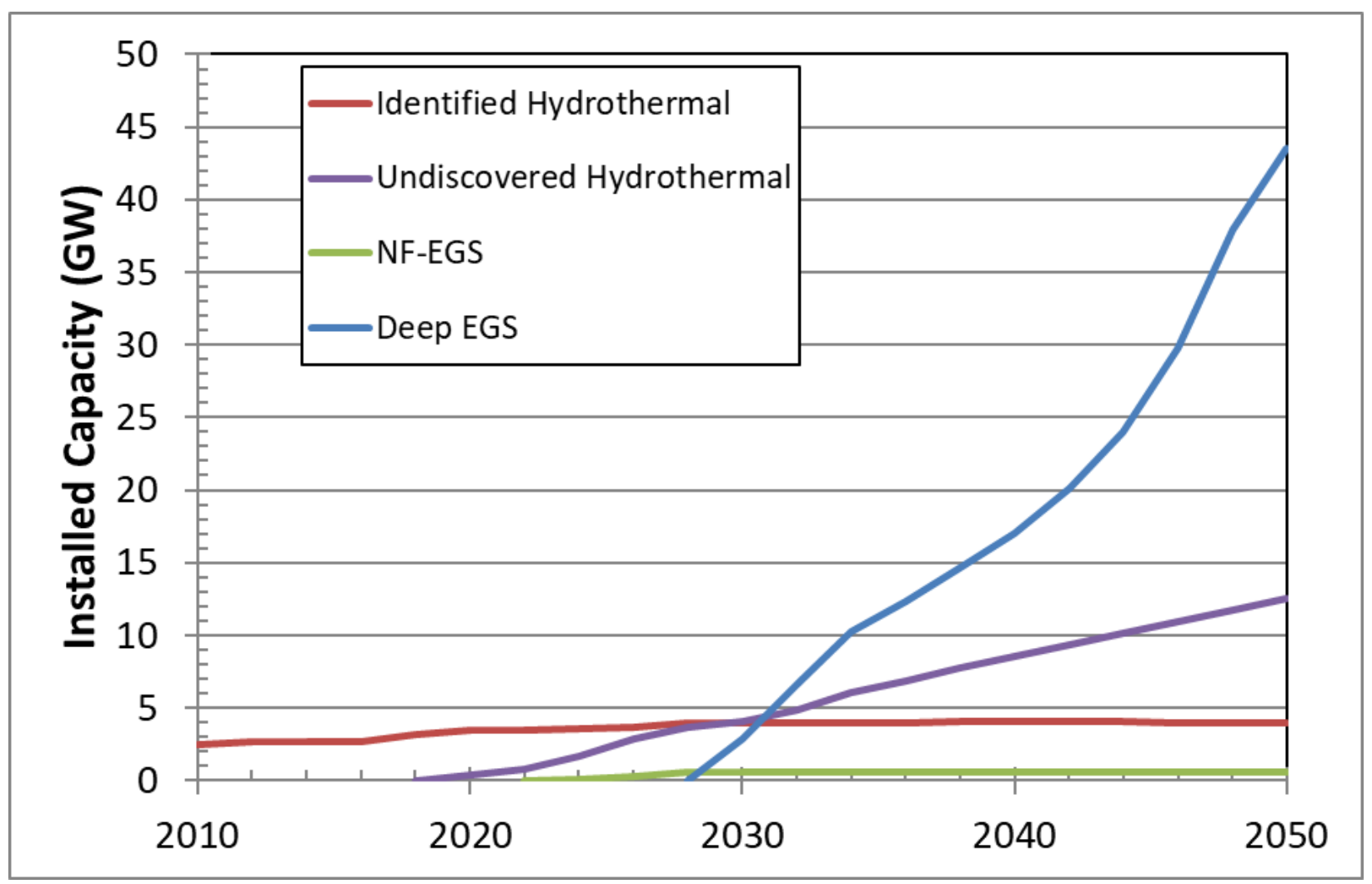

Figure 18. Installed geothermal capacity by year for the TI scenario

The cumulative installed capacity by year for all technologies in ReEDS for the TI scenario is shown in Figure 19, and the annual electricity generation by year for all technologies in ReEDS for the TI scenario is shown in Figure 20. Geothermal in the TI scenario makes up 3.7\% of total installed capacity in 2050 , and it generates $452 \mathrm{TWh}$ of electricity or $8.5 \%$ of all electricity generation. 


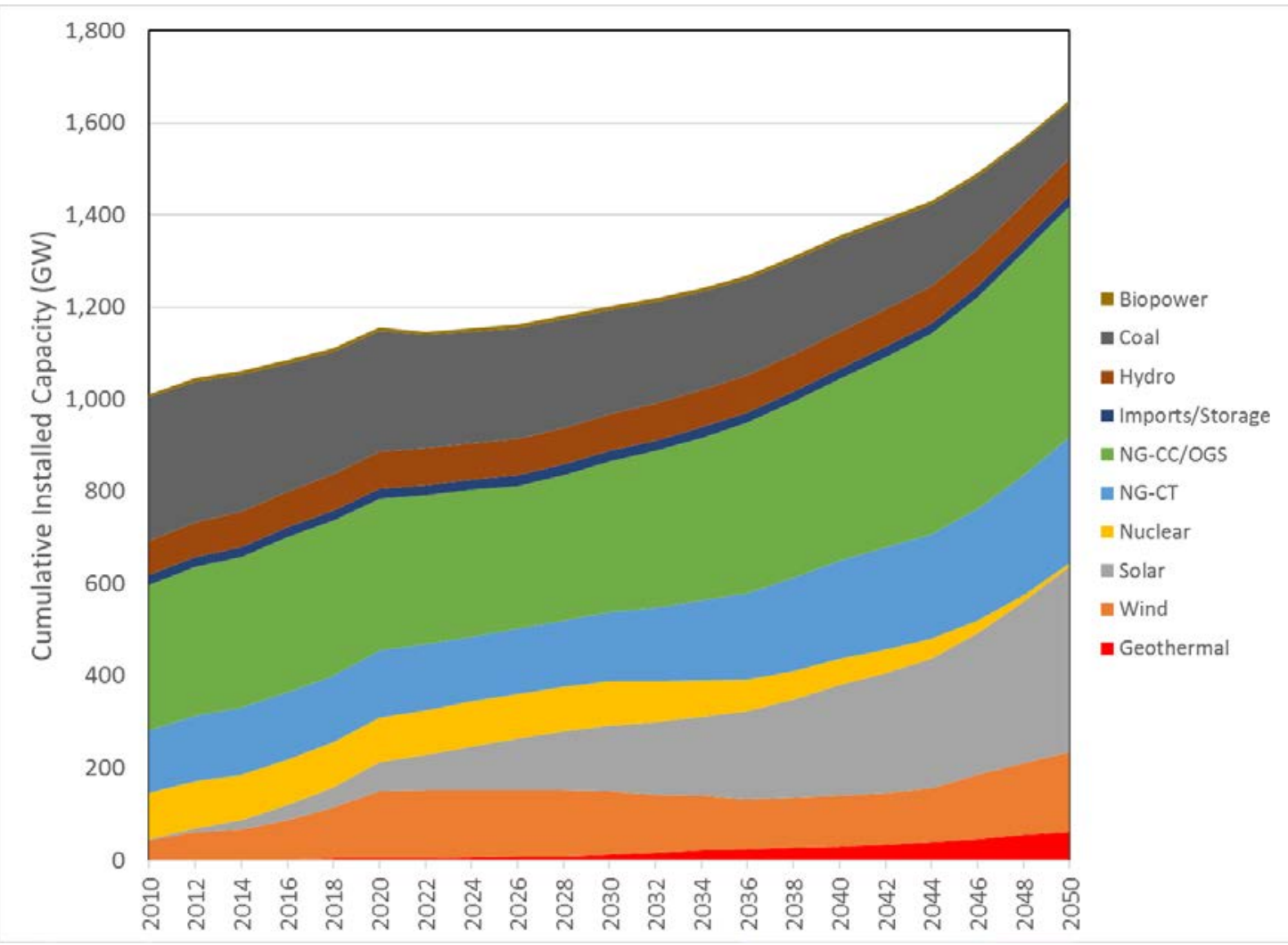

Figure 19. Cumulative installed capacity by year for all technologies in ReEDS for the TI scenario

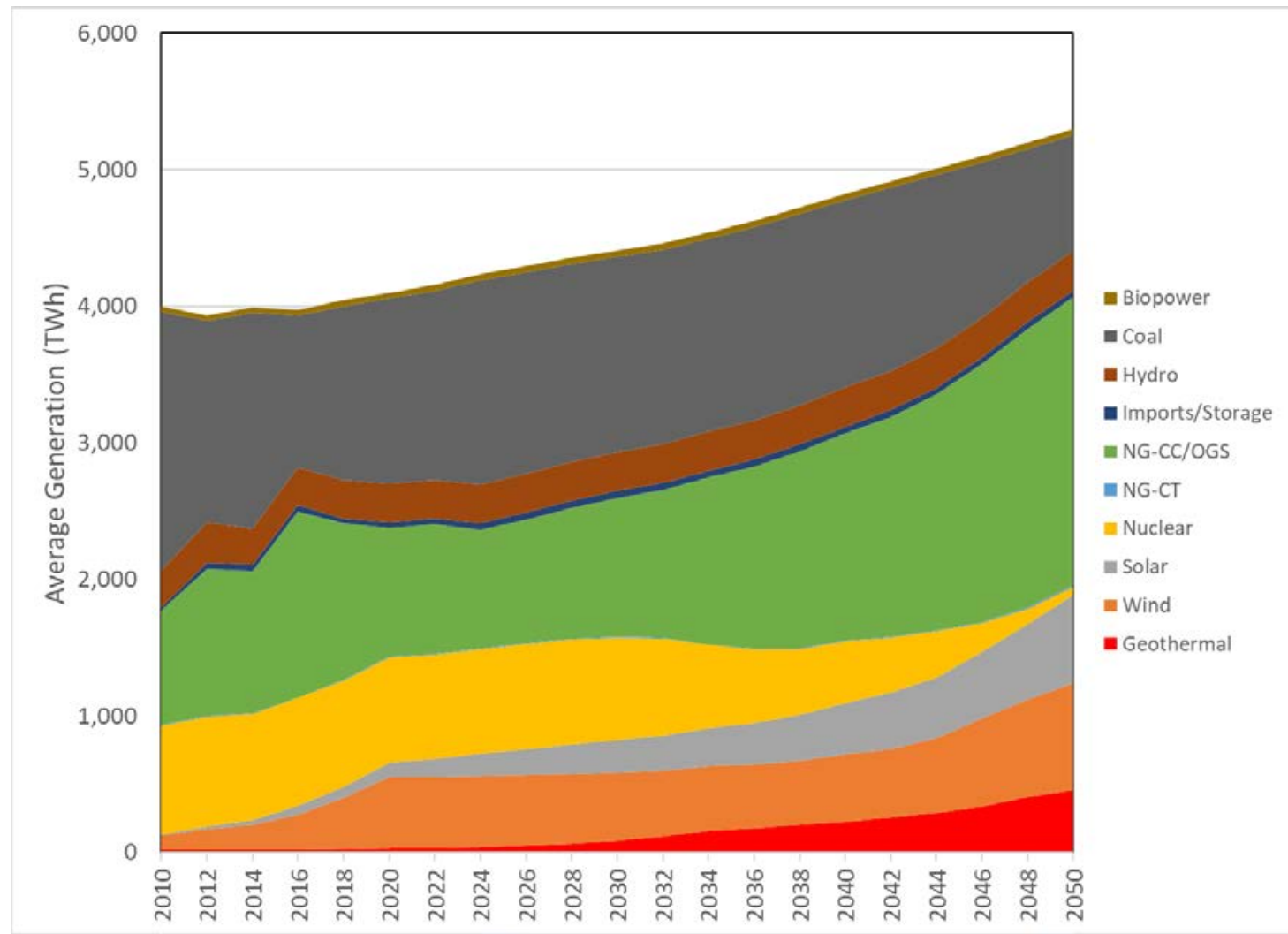

Figure 20. Annual electricity generation by year for all technologies in ReEDS for the TI scenario 
The reason for the discrepancy between the contribution from geothermal to the percentage of installed capacity and total generation is the high capacity factor of the geothermal technologies. Figure 19 shows that the amount of the total U.S. installed capacity from variable generators such as wind and solar grows significantly with time; however, as Figure 21 illustrates, geothermal has a much higher capacity factor, so the installed geothermal capacity generates much more electricity than an equivalent amount of installed solar photovoltaics or wind capacity. Figure 22 demonstrates how the generation from geothermal energy compares to other RE technologies in the TI scenario.

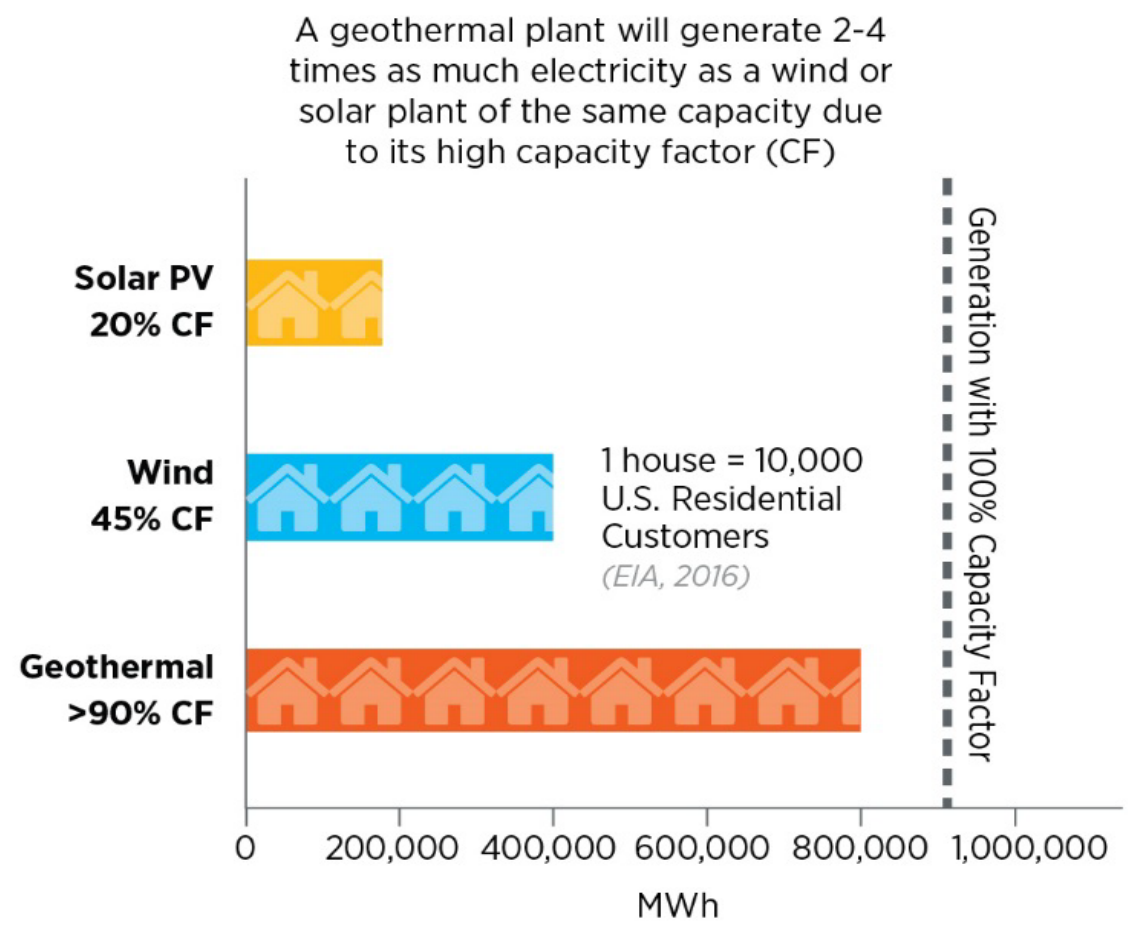

Figure 21. Annual generation (MWh) from equivalent 100-MW solar photovolatic, wind, and geothermal power plants based on average capacity factors (Note: 1 house $=10,000$ U.S. residential customers [EIA 2016e].) 


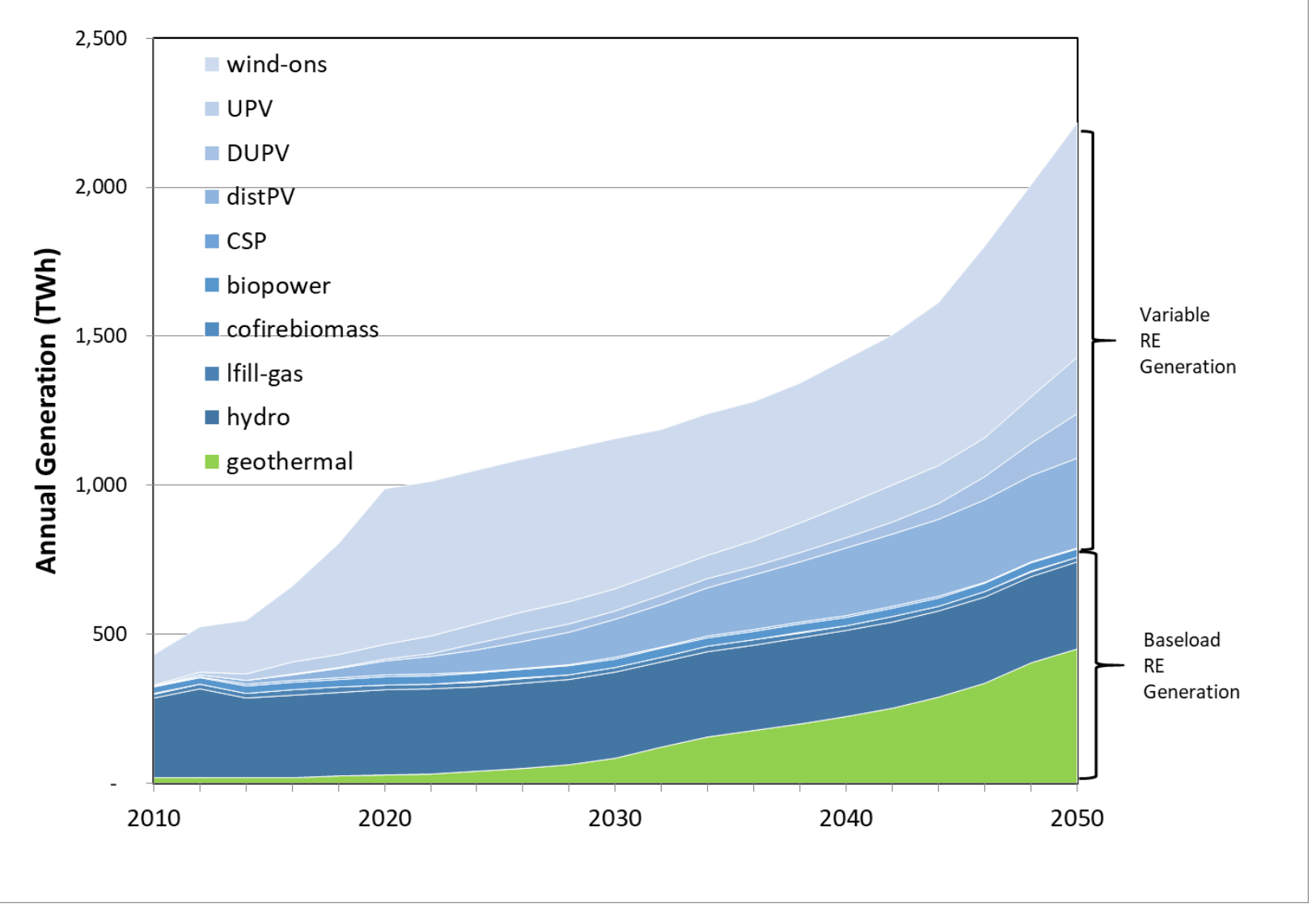

Figure 22. Generation by year for renewable energy technologies in the DOE Office of Energy Efficiency and Renewable Energy portfolio under the GeoVision TI scenario

A map of geothermal capacity additions is shown in Figure 23. The map shows that in the TI scenario, geothermal deployment is still predominantly in the western United States, but deployment covers a much larger geographic area. It also expands into areas such as West Virginia. These results support the idea that with EGS technologies, geothermal can be deployed "anywhere" there is sufficient heat close to the surface. As some of the sensitivity scenario results show (Section 6.4.1), with commercially-feasible EGS technologies, geothermal deployment is limited by the demand for electricity generation more so than the supply of geothermal resources, or more accurately, the existence of conventional hydrothermal systems. 


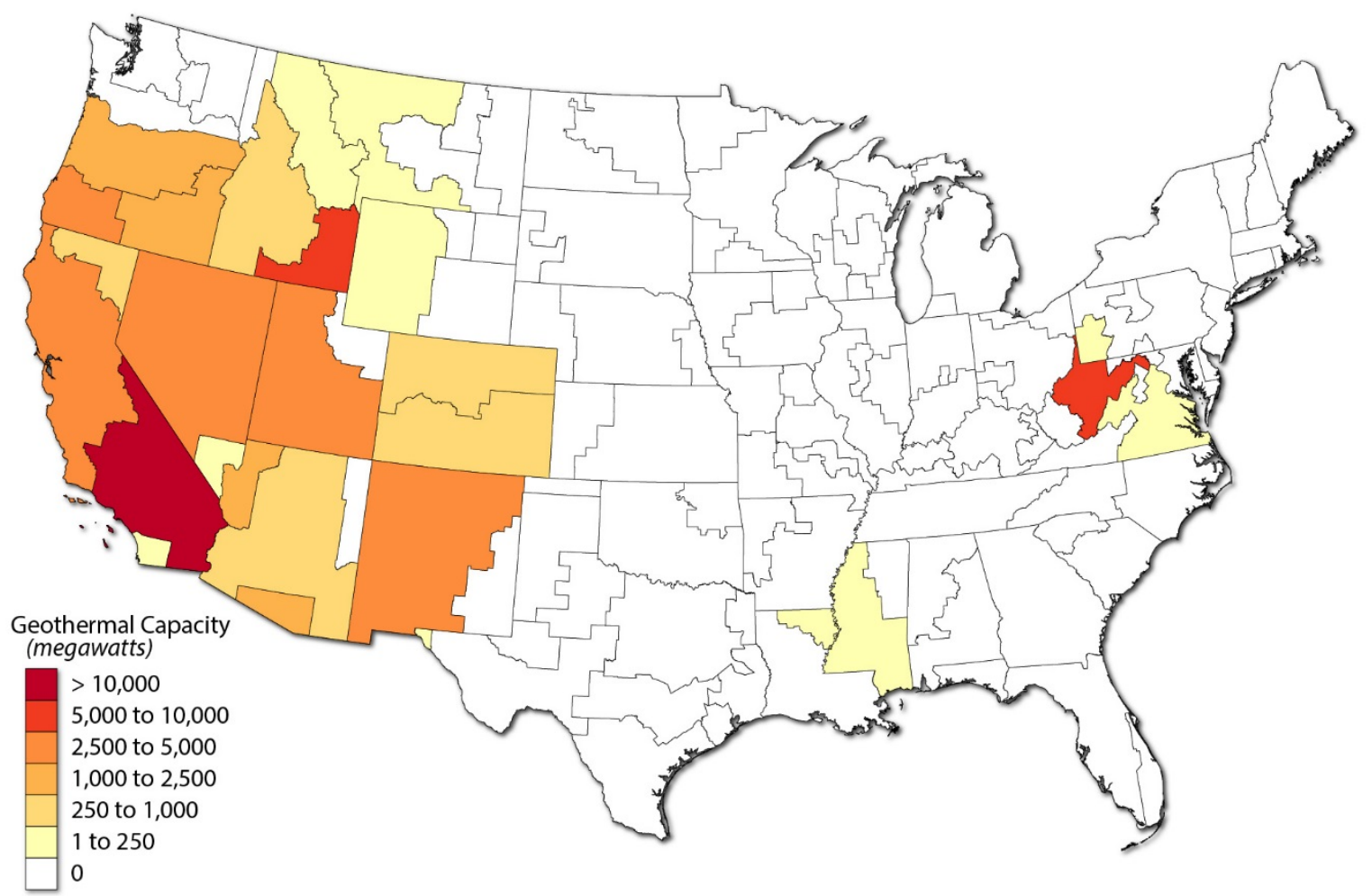

Figure 23. Map of installed geothermal capacity by ReEDS BAA in 2050 for the TI scenario

\subsubsection{Key Results}

The TI scenario demonstrates that EGS can achieve notable deployment rates if there are significant technology improvements and related capital cost and risk reductions. Because of its high capacity factor, generation from geothermal technologies is much larger than from other variable renewable energy technologies for an equivalent amount of installed capacity. In the TI scenario, geothermal can supply $8.5 \%$ of all U.S. electricity generation demand in 2050 from only $60.7 \mathrm{GW}$ of installed capacity. The majority of this $(43.6 \mathrm{GW})$ is from EGS deployments, which do not become commercially available until 2030 , but then the technology is rapidly deployed, with installed capacity steadily increasing through 2050. A significant portion of geothermal capacity comes from undiscovered hydrothermal resources as well, reaching $12.6 \mathrm{GW}$ of installed capacity by 2050 . This again underscores the findings from the other GeoVision scenarios that the exploration and discovery of new geothermal resources are key to increasing conventional hydrothermal deployment. In the TI scenario, hydrothermal technologies also benefit from technology advances and lower costs so that hydrothermal installed capacity is higher than in the IRT scenario, even with the added competition from EGS.

\subsection{Sensitivity Runs}

Some additional sensitivity model runs were performed to probe the results of the GeoVision study and gain further insights. Sensitivity model runs explore variations on assumptions about geothermal technologies and on potential future scenarios. 


\subsubsection{Standard Scenarios}

The first set of sensitivity runs performed was to combine the GeoVision scenario inputs with the ReEDS Standard Scenarios. The Standard Scenarios are a set of power sector scenarios that provide a quantitative examination of how ranges of values of specific inputs impact the development of the power sector (Cole, Mai et al. 2016). These scenarios capture a reasonable breadth of trajectories of costs, performance, policy, and other drivers, and thus enable the scenarios to cover a range of potential futures rather than a single outlook. The Standard Scenarios look at the sensitivity of the ReEDS model results to seven areas:

1. Electricity demand growth

2. Fuel prices

3. Electricity generation technology costs

4. Existing fleet requirements

5. Policy/regulatory environment

6. Earth feedback systems

7. Resource and system constraints.

The Standard Scenarios used for the GeoVision sensitivity scenarios are summarized in Table 11.

Table 11. Summary of the Standard Scenarios ${ }^{a}$

\begin{tabular}{|c|c|c|}
\hline Group & Scenario $^{b}$ & Notes \\
\hline \multirow{4}{*}{ Electricity Demand Growth } & Reference Demand Growth & AEO 2016 Reference \\
\hline & Low Demand Growth & $\begin{array}{l}\text { AEO } 2016 \text { Low Economic } \\
\text { Growth }\end{array}$ \\
\hline & High Demand Growth & $\begin{array}{l}\text { AEO } 2016 \text { High Economic } \\
\text { Growth }\end{array}$ \\
\hline & Vehicle Electrification & $\begin{array}{l}\text { Plug-in electric vehicle/plug-in } \\
\text { hybrid electric vehicle adoption } \\
\text { reaches } 40 \% \text { of sales by } 2050 \text {; } \\
45 \% \text { of charging utility- } \\
\text { controlled, } 55 \% \text { opportunistic }\end{array}$ \\
\hline \multirow{3}{*}{ Fuel Prices } & Reference Natural Gas Prices & AEO 2016 Reference \\
\hline & Low Natural Gas Prices & $\begin{array}{l}\text { AEO } 2016 \text { High Oil and Gas } \\
\text { Resource and Technology }\end{array}$ \\
\hline & High Natural Gas Prices & $\begin{array}{l}\text { AEO } 2016 \text { Low Oil and Gas } \\
\text { Resource and Technology }\end{array}$ \\
\hline \multirow{3}{*}{$\begin{array}{l}\text { Electricity Generation } \\
\text { Technology Costs }\end{array}$} & Mid-Case Technology Cost & $\begin{array}{l}2016 \text { ATB Mid-Case } \\
\text { Projections }\end{array}$ \\
\hline & Low RE Cost & $\begin{array}{l}2016 \text { ATB Renewable Energy } \\
\text { Low-Case Projections }\end{array}$ \\
\hline & High RE Cost & $\begin{array}{l}2016 \text { ATB Renewable Energy } \\
\text { High-Case Projections }\end{array}$ \\
\hline
\end{tabular}




\begin{tabular}{|c|c|c|}
\hline Group & Scenario $^{b}$ & Notes \\
\hline & $\begin{array}{l}\text { Nuclear Technology } \\
\text { Breakthrough }\end{array}$ & $\begin{array}{l}50 \% \text { reduction in nuclear capital } \\
\text { costs over all years }\end{array}$ \\
\hline \multirow{3}{*}{ Existing Fleet Retirements } & Reference Retirement & $\begin{array}{l}\text { Lifetime retirements based on } \\
\text { ABB Velocity Suite database } \\
\text { (ABB 2016) }\end{array}$ \\
\hline & Extended Nuclear Lifetime & Relicensing to 80 years \\
\hline & Accelerated Coal Retirement & $\begin{array}{l}\text { Coal power plant lifetimes } \\
\text { reduced by } 10 \text { years }\end{array}$ \\
\hline \multirow{2}{*}{$\begin{array}{l}\text { Policy/Regulatory } \\
\text { Environment }\end{array}$} & Current Law & $\begin{array}{l}\text { Includes policies as of April 1, } \\
\text { 2016. (Does not include a } \\
\text { Clean Power Plan for } \\
\text { GeoVision) }\end{array}$ \\
\hline & $\begin{array}{l}\text { Extended Incentives for RE } \\
\text { Generation }\end{array}$ & $\begin{array}{l}\text { Extend investment tax } \\
\text { credit/production tax credit } \\
\text { through } 2030 \text { for eligible } \\
\text { technologies }\end{array}$ \\
\hline \multirow[b]{2}{*}{ Earth System Feedbacks } & No Climate Feedback & $\begin{array}{l}\text { No feedback because of } \\
\text { changes in the climate }\end{array}$ \\
\hline & Impacts of Climate Change & $\begin{array}{l}\text { Temperature impacts on } \\
\text { generators, transmission, and } \\
\text { demand; derived from IGSM- } \\
\text { CAM climate scenario }\end{array}$ \\
\hline \multirow{4}{*}{$\begin{array}{l}\text { Resource and System } \\
\text { Constraints }\end{array}$} & Default Resource Constraints & $\begin{array}{l}\text { Used for the Mid-Case } \\
\text { Scenario }\end{array}$ \\
\hline & Reduced RE Resource & $\begin{array}{l}25 \% \text { cut to each resource in } \\
\text { input supply curves }\end{array}$ \\
\hline & $\begin{array}{l}\text { Barriers to Transmission System } \\
\text { Expansion }\end{array}$ & $\begin{array}{l}\text { Expansion three times } \\
\text { transmission capital cost; no } \\
\text { new AC-DC-AC interties; two } \\
\text { times transmission loss factors }\end{array}$ \\
\hline & Restricted Cooling Water Use & $\begin{array}{l}\text { New construction may not use } \\
\text { fresh water for cooling }\end{array}$ \\
\hline
\end{tabular}

a Source: Cole, Mai et al. 2016

${ }^{b}$ Scenarios in bold indicate assumptions used in the mid-case scenario (default assumptions).

The Standard Scenarios were run using the GeoVision BAU and TI scenarios for geothermal technologies. Results of all Standard Scenarios using the GeoVision TI scenario are shown in Figure 24. The scenarios using the GeoVision TI inputs for geothermal technologies can be divided into three groups.

The first group consists of scenarios where the amount of installed geothermal capacity is significantly higher than in the Mid-case scenario, consisting of the High Natural Gas Prices and High RE Cost Standard Scenarios. The High Natural Gas Prices scenario results in the most installed geothermal capacity, with $118 \mathrm{GW}_{\text {e }}$ by 2050, followed closely by the High RE Cost scenario, with $107 \mathrm{GW}$. These scenarios show that geothermal deployment in the GeoVision TI 
scenario can be double what it is in the Mid-case scenario in futures where the cost of competing electricity generation technologies (e.g., natural gas or other renewables) are high. Because of the high capacity factor of geothermal power plants, geothermal accounts for about $16 \%$ of total U.S. electricity generation in 2050 for the High Natural Gas Prices scenario.

The second group consists of scenarios where the amount of installed geothermal capacity is significantly less than in the Mid-case scenario. Only the Low RE Cost scenario fits in this group. When inexpensive renewable energy generation is assumed, geothermal installed capacity drops to about $20 \mathrm{GW}$, or less than one-third of the value in the Mid-case scenario. In this scenario, geothermal deployment is replaced by lower cost renewable energy options.

The third group consists of scenarios where the impact on geothermal deployment does not vary significantly from the Mid-case scenario. The rest of the scenarios fit in this group. The resulting installed geothermal capacity is within $+5 /-20 \mathrm{GW}_{\mathrm{e}}$ of the Mid-case scenario. For the majority of the Standard Scenarios, the potential scenario conditions do not significantly favor or hinder geothermal deployment compared to the Mid-case scenario.

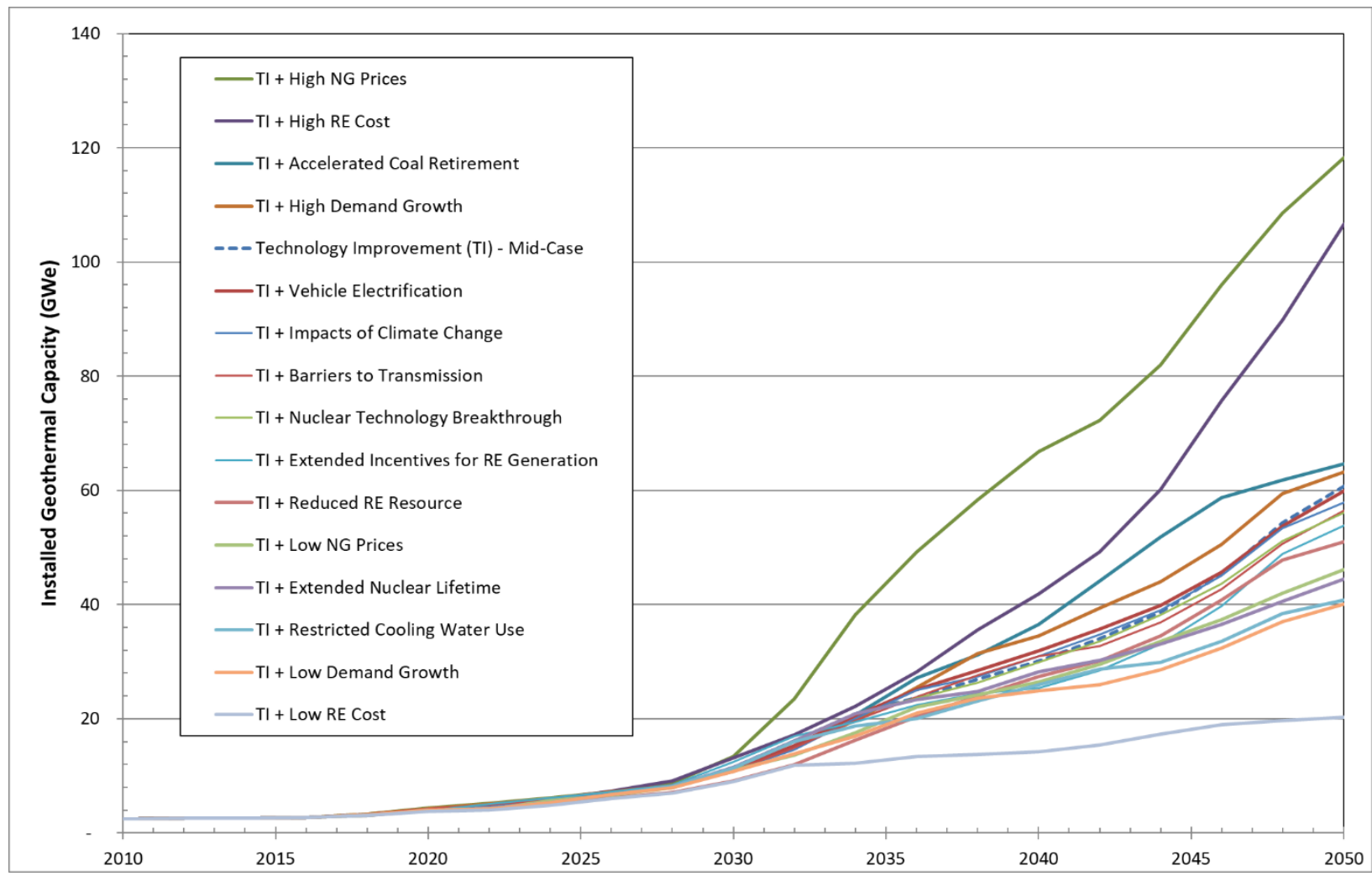

Figure 24. Total installed geothermal capacity for the ReEDS Standard Scenarios assuming the GeoVision TI case. The Standard Scenarios are listed in the legend in order of total installed capacity in 2050, from highest to lowest.

Figure 25 gives a clearer view of the high-geothermal-penetration Standard Scenarios using the GeoVision TI inputs vs. the GeoVision BAU, IRT, and TI scenarios that assume the ReEDS Midcase scenario. For all these high-geothermal-penetration scenarios, the additional geothermal installed capacity compared to the TI case is almost entirely made up of deep EGS resources. In some years, deep EGS is being installed at a rate of $10 \mathrm{GW}_{\mathrm{e}} /$ year. 
The key takeaway from these sensitivity studies is that geothermal technologies, EGS in particular, have large upside potentials in possible future scenarios in which EGS could play a larger role. For high-geothermal-deployment scenarios, geothermal could make up $\sim 16 \%$ of total U.S. generation by 2050 . These alternative future scenarios show EGS is demand limited, not resource limited.

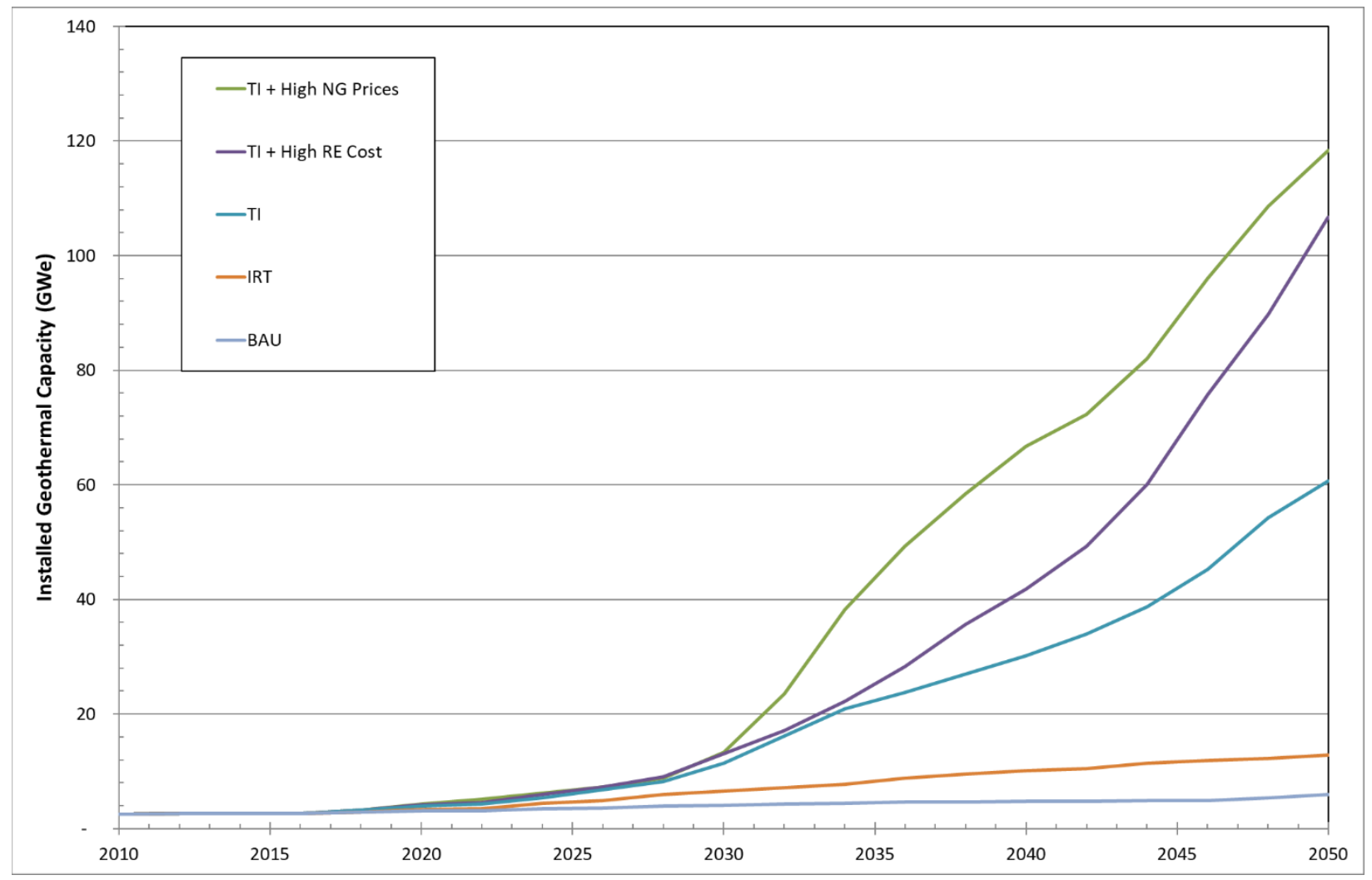

Figure 25. Standard scenarios using the GeoVision TI scenario with highest geothermal electricity generation capacity deployment compared to the Mid-case scenario using all the GeoVision scenarios (BAU, IRT, and TI)

\subsubsection{Drilling Cost Sensitivity}

The sensitivity of the TI scenario to drilling costs was explored. The Intermediate 1 and Intermediate 2 drilling cost curves from Lowry et al. (2017a) were used in place of the Ideal drilling cost curve used in the TI scenario. These curves make less aggressive assumptions about drilling cost improvements than the Ideal cost curve but are improvements over the base drilling cost curve used in the BAU scenario.

Figure 26 shows the difference in the supply curves for deep EGS resources in the TI scenario using each of the drilling cost curves. Of the geothermal resource types considered, deep EGS resources are the most sensitive to drilling cost assumptions. Although the sensitivity study focuses on drilling costs, the net effect is higher overnight capital costs for geothermal resources. Therefore, the results are a proxy for any cost increase from the TI scenario, and, ultimately, they show the sensitivity of geothermal deployment to overnight capital costs. 


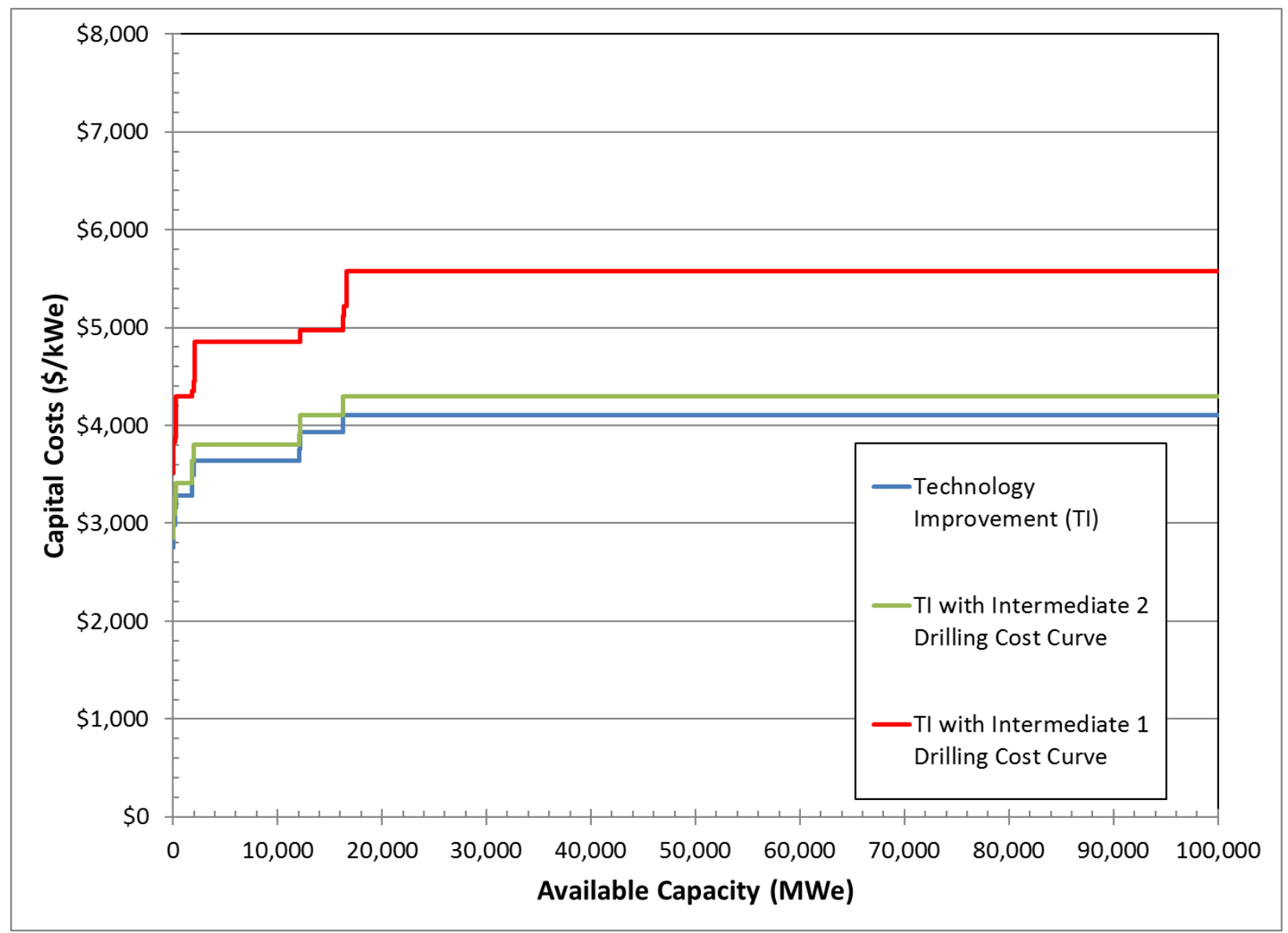

Figure 26. TI scenario deep EGS supply curves using drilling cost curves that assume different levels of drilling cost reductions

ReEDS was run using the TI scenario for the various drilling cost curves. The results are shown in Figure 27. The Intermediate 2 drilling cost curve results in an installed capacity of $45.7 \mathrm{GW}_{\mathrm{e}}$, whereas the Intermediate 1 drilling cost curve has installed capacity of $19 \mathrm{GW}_{\mathrm{e}}$, and the Ideal cost curve deployment was $60.7 \mathrm{GW}_{\mathrm{e}}$. Almost all the difference in deployment among these scenarios is in the deployment of deep EGS resources. Figure 28 shows only the installed deep EGS capacity for the drilling cost sensitivity scenarios. 


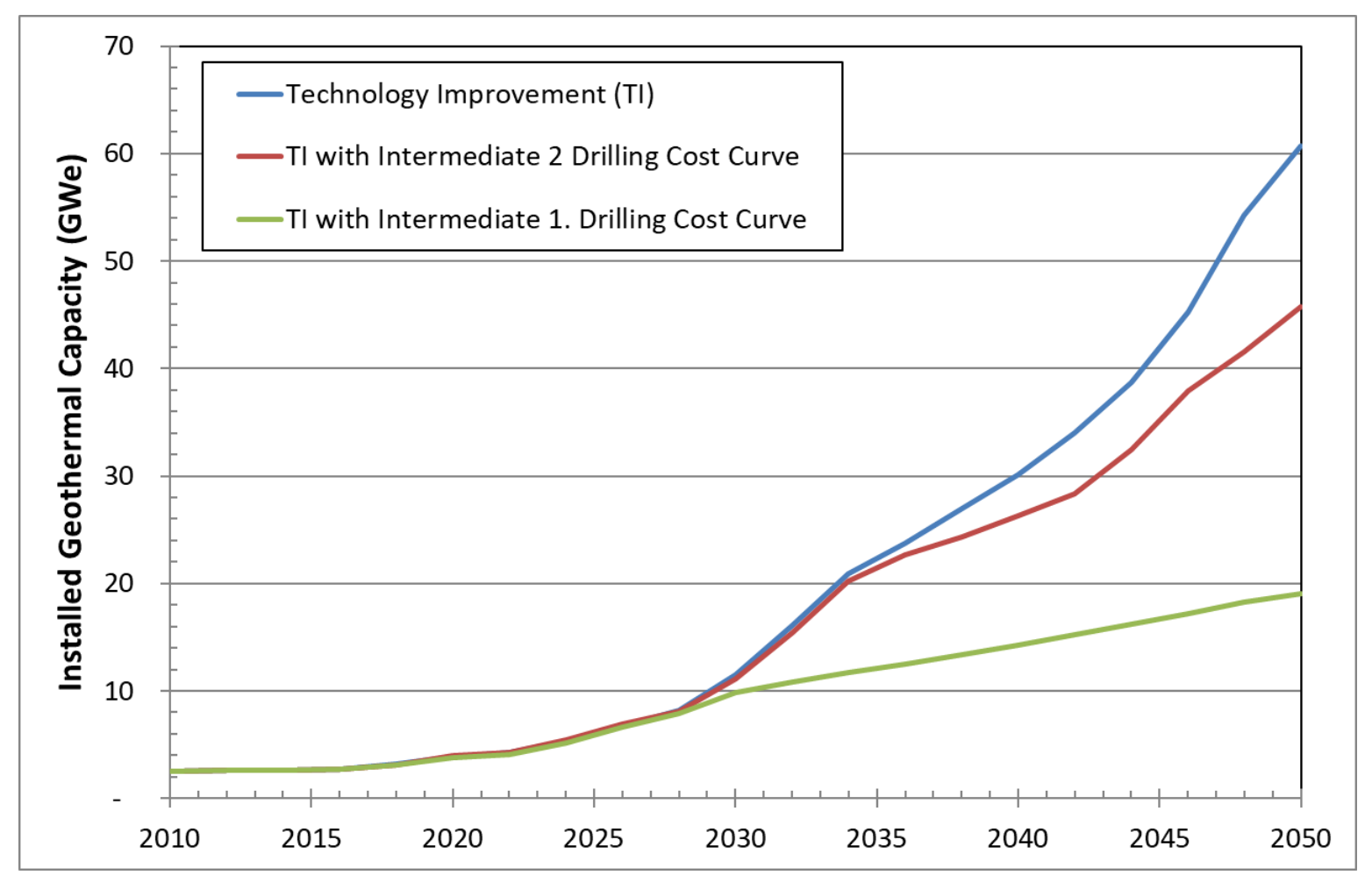

Figure 27. Total installed geothermal capacity for the TI scenario assuming different drilling cost curves

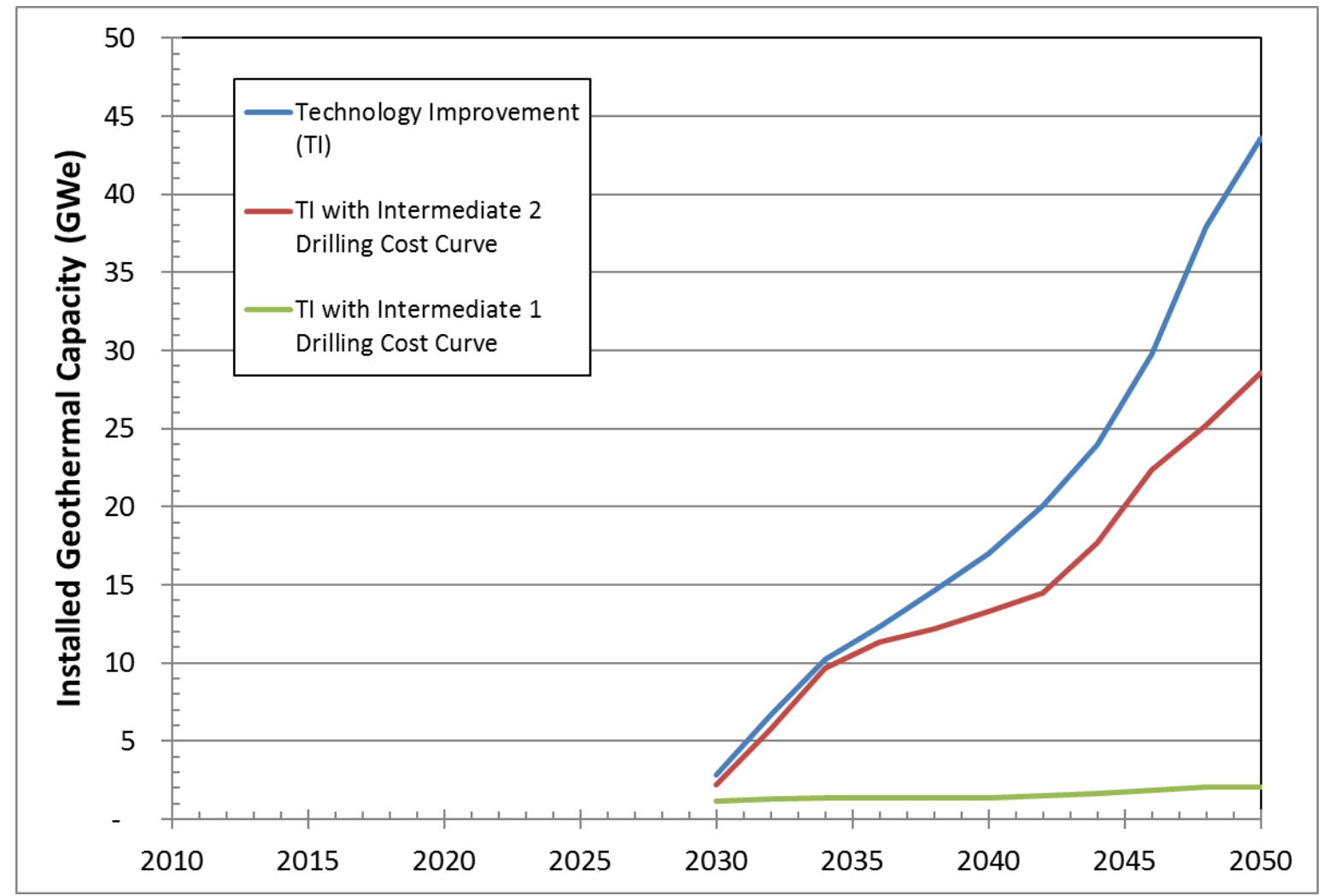

Figure 28. Installed deep EGS geothermal capacity for the TI scenario assuming different drilling cost curves 
A substantial change in the amount of deep EGS deployed is caused by a difference of $\$ 600$ $\$ 700 / \mathrm{kW}_{\mathrm{e}}$ in overnight capital costs for resources that deploy in the Intermediate 2 drilling costs scenario but do not deploy in the Intermediate 1 drilling costs scenario. For the Ideal drilling cost scenario (used in the TI scenario) vs. the Intermediate 2 drilling costs scenario, the difference in overnight capital costs is only $\$ 200 / \mathrm{kW}_{\mathrm{e}}$ at the point where deep EGS resources switch from deploying in one scenario to not deploying in the other.

These results demonstrate that geothermal deployment is sensitive to overnight capital costs. Part of the reason for the large difference in deployed capacity among the scenarios is the flatness of the deep EGS supply curve. The deep EGS supply curve has large portions of resource, in the range of tens to hundreds of $\mathrm{GW}_{e}$, at the overnight capital cost value on the supply curve where it is deploying in the ReEDS model (for example, see Figure 26 at about $20,000 \mathrm{GW}_{\mathrm{e}}$ of available capacity). This means that if deep EGS is competitive in the model for one scenario but not another, there will be a lot of it available for potential deployment at that competitive overnight capital cost in that scenario.

\subsubsection{Drilling Cost Sensitivity: Construction Timeline}

In addition to reducing the capital costs associated with drilling, the Ideal drilling cost scenario described in Lowry et al. (2017a) would also result in faster drilling times. For a typical geothermal project, drilling times could be reduced from 18 months for drilling the entire well field down to 6 months, a reduction of 1 year. These time savings could decrease the overall project costs by reducing the construction timeline, which leads to reduced project financing costs.

To see the impact this could have, it was assumed that the entire year of reduced drilling time could be captured and taken advantage of to decrease the overall construction time (see Table 7) by 1 year. This aggressive construction timeline scenario results in project development times of 3-4 four years for hydrothermal and EGS projects, respectively, for the TI scenario. The results of the improved construction timeline scenario are shown in Figure 29. Reducing the construction timeline by 1 year results in an additional $5 \mathrm{GW}_{\mathrm{e}}$ for the TI scenario. As in the IRT scenario, this illustrates how shorter construction times result in reduced overall project costs and increased deployment; however, this scenario demonstrates that construction timeline reductions can be achieved through technology improvements as well as improvements to the regulatory and permitting processes. 


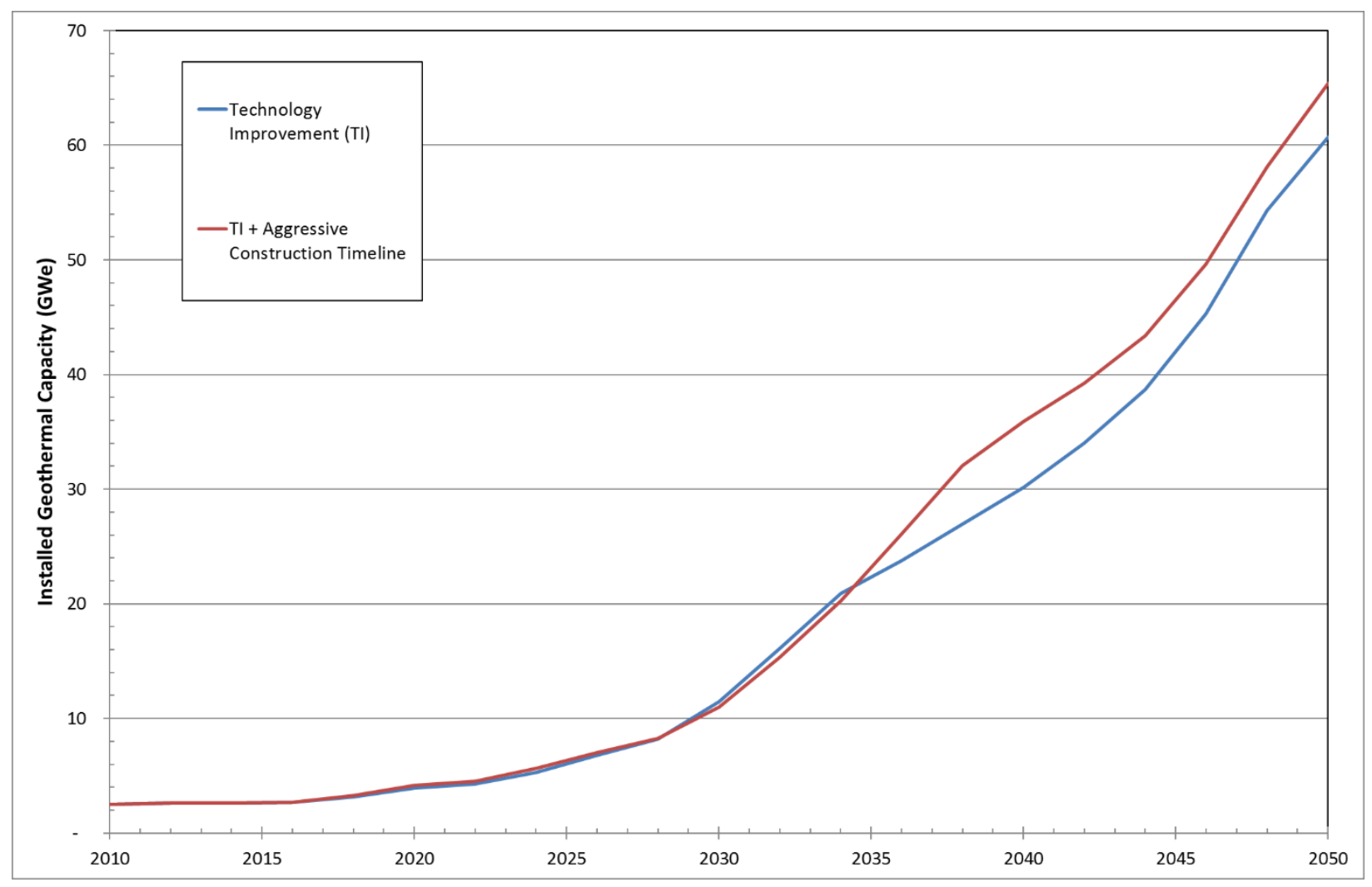

Figure 29. Total installed geothermal capacity for the TI scenario assuming an improved construction timeline that reduces the project development times by 1 year

\subsubsection{Regional EGS Resource Assessment}

A close look at the results of the TI scenario shows that most of the deep EGS resources deployed are high-temperature resources with reservoir temperatures of $250^{\circ} \mathrm{C}$ or higher. For geothermal, temperature is a measure of the quality of the resource. Higher temperature resources have more power generation potential per unit mass of brine produced, so as temperature increases, project costs on the basis of dollars per kilowatt tend to decrease. A key to increasing EGS deployment is to identify the most favorable (e.g., shallow, high-temperature) EGS resources.

The deep EGS resource potential was calculated using temperature-at-depth maps, at depths from $3.5 \mathrm{~km}$ to $6.5 \mathrm{~km}$, developed as part of a national-scale project by the SMU Geothermal Laboratory. The sparse data in many areas and the use of a grid interval of about $5 \mathrm{~km}$, or 3 miles in the SMU temperature-at-depth maps led to generalized temperature maps that do not typically show local, high-amplitude thermal anomalies (Blackwell et al. 2011). As a result, the GeoVision EGS resource potential estimate likely does not include many of the shallow $(<3.5 \mathrm{~km})$, hightemperature EGS resources that would be the least expensive to develop.

The purpose of this sensitivity study is to measure the impact that more-detailed resource assessments could have on geothermal deployment projections by comparing resource potential estimates and EGS deployment projections from regional-scale EGS resource assessments that include shallow resources to the national-scale EGS resource assessment used in the GeoVision study. Two sources of regional-scale EGS resource assessments were available. The first is a 
study of temperature-at-depth maps between ranges from 1-4 km for the Cascades region (Frone et al. 2015) (Figure 30), and the second is a temperature map of the Great Basin at a depth of $3 \mathrm{~km}$ (Coolbaugh et al. 2005) (Figure 31). Both maps have a much more detailed analysis of temperature at depths shallower than in the SMU maps.

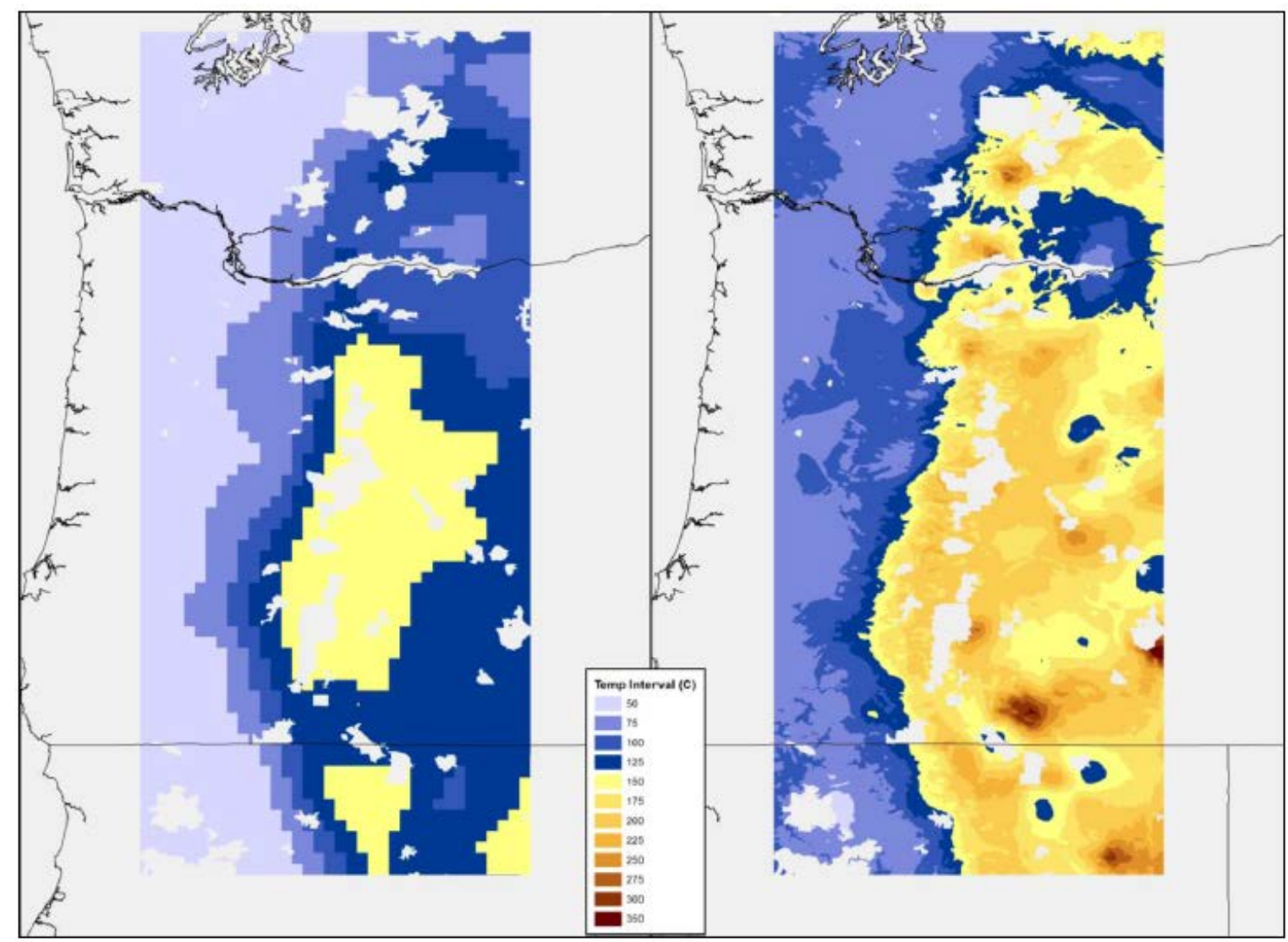

Source: Frone et al. 2015

Figure 30. Comparison of SMU temperature estimates at a depth of $3.5 \mathrm{~km}$ (left) and temperature estimates at $3 \mathrm{~km}$ from a detailed regional study of the Cascades region by Frone et al. (2015) 


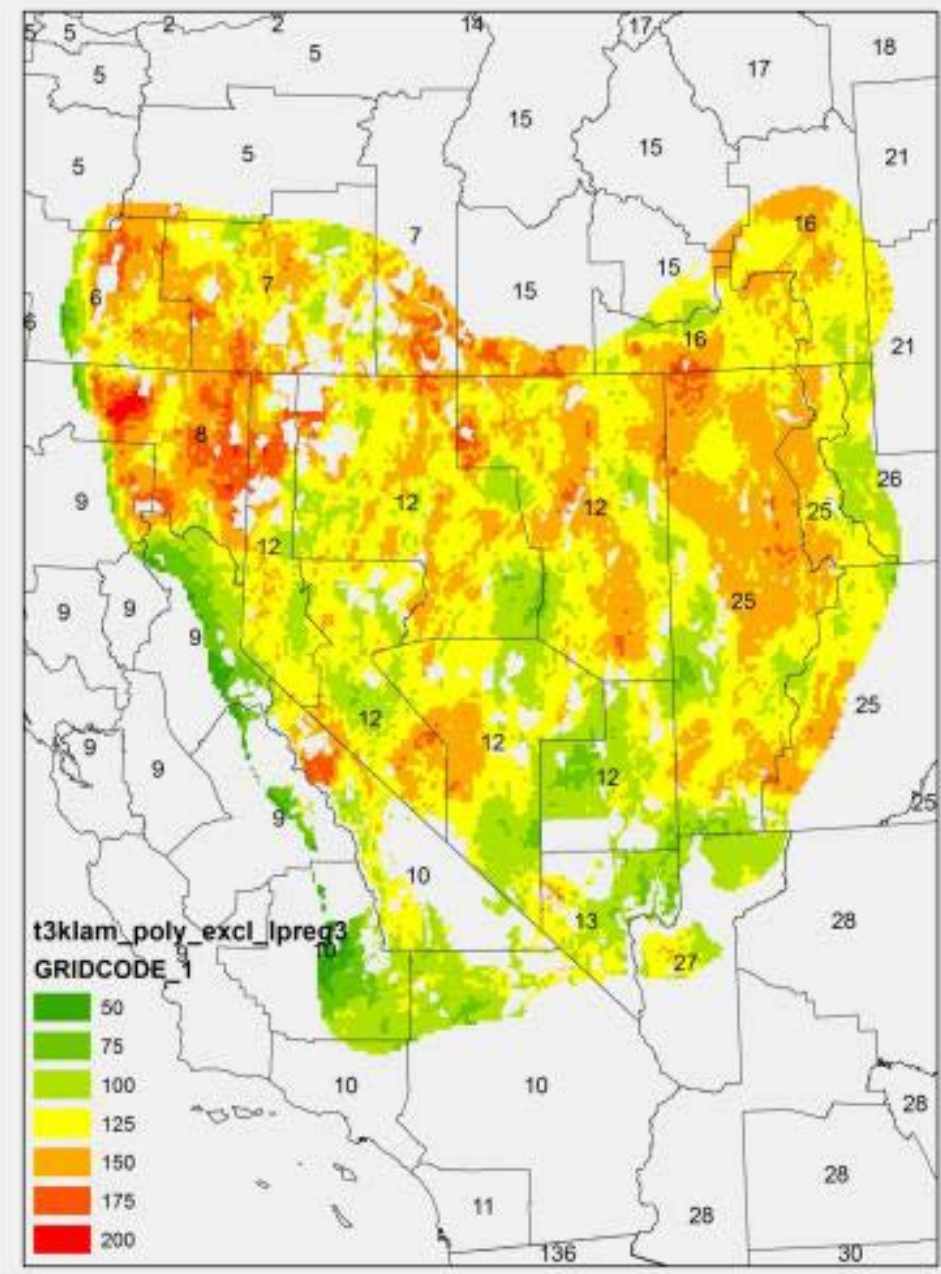

Source: Coolbaugh et al. 2005. Courtesy of the Nevada Bureau of Mines and Geology, Map 151.

Figure 31. Temperature estimates at a depth of $3 \mathrm{~km}$ from a regional study of the Great Basin

These maps were analyzed using the same methodology for the deep EGS resource potential as described in Augustine (2016) to develop a more detailed estimate of the EGS resource potential for these areas. The additional resource potential estimates were appended to the GeoVision deep EGS resource potential estimate. For cases where data from the three maps overlapped, one data source was chosen to avoid double-counting the EGS resource. The Cascades map data at 3 and $4 \mathrm{~km}$ were used in place of the SMU map data at 3.5 and $4.5 \mathrm{~km}$, respectively. The Great Basin map data at $3 \mathrm{~km}$ were used in place of the SMU map data at $3.5 \mathrm{~km}$. Table 12 shows the difference in EGS resource potential estimates from the two studies. The Cascades and Great Basin 3-km maps overlapped in some ReEDS BAAs. Generally, the Cascades map was used, except for in BAA 9, where the Great Basin map covers a larger area of the BAA.

The results were an additional $63 \mathrm{GW}_{\mathrm{e}}$ of EGS resource potential using the regional maps compared to the SMU maps. Moreover, resources from the regional maps tend to have higher temperature estimates than from the SMU maps. 
Table 12. Comparison of EGS Resource Potential Estimates for the Great Basin from GeoVision Deep EGS Resource Potential at $3.5 \mathrm{~km}$ vs. from Analysis of Regional Great Basin Temperature Map (Coolbaugh 2005) at 3 km. (Resource Estimate Values are in MWe.)

\begin{tabular}{|c|c|c|r|r|c|}
\hline \multirow{2}{*}{$\begin{array}{c}\text { Temperature } \\
\text { Interval }\end{array}$} & \multicolumn{6}{|c|}{ 2011 National Map (Augustine, 2011) } \\
\cline { 2 - 6 } & NV & OR & \multicolumn{1}{c|}{ ID } & CA & UT \\
\hline $\mathbf{1 5 0 - 1 7 5}$ & 2,321 & 7,477 & 12,407 & 6,858 & 611 \\
\hline $\mathbf{1 7 5 - 2 0 0}$ & - & - & 539 & 1,704 & - \\
\hline $\mathbf{2 0 0 - 2 2 5}$ & - & - & 95 & - & - \\
\hline \multirow{2}{*}{ Totals } & 2,321 & 7,477 & 13,041 & 8,562 & 611 \\
\cline { 2 - 6 } & \multicolumn{5}{|c|}{32,012} \\
\hline \multirow{2}{*}{$\begin{array}{c}\text { Temperature } \\
\text { Interval }\end{array}$} & NV & OR & ID & CA & UT \\
\hline $\mathbf{1 5 0 - 1 7 5}$ & 32,902 & 17,273 & 10,238 & 10,182 & 28,910 \\
\hline $\mathbf{1 7 5 - 2 0 0}$ & 3,828 & 3,186 & 1,381 & 6,055 & 1,297 \\
\hline $\mathbf{2 0 0 - 2 2 5}$ & 61 & 6 & 19 & 838 & \\
\hline \multirow{2}{*}{ Totals } & 36,792 & 20,465 & 11,638 & 17,076 & 30,207 \\
\cline { 2 - 6 } & \multicolumn{5}{|c|}{116,178} \\
\hline
\end{tabular}

Overnight capital and O\&M costs were estimated using the GETEM for the new, shallower EGS sites from the maps. Costs were estimated using both the ideal drilling cost curve and the Intermediate 1 drilling cost curve. The resulting supply curves for deep EGS are shown in Figure 32.

The capital and O\&M costs were combined with the updated EGS resource potential map using regional data to develop an updated supply curve, and this supply curve was used in ReEDS for the sensitivity runs. The ReEDS model was run using the TI scenario using the GeoVision EGS resource potential and the regional EGS resource potentials. A comparison of the geothermal installed capacity is shown in Figure 33.

The TI plus regional EGS scenario results in nearly an identical amount of geothermal deployment as the TI scenario, although the regional EGS scenario deploys EGS more quickly after EGS resources become commercially available in 2030. This is because of several factors. The regional EGS studies have more EGS resources, and they have lower cost EGS resources because the regional EGS studies have EGS resources that are both shallower and higher temperature than in the original SMU maps. As Figure 32 shows, this results in the regional EGS scenario having a supply curve with resources at lower costs than in the TI scenario. These are the resources that are deployed earlier in Figure 33. However, the difference between the scenarios is somewhat muted by the shape of the supply curves because the supply curves eventually meet up again and coincide for a long stretch of resource capacity in the area of interest. The result is that the TI scenario catches up in deployments, so the installed capacity in 2050 is about the same for both scenarios.

This analysis also compared the national and regional EGS supply curves assuming the Intermediate 1 drilling cost curve. In this comparison, the regional EGS supply curve results in 


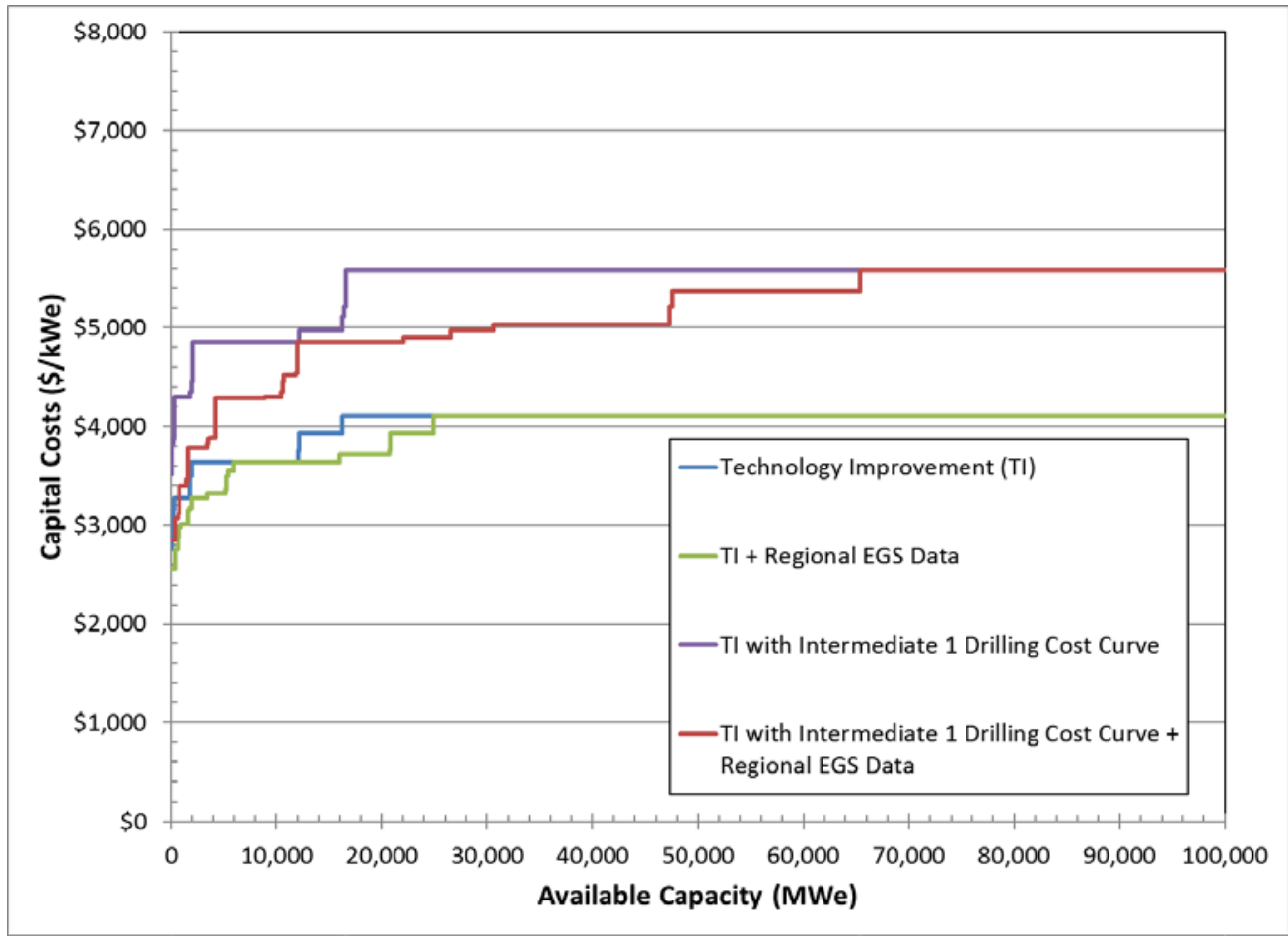

Figure 32. Supply curves for deep EGS resources using the TI scenario and the impact of using regional EGS resource potential data. Costs use both the Ideal and Intermediate 1 drilling cost curves.

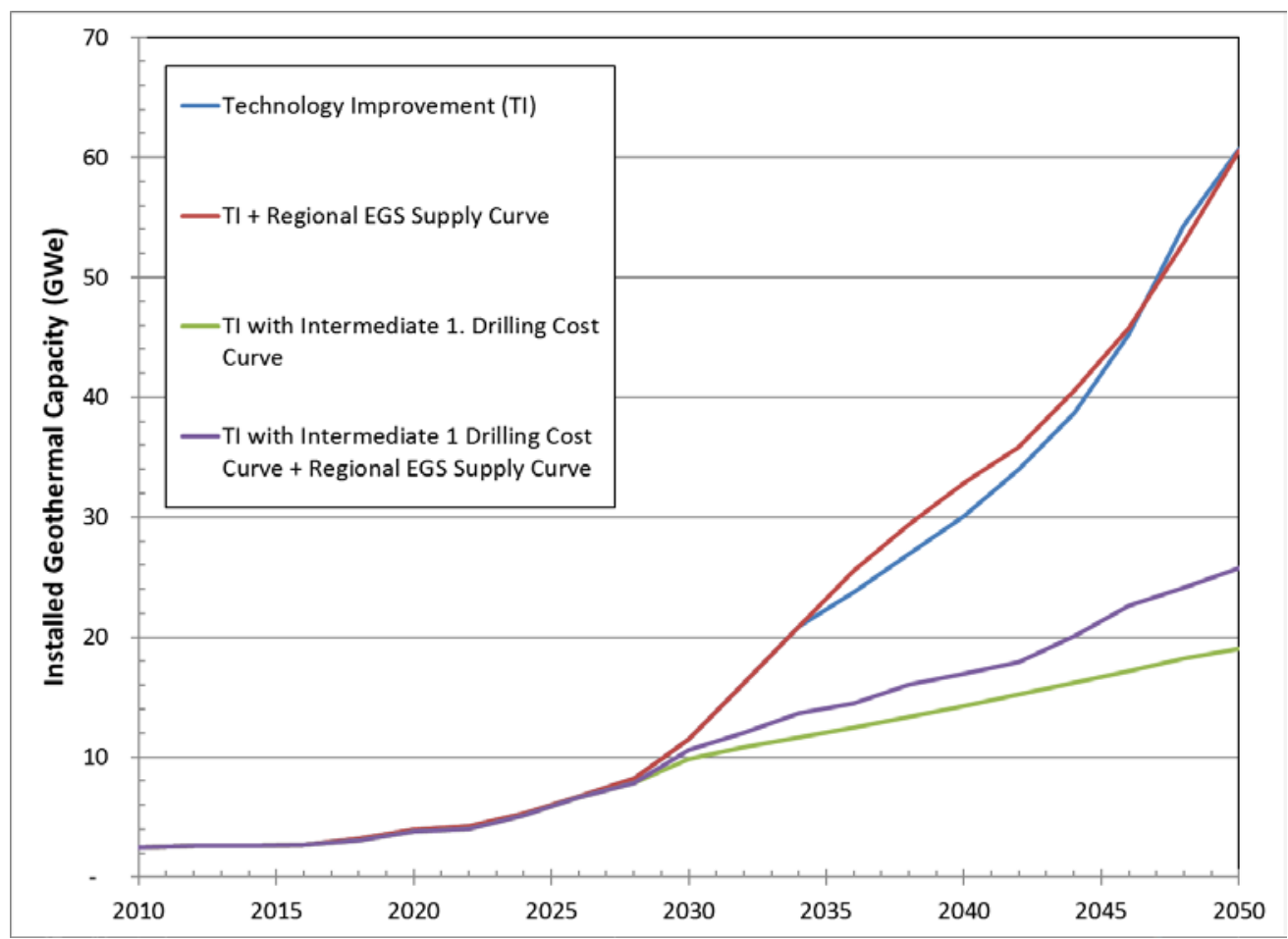

Figure 33. Comparison of total installed geothermal capacity projections showing the impact of using EGS resource potential values from regional maps in the Cascades and Great Bain vs. national maps 
an additional 6,723 $\mathrm{MW}_{\mathrm{e}}$ of installed geothermal capacity. This is because of a more pronounced difference in the supply curves in the area of the curves where the deep EGS resources are deployed by the ReEDS model.

The results illustrate why detailed regional resource studies are needed to identify the most favorable EGS resources and indicate that the EGS resource is likely larger and of higher quality than the currently available national-scale data used in the GeoVision study suggests. 


\section{Conclusions}

The Electric Sector Potential to Penetration Task Force was responsible for determining the potential amount of geothermal electricity generation capacity that could be deployed under future scenarios as part of the larger GeoVision study. To achieve this, the potential of hydrothermal and EGS resources was assessed and assembled. The GETEM was used to estimate the capital and O\&M costs of developing these resources under the Business-as-Usual (BAU), Improved Regulatory Timeline (IRT), and Technology Improvement (TI) scenarios developed as part of the GeoVision study. The resource potential and development costs were combined to develop supply curves for each of the geothermal resources considered, and these were used as inputs in the ReEDS capacity deployment model. ReEDS used the Mid-case scenario, the base or "most likely" scenario from NREL's suite of Standard Scenarios, to describe electricity demand, fuel prices, policy assumptions, the transmission grid, and the costs and attributes of other electricity generation technologies and to model electricity capacity deployment in the contiguous United States through 2050.

From the results and analysis of these modeling efforts, the Potential to Penetration Task Force determined the following key takeaways:

- The BAU scenario in ReEDS projects 5,924 MWe of total installed geothermal capacity by 2050 . This is consistent with a projected capacity of $5,120 \mathrm{MW}$ assuming that the geothermal industry continues on its current growth trajectory of $2 \%$ per year from 2,542 $\mathrm{MW}_{\mathrm{e}}$ of installed capacity in 2016.

- The IRT scenario in ReEDS estimates 12,891 MWe of total installed geothermal capacity by 2050 . This increase is more than double the installed capacity in the BAU scenario. The IRT scenario considers only streamlined regulations and reduced permitting timelines, which impact the assumed hydrothermal discovery rate (increasing it from 1\% per year to $3 \%$ per year) and project construction timelines, and it does not assume any technology advances compared to the BAU scenario. This implies that the geothermal industry could greatly increase its deployment through regulatory reforms alone.

- Undiscovered hydrothermal resources make up most of the newly deployed geothermal capacity in both the BAU and IRT scenarios. This highlights the importance of continued exploration and discovery of new geothermal resources and the impact that improved exploration techniques and technologies could have on the industry. EGS technologies do not deploy in either the BAU or IRT scenario because the technology is not advanced enough to be commercially feasible

- In the TI scenario, total installed geothermal capacity reaches $60.701 \mathrm{MW}$ e by 2050 . Most of the installed capacity comes from the rapid deployment of EGS resources starting in 2030. The TI scenario demonstrates the large impact that advancing EGS technologies could have on the geothermal industry. Geothermal in the TI scenario makes up $3.7 \%$ of total installed capacity in 2050 , and it generates $452 \mathrm{TWh}$ of electricity or $8.5 \%$ of all electricity generation, compared to $0.4 \%$ now. The large discrepancy in the percentage of installed capacity and total generation is the result of the high capacity factor of geothermal power plants. 
- The TI scenario was run with the suite of NREL's Standard Scenarios. These scenarios show that geothermal deployment in the GeoVision TI scenario can be double what it is in the Mid-case scenario in futures where the cost of competing electricity generation technologies (e.g., natural gas or other renewables) are high. For the High Natural Gas Prices scenario, geothermal makes up about $16 \%$ of total electricity generation in the United States by 2050, mostly from EGS resources. This demonstrates the abundance of EGS resources and shows that EGS deployment is demand limited, not supply limited.

- Conversely, in futures where the cost of competing renewable electricity generation technologies is low, total geothermal deployment in 2050 is limited to less than one-third of the value in the Mid-case scenario. For most of the Standard Scenarios, the potential scenario conditions do not significantly favor or hinder geothermal deployment compared to the Mid-case scenario.

- The TI scenario assumes aggressive technology improvements, especially in terms of drilling costs; however, drilling cost sensitivity scenarios using less aggressive drilling cost improvement scenarios developed for the GeoVision study show that geothermal can still make significant gains without fully realizing the technology assumptions in the TI scenario. Even in these scenarios, the difference in deployment is almost entirely a result of EGS deployment. The supply curves input to ReEDS for these sensitivity scenarios can be used as a proxy to explore EGS deployment sensitivity to overnight capital costs regardless of the driver for cost differences.

- Detailed regional maps of EGS resources are needed to identify the most favorable EGS resources. Sensitivity scenarios using EGS resource potential inputs from detailed maps of the Cascades and Great Basin illustrated that not only do these maps identify more and better quality (hotter) resources at shallower depths than national-level EGS resource maps, but they also result in increased and faster deployment of EGS resources in ReEDS scenarios. The differences in deployment become more pronounced as assumptions about technology advances such as drilling cost reductions are relaxed. These runs suggest that the EGS resource is likely larger than presented in the GeoVision study and that significant deployment gains can be achieved even if the aggressive EGS cost reductions assumed in the GeoVision study are not fully realized.

Overall, the Potential to Penetration Task Force results show that in the near term, hydrothermal resources could experience increased rates of deployment from regulatory reforms and by focusing on exploration technologies and techniques to increase the rate of discovery of hydrothermal resources. In the long term, the geothermal industry could experience significant growth from EGS resources by focusing on research and development to enable and advance EGS technologies. 


\section{References}

ABB. 2016. “ABB Velocity Suite.” http://new.abb.com/enterprise-software/energyportfoliomanagement/market-intelligence-services/velocity-suite.

Augustine, C. 2011. Updated U.S. Geothermal Supply Characterization and Representation for Market Penetration Model Input. Golden, CO: National Renewable Energy Laboratory. NREL/TP-6A2-47459. http://www.nrel.gov/docs/fy12osti/47459.pdf.

Augustine, C. 2016. "Update to Enhanced Geothermal System Resource Potential Estimate." Geothermal Resources Council Transactions 40: 673-677. http://pubs.geothermallibrary.org/lib/grc/1032382.pdf.

Augustine, C., J. Ho, and N. Blair. 2018. GeoVision Analysis: Electric Sector Potential to Penetration Task Force Report. Golden, CO: National Renewable Energy Laboratory. NREL/TP-6A20-71833. https://www.nrel.gov/docs/fy18osti/71833.pdf.

Bertani, R. 2015. "Geothermal Power Generation in the World 2010-2014 Update Report." Presented at the World Geothermal Congress, Melbourne, Australia, April 19-25.

Blackwell, D., M. Richards, Z. Frone, J. Batir, A. Ruzo, R. Dingwall, and M. Williams. 2011. "Temperature-at-Depth Maps for the Conterminous U.S. And Geothermal Resource Estimates." Geothermal Resources Council Transactions 35: 1,545-1,550.

Bloomberg LP. 2016a. Chevron: CVX U.S. Equity WACC. As of December 2016. https://www.bloomberg.com/quote/CVX:US.

Bloomberg LP. 2016b. Exxon: XOM U.S. Equity WACC. As of December 2016. https://www.bloomberg.com/quote/XOM:US.

Bloomberg LP. 2016c. Ormat: ORA U.S. Equity WACC. As of December 2016. https://www.bloomberg.com/quote/ORA:US

Bloomberg LP. 2016d. U.S. Geothermal: HTM U.S. Equity WACC. As of December 2016.

Chabora, E., and E. Zemak. 2013. "Desert Peak EGS Project." Presented at the Geothermal Technologies Office 2013 Peer Review. Washington, D.C.: U.S. Department of Energy. https://energy.gov/sites/prod/files/2014/02/f7/desert_peak_egs_peer2013.pdf.

Cole, W., P. Kurup, M. Hand, D. Feldman, B. Sigrin, E. Lantz, T. Stehly, C. Augustine, C. Turchi, P. O'Connor, and C. Waldoch. 2016. 2016 Annual Technology Baseline (ATB). Golden, CO: National Renewable Energy Laboratory. NREL/PR-6A20-66944. https://www.nrel.gov/docs/fy16osti/66944.pdf.

Cole, W., T. Mai, J. Logan, D. Steinberg, J. McCall, J. Richards, B. Sigrin, and G. Porro. 2016. 2016 Standard Scenarios Report: A U.S. Electricity Sector Outlook (NREL/TP-6A20-66939. http://www.nrel.gov/docs/fy17osti/66939.pdf. 
Coolbaugh, M., R. Zehner, C. Kreemer, D. Blackwell, G. Oppliger, D. Sawatzky, G. Blewitt, A. Pancha, M. Richards, C. Helm-Clark, L. Shevenell, G. Raines, G. Johnson, T. Minor, and T. Boyd. 2005. "Geothermal Potential Map of the Great Basin, Western United States: Nevada Bureau of Mines and Geology Map 151." Nevada Bureau of Mines and Geology, University of Nevada, Reno. Map obtained via personal communication with M. Coolbaugh. http://pubs.nbmg.unr.edu/Geoth-Great-Basin-75-percent-p/m151a.htm.

DeAngelo, J. and C.F. Williams. 2010. Identified Moderate and High Temperature Geothermal Systems of the Western United States including AK and HI. Downloadable GIS Data. Menlo Park, CA: U.S. Geological Survey.

https://certmapper.cr.usgs.gov/data/geothermal/western us/spatial/shape/identifiedgeothermalsys tems.zip.

DiChristopher, T. 2015. "Oil Firms Are Swimming in Data They Don't Use." CNBC, March 5, 2015. http://www.cnbc.com/2015/03/05/us-energy-industry-collects-a-lot-of-operational-databut-doesnt-use-it.html.

DiPippo, R. 2004. "Second Law Assessment of Binary Plants for Power Generation from LowTemperature Geothermal Fluids.” Geothermics 33: 565-586.

Dobbie, T.P., and A.J. Menzies. 1979. "Geothermal Wastewater Reinjection Trials, Mahiao Reservoir Republic of the Philippines." Geothermal Resources Council Transactions 3. http://pubs.geothermal-library.org/lib/grc/1000347.pdf.

Doughty, C., P. Dobson, A. Wall, T. McLing, and C. Weiss. 2018. GeoVision Analysis Supporting Task Force Report: Exploration. Berkeley, CA: Lawrence Berkeley National Laboratory. LBNL-2001120. https://escholarship.org/uc/item/4v7054cw.

Forte, N. 1996. "The 125-MW Upper Mahiao Geothermal Power Plant," Geothermal Resources Council Transactions 20, Sept/Oct. http://pubs.geothermal-library.org/lib/grc/1014809.pdf.

Frone, Z., M. Richards, D. Blackwell, and C. Augustine. 2015. "Shallow EGS Resource Potential Maps of the Cascades.” 40th Workshop on Geothermal Reservoir Engineering, Stanford University, California, January 26-28.

Gehringer, M. and L. Victor. 2012. Geothermal Handbook: Planning and Financing Power Generation. Washington, D.C.: World Bank. ESMAP technical report; no. 002/12. C World Bank. https://openknowledge.worldbank.org/handle/10986/23712. License: CC BY 3.0 IGO.

Geothermal Energy Administration (GEA). 2016. 2016 Annual U.S. \& Global Geothermal Power Production Report. Washington, D.C. http://geoenergy.org/reports/2016/2016\%20Annual\%20US\%20Global\%20Geothermal\%20Power\%20Pro duction.pdf.

Glacier Partners. 2009. Geothermal Economics 101 - Economics of a 35 MW Binary Cycle Geothermal Plant. New York, New York: Glacier Partners. https://openei.org/wiki/File:Geothermal_Economics_101__Glacier_Partners.pdf. 
Informatics. 2018. "The Raft River Enhanced Geothermal System Project." EGI in the News. https://egi.utah.edu/raft-river-geothermal/.

Kaleikini, M., P. Spielman, and T. Buchanan. 2011. "Puna Geothermal Venture 8-MW Expansion." GRC Transactions 35. http://pubs.geothermal-library.org/lib/grc/1029420.pdf.

Khan, M.A. 2010. "The Geysers Geothermal Field, an Injection Success Story." Presented at the World Geothermal Congress, Bali, Indonesia, April 25-29. https://www.geothermalenergy.org/pdf/IGAstandard/WGC/2010/0620.pdf.

Koorey, K. 2008. "Ngawha Geothermal Field Expansion Project: Geothermal Fluid Conveyance System." Presented at the 30th New Zealand Geothermal Workshop, University of Auckland, p. 208-213.

Legmann, H. 2000. "The 60-MW Mokai Geothermal Project." Geothermal Resources Council Transactions 24, Sept. 24-27. http://pubs.geothermal-library.org/lib/grc/1016839.pdf.

Legmann, H., and P. Sullivan. 2003. "The 30-MW Rotokawa I Geothermal Project: Five Years of Operation." Presented at the International Geothermal Conference, Reykjavík, Iceland, September. http://www.jardhitafelag.is/media/PDF/S01Paper068.pdf.

Legmann, H. 2015. "The 100-MW Ngatamariki Geothermal Power Station: A Purpose-Built Plant for High Temperature, High Enthalpy Resource." Presented at the World Geothermal Congress 2015. Melbourne, Australia, April 19-25, 2015. http://www.geothermalenergy.org/pdf/IGAstandard/WGC/2015/06023.pdf.

Liu, X., P. Hughes, K. McCabe, J. Spitler, and L. Southard. 2019. GeoVision Analysis Supporting Task Force Report: Thermal Applications-Geothermal Heat Pumps. Oak Ridge, Tennessee: Oak Ridge National Laboratory. ORNL/TM-2019/502. https:/info.ornl.gov/sites/publications/Files/Pub103860.pdf

Lowry, T., J. Finger, C. Carrigan, A. Foris, M. Kennedy, T. Corbet, C. Doughty, S. Pye, and E. Sonnenthal. 2017a. GeoVision Analysis Supporting Task Force Report: Reservoir Maintenance and Development. Albuquerque, NM: Sandia National Laboratories. SAND2017-9977. https://www.osti.gov/biblio/1394062.

Lowry, T. S., A. Foris, J.T. Finger, S. Pye, and D.A. Blankenship. 2017b. "Implications of Drilling Technology Improvements on the Availability of Exploitable EGS Resources." Presented at the 42nd Workshop on Geothermal Reservoir Engineering. Stanford University, Stanford, California, February 13-15. https://www.geothermalenergy.org/pdf/IGAstandard/SGW/2017/Lowry.pdf.

McCabe, K., K. Beckers, K.R. Young, and N. Blair. 2019. GeoVision Analysis Supporting Task Force Report: Thermal Applications-Quantifying Technical, Economic, and Market Potential of Geothermal District Heating Systems in the United States. Golden, CO: National Renewable Energy Laboratory. NREL/TP-6A20- 71715. https:/www.nrel.gov/docs/fy19osti/71715.pdf. 
McPherson, G., and K. Koorey. 2013. “Kawerau Toppi Geothermal Fluid Supply.” Presented at the 35th New Zealand Geothermal Workshop, Rotorua, New Zealand.

Millstein, D., J. McCall, J. Macknick, S. Nicholson, D. Keyser, S. Jeong, and G. Heath. 2019. GeoVision Analysis Supporting Task Force Report: Impacts-The Employment Opportunities, Water Impacts, Emission Reductions, and Air Quality Improvements of Achieving High Penetrations of Geothermal Power in the United States. Berkeley, CA and Golden, CO: Lawrence Berkeley National Laboratory and National Renewable Energy Laboratory. NREL/TP6A20-71933. https://emp.lbl.gov/publications/geovision-analysis-impacts-task-force and https://www.nrel.gov/docs/fy19osti/71933.pdf.

Mines, G.L. 2016. GETEM User Manual (INL/EXT-16-38751). Idaho Falls, ID: Idaho National Laboratories. https://workingincaes.inl.gov/SiteAssets/CAES\%20Files/FORGE/inl_ext-1638751\%20GETEM\%20User\%20Manual\%20Final.pdf.

Muffler, L.J. 1979. "Assessment of Geothermal Resources of the United States: 1978. U.S. Geological Survey Circular 790.” Washington, D.C.: U.S. Department of Interior. http://pubs.er.usgs.gov/publication/cir790.

National Renewable Energy Laboratory (NREL). 2016. "2016 ATB Cost and Performance Summary." Golden, CO: National Renewable Energy Laboratory. Accessed January 25, 2019. https://atb.nrel.gov/electricity/2016/summary.html.

National Renewable Energy Laboratory (NREL). 2018a. "Annual Technology Baseline and Standard Scenarios." http://www.nrel.gov/analysis/data tech baseline.html.

National Renewable Energy Laboratory (NREL). 2018b. "Regional Energy Deployment System Model.” https://www.nrel.gov/analysis/reeds/.

Petty, S. and G. Porro. 2007. "Updated U.S. Geothermal Supply Characterization (NREL/CP640-41073)." Presented at the 32nd Workshop on Geothermal Reservoir Engineering, Stanford University, California, January 22-24.

Richard, M. 1990. "The Puna Geothermal Venture Project Power for the Island of Hawaii." Geothermal Resources Council Transactions 14, Part I.

RWTH Aachen University. 2016. "Assessing the Economics of Microdrilling for Geothermal Exploration.” http://www.fcn.eonerc.rwth-aachen.de/cms/E-ON-ERC-

FCN/Forschung/Abgeschlossene-Projekte/ emvf/Assessing-the-Economics-of-

Microdrilling/?lidx=1.

Salmon, J.P., J. Meurice, N. Wobus, F. Stern, and M. Duaime. 2011. Guidebook to Geothermal Power Finance. Golden, CO: National Renewable Energy Laboratory. NREL/SR-6A20-49391. https://www.nrel.gov/docs/fy11osti/49391.pdf.

Tassew, M. 2010. "Maintenance and Operational Experience Gained By Operating the Aluto Langano Geothermal Pilot Power Plant.” Presented at the World Geothermal Congress, Bali, Indonesia, April 25-29. 
Tester, J.W., et al. 2006. The Future of Geothermal Energy: Impact of Enhanced Geothermal Systems (EGS) on the United States in the 21st Century. Cambridge, MA, Massachusetts Institute of Technology. https://www1.eere.energy.gov/geothermal/pdfs/future_geo_energy.pdf.

U.S. Department of Energy (DOE). 2016. "Geothermal Electricity Technology Evaluation Model." https://energy.gov/eere/geothermal/geothermal-electricity-technology-evaluation-model.

U.S. Department of Energy (DOE). 2018a. "Enhanced Geothermal Systems Demonstration Projects." https://energy.gov/eere/geothermal/enhanced-geothermal-systems-demonstrationprojects.

U.S. Department of Energy (DOE). 2018b. "Frontier Observatory for Research in Geothermal Energy (FORGE)." https://www.energy.gov/eere/forge/forge-home.

U.S. Department of Energy (DOE). 2019. GeoVision: Harnessing the Heat Beneath Our Feet. Washington D.C.: U.S. Department of Energy. DOE/EE-1306.

U.S. Energy Information Administration (EIA). 2011. Annual Energy Review 2010. Washington, D.C.: October 19, 2011. DOE/EIA-0384(2010). https://www.eia.gov/totalenergy/data/annual/archive/038410.pdf.

U.S. Energy Information Administration (EIA). 2016a. "1990 - 2015 Existing Nameplate and Net Summer Capacity by Energy Source, Producer Type and State (EIA-860)." Washington, D.C.: October 12, 2016. Accessed April 6, 2017. https://www.eia.gov/electricity/data/state/.

U.S. Energy Information Administration (EIA). 2016b. "Net Generation by State by Type of Producer by Energy Source (EIA-906, EIA-920, and EIA-923) - 2015." Washington, D.C.: October 2016. Accessed May 26, 2017. https://www.eia.gov/electricity/data/state/.

U.S. Energy Information Administration (EIA). 2016c. "2015 Form EIA-860 Data." Form EIA860 Detailed Data. Washington, D.C. Accessed April 13, 2017. https://www.eia.gov/electricity/data/eia860/.

U.S. Energy Information Administration (EIA). 2016d. Annual Energy Outlook 2016 (Early Release: May). Washington, D.C. https://www.eia.gov/outlooks/aeo/pdf/0383(2016).pdf.

U.S. Energy Information Administration (EIA). 2016e. "Frequently Asked Questions: How Much Electricity Does an American Home Use?" Washington, D.C.: October 18, 2016. Accessed October 31, 2017. https://www.eia.gov/tools/faqs/faq.php?id=97\&t=3.

U.S. Energy Information Administration (EIA). 2017a. March 2017 Monthly Energy Review. DOE/EIA-0035(2017/3). Washington, D.C.: March 28, 2017. Accessed April 6, 2017. https://www.eia.gov/totalenergy/data/monthly/archive/00351703.pdf.

U.S. Energy Information Administration (EIA). 2017b. Electric Power Monthly with Data for January 2017. Washington, D.C.: March 24, 2017. Accessed April 6, 2017. https://www.eia.gov/electricity/monthly/archive/march2017.pdf. 
Wall, A., and K. Young. 2016. Doubling Geothermal Generation Capacity by 2020: A Strategic Analysis. Golden, CO: National Renewable Energy Laboratory. NREL/TP-6A20-64925. https://www.nrel.gov/docs/fy16osti/64925.pdf.

Wall, A.M., and P.F. Dobson. 2016. "Refining the Definition of a Geothermal Exploration Success Rate." Presented at the 41st Workshop on Geothermal Reservoir Engineering, Stanford University, California, February 22-24, 2016. https://pangea.stanford.edu/ERE/pdf/IGAstandard/SGW/2016/Wall2.pdf.

Wall, A.M., P.F. Dobson, and H. Thomas. 2017. "Geothermal Costs of Capital: Relating Market Valuation to Project Risk and Technology." Geothermal Resources Council Transactions 41. https://www.geothermal-library.org/index.php?mode=pubs\&action=view\&record=1033704.

Walters, W. 2013. Demonstration of an Enhanced Geothermal System at the Northwest Geysers Geothermal Field, CA." Presented at the Geothermal Technologies Office 2013 Peer Review. Washington, D.C.: U.S. Department of Energy. https://energy.gov/sites/prod/files/2014/02/f7/egs calpine peer2013.pdf.

Wang, B. 2016. "Reviewing Energy and the Next Big Future of Energy." Next Big Future. Available at: http://www.nextbigfuture.com/2016/12/reviewing-energy-and-next-big-futureof.html.

Wendt, D. G. Neupane, C. Davidson, R. Zheng, and M. Bearden. 2018. GeoVision Analysis Supporting Task Force Report: Geothermal Hybrid Systems. Idaho Falls, ID and Richland, WA: Idaho National Laboratory and Pacific Northwest National Laboratory. INL/EXT-17-42891 and PNNL-27386. https://www.osti.gov/biblio/1460735.

Williams, C.F., M.J. Reed, and R.H. Mariner. 2008. A Review of Methods Applied by the U.S. Geological Survey in the Assessment of Identified Geothermal Resources: U.S. Geological Survey Open-File Report 2008-1296. Washington, D.C.: U.S. Department of Interior. Open-File Report 2008-1296. http://pubs.usgs.gov/of/2008/1296/pdf/of2008-1296.pdf.

Williams, C. F., M.J. Reed, R.H. Mariner, J. DeAngelo, and S.P. Galanis Jr. 2008. Assessment of Moderate- and High-Temperature Geothermal Resources of the United States. Washington, D.C.: U.S. Geological Survey. U.S. Geological Survey Fact Sheet 2008-3082. https://pubs.usgs.gov/fs/2008/3082.

Wolf, N., and A. Gabbay. 2015. "Sarulla 330-MW Geothermal Project Key Success Factors in Development." Presented at the World Geothermal Congress, Melbourne, Australia, April 1925 .

Young, K., A. Levine, J. Cook, D. Heimiller, and J. Ho. 2019. GeoVision Analysis Supporting Task Force Report: Barriers-An Analysis of Non-Technical Barriers to Geothermal Deployment and Potential Improvement Scenarios. Golden, CO: National Renewable Energy Laboratory. NREL/PR-6A20-71641. https://www.nrel.gov/docs/fy19osti/71641.pdf. 


\section{Appendix}

Table A-1. GETEM Inputs for BAU and IRT GeoVision Scenarios ${ }^{a}$

\begin{tabular}{|c|c|c|c|c|c|c|c|c|}
\hline & \multicolumn{4}{|c|}{ GREENFIELD } & \multicolumn{4}{|c|}{ BROWNFIELD } \\
\hline Resource Type (Hydrothermal/EGS) & Hydrothermal & Hydrothermal & EGS & EGS & Hydrothermal & Hydrothermal & EGS & EGS \\
\hline Plant Type (Binary/Flash) & Binary & Flash & Binary & Flash & Binary & Flash & Binary & Flash \\
\hline \multicolumn{9}{|l|}{ ECONOMIC PARAMETERS } \\
\hline \multicolumn{9}{|l|}{ General Project Variables: } \\
\hline Reference Year $\$$ & 2016 & 2016 & 2016 & 2016 & 2016 & 2016 & 2016 & 2016 \\
\hline Contingency (\%) & 0.15 & 0.15 & $15 \%$ & $15 \%$ & $15 \%$ & $15 \%$ & $15 \%$ & $15 \%$ \\
\hline \multicolumn{9}{|l|}{ PERMITTING } \\
\hline $\begin{array}{r}\text { Permitting Process Costs for Pre- } \\
\text { Drilling Activities (per location) }\end{array}$ & $\$ 60,000$ & $\$ 60,000$ & $\$ 60,000$ & $\$ 60,000$ & $\$ 60,000$ & $\$ 60,000$ & $\$ 60,000$ & $\$ 60,000$ \\
\hline $\begin{array}{r}\text { Permitting Process Costs for } \\
\text { Exploration Early Project Drilling } \\
\text { (per site) }\end{array}$ & $\$ 250,000$ & $\$ 250,000$ & $\$ 250,000$ & $\$ 250,000$ & $\$ 250,000$ & $\$ 250,000$ & $\$ 250,000$ & $\$ 250,000$ \\
\hline $\begin{array}{r}\text { Permitting (Utilization Plant) Cost for } \\
\text { Well Field \& Power Plant }\end{array}$ & $\$ 1,000,000$ & $\$ 1,000,000$ & $\$ 1,000,000$ & $\$ 1,000,000$ & $\$ 1,000,000$ & $\$ 1,000,000$ & $\$ 1,000,000$ & $\$ 1,000,000$ \\
\hline \multicolumn{9}{|l|}{ RESOURCE EXPLORATION } \\
\hline \multicolumn{9}{|l|}{ Exploration Parameters: } \\
\hline Resource status before development & Greenfield & Greenfield & Greenfield & Greenfield & $\begin{array}{c}\text { Field } \\
\text { Expansion }\end{array}$ & $\begin{array}{c}\text { Field } \\
\text { Expansion }\end{array}$ & $\begin{array}{c}\text { Field } \\
\text { Expansion }\end{array}$ & $\begin{array}{c}\text { Field } \\
\text { Expansion }\end{array}$ \\
\hline $\begin{array}{r}\text { Will the Project have } \\
\text { Exploration Drilling? }\end{array}$ & Yes & Yes & Yes & Yes & Yes & Yes & Yes & Yes \\
\hline \multicolumn{9}{|l|}{ Exploration - Pre-Drilling Costs: } \\
\hline $\begin{array}{r}\text { Number of Locations Evaluated } \\
\text { Before Exploration Drilling Begins } \\
\text { (per project) }\end{array}$ & 1 & 1 & 1 & 1 & 1 & 1 & 1 & 1 \\
\hline $\begin{array}{l}\text { Lump Sum Cost for Pre-Drilling } \\
\text { Exploration Activities at each site }\end{array}$ & $\$ 900,000$ & $\$ 1,200,000$ & $\$ 250,000$ & $\$ 250,000$ & $\$ 600,000$ & $\$ 800,000$ & $\$ 250,000$ & $\$ 250,000$ \\
\hline \multicolumn{9}{|l|}{ Exploration - Drilling Costs: } \\
\hline $\begin{array}{r}\text { Number of Sites where Exploration } \\
\text { Drilling Occurs }\end{array}$ & 1 & 1 & 1 & 1 & 1 & 1 & 1 & 1 \\
\hline $\begin{array}{r}\text { Site Exploration Drilling Cost (includes } \\
\text { all temperature gradient, slimhole, } \\
\text { corehole wells drilled) }\end{array}$ & $\$ 5,400,000$ & $\$ 5,400,000$ & $\$ 5,000,000$ & $\$ 5,000,000$ & $\$ 3,300,000$ & $\$ 3,300,000$ & $\$ 1,500,000$ & $\$ 1,500,000$ \\
\hline $\begin{array}{r}\text { Number of sites with full-sized wells } \\
\text { drilled }\end{array}$ & 1 & 1 & 1 & 1 & 1 & 1 & 1 & 1 \\
\hline
\end{tabular}




\begin{tabular}{|c|c|c|c|c|c|c|c|c|}
\hline \multirow[b]{2}{*}{ Resource Type (Hydrothermal/EGS) } & \multicolumn{4}{|c|}{ GREENFIELD } & \multicolumn{4}{|c|}{ BROWNFIELD } \\
\hline & Hydrothermal & Hydrothermal & EGS & EGS & Hydrothermal & Hydrothermal & EGS & EGS \\
\hline Plant Type (Binary/Flash) & Binary & Flash & Binary & Flash & Binary & Flash & Binary & Flash \\
\hline $\begin{array}{r}\text { Number of full-size wells drilled at } \\
\text { each unsuccessful site }\end{array}$ & 2.0 & 2.0 & 1.0 & 1.0 & 0.0 & 0.0 & 1.0 & 1.0 \\
\hline $\begin{array}{r}\text { Number of full-sized test wells drilled } \\
\text { to get successful well }\end{array}$ & 2 & 2 & 2 & 2 & 2 & 2 & 2 & 2 \\
\hline Multiplier for Test Well Costs $(>=1)$ & 1.2 & 1.2 & 1.5 & 1.5 & 1.2 & 1.2 & 1.5 & 1.5 \\
\hline \# successful full sized wells needed & 3 & 3 & 9 & 9 & 2 & 2 & 9 & 9 \\
\hline Number of full-sized wells stimulated & 0 & 0 & 9 & 9 & 0 & 0 & 9 & 9 \\
\hline \multicolumn{9}{|l|}{ Leasing } \\
\hline $\begin{array}{l}\text { Leasing Acreage } \\
\end{array}$ & 2600 & 2600 & 2600 & 2600 & 2600 & 2600 & 2600 & 2600 \\
\hline $\begin{array}{r}\text { Leasing Cost (assume } 45 \text { acre per } \\
\text { well per location) (\$/acre) }\end{array}$ & $\$ 35$ & $\$ 35$ & $\$ 35$ & $\$ 35$ & $\$ 35$ & $\$ 35$ & $\$ 35$ & $\$ 35$ \\
\hline $\begin{array}{r}\text { Additional Costs Incurred not } \\
\text { Associated with Drilling Exploration } \\
\text { Wells (per site) }\end{array}$ & $4 \%$ & $4 \%$ & $5 \%$ & $5 \%$ & $4 \%$ & $4 \%$ & $5 \%$ & $5 \%$ \\
\hline $\begin{array}{r}\text { Potential Resource found by } \\
\text { Exploration \& Confirmation activities } \\
(\mathrm{MW})\end{array}$ & 90 & 120 & 100 & 120 & 90 & 120 & 100 & 120 \\
\hline $\begin{array}{r}\text { Are Exploration costs to be } \\
\text { proportioned based on Potential } \\
\text { Resource? }\end{array}$ & No & No & No & No & No & No & No & No \\
\hline \multicolumn{9}{|l|}{ Well Field Details } \\
\hline $\begin{array}{r}\text { Drilling Success Rate during well field } \\
\text { development }\end{array}$ & $75 \%$ & $75 \%$ & $75 \%$ & $75 \%$ & $75 \%$ & $75 \%$ & $75 \%$ & $75 \%$ \\
\hline $\begin{array}{r}\text { Will new wells be required for fluid } \\
\text { disposal (injection)? }\end{array}$ & Yes & Yes & Yes & Yes & Yes & Yes & Yes & Yes \\
\hline $\begin{array}{r}\text { Are unsuccessful wells to be used to } \\
\text { supplement injection? }\end{array}$ & Yes & Yes & No & No & Yes & Yes & No & No \\
\hline $\begin{array}{r}\text { Productivity of unsuccessful wells } \\
\text { relative to successful wells }\end{array}$ & 0.3 & 0.3 & 0.0 & 0.0 & 0.3 & 0.3 & 0.0 & 0.0 \\
\hline $\begin{array}{r}\text { Production to Injection Well Flow } \\
\text { Ratio }\end{array}$ & 0.75 & 0.75 & 0.5 & 0.5 & 0.75 & 0.75 & 0.5 & 0.5 \\
\hline Number of Spare Production Wells & 0 & 0 & 0 & 0 & 0 & 0 & 0 & 0 \\
\hline $\begin{array}{r}\text { Ratio Injection Well to Production Well } \\
\text { Depth }\end{array}$ & 1 & 1 & 1 & 1 & 1 & 1 & 1 & 1 \\
\hline $\begin{array}{r}\text { Production capacity needed to obtain } \\
\text { PPA }\end{array}$ & $60 \%$ & $60 \%$ & $60 \%$ & $60 \%$ & $60 \%$ & $60 \%$ & $60 \%$ & $60 \%$ \\
\hline
\end{tabular}




\begin{tabular}{|c|c|c|c|c|c|c|c|c|}
\hline & \multicolumn{4}{|c|}{ GREENFIELD } & \multicolumn{4}{|c|}{ BROWNFIELD } \\
\hline Resource Type (Hydrothermal/EGS) & Hydrothermal & Hydrothermal & EGS & EGS & Hydrothermal & Hydrothermal & EGS & EGS \\
\hline Plant Type (Binary/Flash) & Binary & Flash & Binary & Flash & Binary & Flash & Binary & Flash \\
\hline Production and Injection Well size & $\begin{array}{l}\text { Larger } \\
\text { Diameter }\end{array}$ & $\begin{array}{l}\text { Smaller } \\
\text { Diameter }\end{array}$ & $\begin{array}{c}\text { Larger } \\
\text { Diameter }\end{array}$ & $\begin{array}{l}\text { Smaller } \\
\text { Diameter }\end{array}$ & $\begin{array}{l}\text { Larger } \\
\text { Diameter }\end{array}$ & $\begin{array}{l}\text { Smaller } \\
\text { Diameter }\end{array}$ & $\begin{array}{l}\text { Larger } \\
\text { Diameter }\end{array}$ & $\begin{array}{l}\text { Smaller } \\
\text { Diameter }\end{array}$ \\
\hline $\begin{array}{l}\text { Is production/injection interval open } \\
\text { hole or cased (slotted/perforated)? }\end{array}$ & Open Hole & Open Hole & $\begin{array}{c}\text { Perforated / } \\
\text { Slotted } \\
\text { Liner } \\
\end{array}$ & $\begin{array}{l}\text { Perforated } \\
\text { / Slotted } \\
\text { Liner }\end{array}$ & Open Hole & Open Hole & $\begin{array}{l}\text { Perforated } \\
\text { / Slotted } \\
\text { Liner }\end{array}$ & $\begin{array}{c}\text { Perforated / } \\
\text { Slotted } \\
\text { Liner }\end{array}$ \\
\hline Well Drilling Cost Curve Used: & Base & Base & Base & Base & Base & Base & Base & Base \\
\hline \multicolumn{9}{|l|}{ Well Stimulation } \\
\hline Are wells stimulated? & No & No & Yes & Yes & No & No & Yes & Yes \\
\hline Wells to be stimulated & & & Injection & Injection & & & Injection & Injection \\
\hline $\begin{array}{r}\text { Input Fixed Stimulation Cost per well } \\
(\$ / \text { well })\end{array}$ & $\$ 0$ & $\$ 0$ & $\$ 1,250,000$ & $\$ 1,250,000$ & $\$ 0$ & $\$ 0$ & $\$ 1,250,000$ & $\$ 1,250,000$ \\
\hline $\begin{array}{l}\text { Stimulation Success rate } \\
\end{array}$ & 0 & 0 & $75 \%$ & $75 \%$ & 0 & 0 & $75 \%$ & $75 \%$ \\
\hline \multicolumn{9}{|l|}{ Other Costs } \\
\hline Well Testing Cost at each site & $\$ 150,000$ & $\$ 150,000$ & $\$ 500,000$ & $\$ 500,000$ & $\$ 150,000$ & $\$ 150,000$ & $\$ 500,000$ & $\$ 500,000$ \\
\hline $\begin{array}{r}\text { How are non-drilling costs to be } \\
\text { determined ? }\end{array}$ & $\%$ of Costs & $\%$ of Costs & $\%$ of Costs & $\%$ of Costs & $\%$ of Costs & $\%$ of Costs & $\%$ of Costs & $\%$ of Costs \\
\hline $\begin{array}{r}\% \text { of total cost for indirect costs } \\
\text { (exclusive of permitting) }\end{array}$ & $5.0 \%$ & $5.0 \%$ & $5.0 \%$ & $5.0 \%$ & $5.0 \%$ & $5.0 \%$ & $5.0 \%$ & $5.0 \%$ \\
\hline \multicolumn{9}{|l|}{$\begin{array}{l}\text { GEOFLUID GATHERING SYSTEM \& } \\
\text { PUMPING }\end{array}$} \\
\hline \multicolumn{9}{|l|}{ Other Field Costs } \\
\hline $\begin{array}{r}\text { How are surface equipment costs } \\
\text { determined? }\end{array}$ & Calculated & Calculated & Calculated & Calculated & Calculated & Calculated & Calculated & Calculated \\
\hline $\begin{array}{r}\text { Average distance from well to plant } \\
\text { (meter) }\end{array}$ & 750 & 750 & 500 & 500 & 750 & 750 & 500 & 500 \\
\hline $\begin{array}{r}\text { Maximum pressure drop in Surface } \\
\text { Piping (psi) }\end{array}$ & 10 & 5 & 10 & 5 & 10 & 5 & 10 & 5 \\
\hline \multicolumn{9}{|l|}{$\begin{array}{r}\text { Calculated Surface Equipment Cost } \\
(\$ / \text { well }) \\
\end{array}$} \\
\hline \multicolumn{9}{|l|}{ Geothermal pumps } \\
\hline $\begin{array}{r}\text { Pump \& Driver Efficiency for } \\
\text { Production and Injection Pump }\end{array}$ & $67.5 \%$ & $67.5 \%$ & $67.5 \%$ & $67.5 \%$ & $67.5 \%$ & $67.5 \%$ & $67.5 \%$ & $67.5 \%$ \\
\hline \multicolumn{9}{|l|}{ Production Pump: } \\
\hline Are Production Wells pumped? & Yes & No & Yes & No & Yes & No & Yes & No \\
\hline $\begin{array}{r}\text { Calculate or Input production pump } \\
\text { depth? }\end{array}$ & Calculate & Calculate & Calculate & Calculate & Calculate & Calculate & Calculate & Calculate \\
\hline Calculation Pump Depth: & & & & & & & & \\
\hline
\end{tabular}




\begin{tabular}{|c|c|c|c|c|c|c|c|c|}
\hline \multirow[b]{2}{*}{ Resource Type (Hydrothermal/EGS) } & \multicolumn{4}{|c|}{ GREENFIELD } & \multicolumn{4}{|c|}{ BROWNFIELD } \\
\hline & Hydrothermal & Hydrothermal & EGS & EGS & Hydrothermal & Hydrothermal & EGS & EGS \\
\hline Plant Type (Binary/Flash) & Binary & Flash & Binary & Flash & Binary & Flash & Binary & Flash \\
\hline $\begin{array}{r}\text { Excess Pressure at pump Suction } \\
\text { and/or well head (psi) }\end{array}$ & 50.0 & 50.0 & 50.0 & 50.0 & 50.0 & 50.0 & 50.0 & 50.0 \\
\hline $\begin{array}{r}\text { Diameter of production pump casing } \\
\text { (inch) }\end{array}$ & 9.625 & 9.625 & 9.625 & 9.625 & 9.625 & 9.625 & 9.625 & 9.625 \\
\hline $\begin{array}{r}\text { Calculate or Input production pump } \\
\text { cost? }\end{array}$ & Calculate & Calculate & Calculate & Calculate & Calculate & Calculate & Calculate & Calculate \\
\hline \multicolumn{9}{|l|}{ Calculate Pump Cost: } \\
\hline Other Costs & $\$ 10,000$ & $\$ 10,000$ & $\$ 10,000$ & $\$ 10,000$ & $\$ 10,000$ & $\$ 10,000$ & $\$ 10,000$ & $\$ 10,000$ \\
\hline Installation Cost $(\$ / \mathrm{ft})$ & $\$ 5.00$ & $\$ 5.00$ & $\$ 5.00$ & $\$ 5.00$ & $\$ 5.00$ & $\$ 5.00$ & $\$ 5.00$ & $\$ 5.00$ \\
\hline Casing cost $(\$ / \mathrm{ft})$ & $\$ 44.74$ & $\$ 44.74$ & $\$ 44.74$ & $\$ 44.74$ & $\$ 44.74$ & $\$ 44.74$ & $\$ 44.74$ & $\$ 44.74$ \\
\hline \multicolumn{9}{|l|}{ Injection Pump : } \\
\hline $\begin{array}{r}\text { Surface Equipment } \Delta \mathrm{P} \text { for binary } \\
\text { conversion system (psi) }\end{array}$ & 40.0 & 40.0 & 40.0 & 40.0 & 40.0 & 40.0 & 40.0 & 40.0 \\
\hline $\begin{array}{r}\text { Calculations determine pumping to } \\
\text { provide } 1 \text { psi excess pressure - Is } \\
\text { Additional Injection Pressure } \\
\text { Required?? }\end{array}$ & No & No & No & No & No & No & No & No \\
\hline Additional Injection Pressure & 1.0 & 1.0 & 1.0 & 1.0 & 1.0 & 1.0 & 1.0 & 1.0 \\
\hline $\begin{array}{r}\text { Other Costs (\% of GF Gathering } \\
\text { System \& Pump Costs) }\end{array}$ & $12.0 \%$ & $12.0 \%$ & $12.0 \%$ & $12.0 \%$ & $12.0 \%$ & $12.0 \%$ & $12.0 \%$ & $12.0 \%$ \\
\hline \multicolumn{9}{|l|}{ RESERVOIR DEFINITION } \\
\hline \multicolumn{9}{|l|}{ Well Flow Rate } \\
\hline Production Well Flow Rate $(\mathrm{kg} / \mathrm{s})$ & 110 & 80 & 40 & 40 & 110 & 80 & 40 & 40 \\
\hline \multicolumn{9}{|l|}{ Hydraulic Drawdown } \\
\hline $\begin{array}{r}\text { Input Production Well Drawdown } \\
\text { (psi-h/1000lb) }\end{array}$ & 0.4 & 0.4 & 4 & 4 & 0.4 & 0.4 & 4 & 4 \\
\hline $\begin{array}{r}\text { Ratio of Injection Well Buildup to } \\
\text { Production Well Drawdown }\end{array}$ & 1 & 1 & 1 & 1 & 1 & 1 & 1 & 1 \\
\hline \multicolumn{9}{|l|}{ Thermal Drawdown } \\
\hline Annual Rate of Decline (\%/.yr) & $0.50 \%$ & $0.50 \%$ & $0.50 \%$ & $0.50 \%$ & $0.50 \%$ & $0.60 \%$ & $0.50 \%$ & $0.50 \%$ \\
\hline $\begin{array}{r}\text { Use Calc Maximum Allowable } \\
\text { Temperature Decline? }\end{array}$ & Yes & Yes & Yes & Yes & Yes & Yes & Yes & Yes \\
\hline \multicolumn{9}{|l|}{ Water Loss } \\
\hline $\begin{array}{r}\text { Subsurface Water loss as \% of } \\
\text { injected flow }(\geq 0)\end{array}$ & $0 \%$ & $0 \%$ & $5 \%$ & $5 \%$ & $0 \%$ & $0 \%$ & $5 \%$ & $5 \%$ \\
\hline $\begin{array}{r}\text { Is water loss for Flash Cooling system } \\
\text { to be made-up? }\end{array}$ & No & No & No & Yes & No & No & No & Yes \\
\hline Makeup Water cost (\$/acre-ft) & $\$ 300$ & $\$ 300$ & $\$ 300$ & $\$ 300$ & $\$ 300$ & $\$ 300$ & $\$ 300$ & $\$ 300$ \\
\hline
\end{tabular}




\begin{tabular}{|c|c|c|c|c|c|c|c|c|}
\hline \multirow[b]{2}{*}{ Resource Type (Hydrothermal/EGS) } & \multicolumn{4}{|c|}{ GREENFIELD } & \multicolumn{4}{|c|}{ BROWNFIELD } \\
\hline & Hydrothermal & Hydrothermal & EGS & EGS & Hydrothermal & Hydrothermal & EGS & EGS \\
\hline Plant Type (Binary/Flash) & Binary & Flash & Binary & Flash & Binary & Flash & Binary & Flash \\
\hline $\begin{array}{r}\text { Flow into/out of multiple zones in } \\
\text { production/injection interval? }\end{array}$ & No & No & Yes & Yes & No & No & Yes & Yes \\
\hline \multicolumn{9}{|l|}{ OPERATION \& MAINTENANCE } \\
\hline $\begin{array}{r}\text { Input Annual O\&M Costs or } \\
\text { Calculate? }\end{array}$ & Calculate & Calculate & Calculate & Calculate & Calculate & Calculate & Calculate & Calculate \\
\hline \multicolumn{9}{|l|}{ Operating Cost Calculation } \\
\hline \multicolumn{9}{|l|}{ Labor Costs } \\
\hline $\begin{array}{r}\text { Fraction of operator labor assigned to } \\
\text { field }\end{array}$ & $25 \%$ & $25 \%$ & $25 \%$ & $25 \%$ & $25 \%$ & $25 \%$ & $25 \%$ & $25 \%$ \\
\hline Labor multiplier (burdened labor cost) & 1.8 & 1.8 & 1.8 & 1.8 & 1.8 & 1.8 & 1.8 & 1.8 \\
\hline \multicolumn{9}{|l|}{ Staff Count } \\
\hline \multicolumn{9}{|l|}{ Field Maintenance } \\
\hline $\begin{array}{r}\text { Annual Maintenance non-labor } \\
\text { (fraction of field cost) }(\%)\end{array}$ & $1.5 \%$ & $1.5 \%$ & $1.5 \%$ & $1.5 \%$ & $1.5 \%$ & $1.5 \%$ & $1.5 \%$ & $1.5 \%$ \\
\hline $\begin{array}{r}\text { Geothermal fluid treatment - chemical } \\
\text { dosage (ppm) }\end{array}$ & 0 & 0 & 0 & 0 & 0 & 0 & 0 & 0 \\
\hline Chemical cost (\$/gal) & & $\$ 22.50$ & & $\$ 22.50$ & & $\$ 22.50$ & & $\$ 22.50$ \\
\hline \multicolumn{9}{|l|}{ Power Plant Maintenance } \\
\hline $\begin{array}{r}\text { Annual O\&M non-labor (fraction of } \\
\text { plant cost) }(\%)\end{array}$ & $1.8 \%$ & $1.8 \%$ & $1.8 \%$ & $1.8 \%$ & $1.8 \%$ & $1.8 \%$ & $1.8 \%$ & $1.8 \%$ \\
\hline \multicolumn{9}{|l|}{$\begin{array}{r}\text { Cooling water treatment chemical } \\
\text { dosage (ppm) }\end{array}$} \\
\hline Chemical cost $(\$ /$ gal $)$ & & $\$ 1.70$ & & $\$ 1.70$ & & $\$ 1.70$ & & $\$ 1.70$ \\
\hline \multicolumn{9}{|l|}{$\begin{array}{l}\text { Geothermal Production Pump } \\
\text { Maintenance }\end{array}$} \\
\hline Type of production pump used & Lineshaft & Lineshaft & Lineshaft & Lineshaft & Lineshaft & Lineshaft & Lineshaft & Lineshaft \\
\hline Lineshaft pump operating life [p] (yr) & 3 & 3 & 3 & 3 & 3 & 3 & 3 & 3 \\
\hline Reference Pump Depth (ft) & 500.0 & 500.0 & 500.0 & 500.0 & 500.0 & 500.0 & 500.0 & 500.0 \\
\hline Annual Lube Oil Cost (\$/yr) & $\$ 4,300$ & $\$ 4,300$ & $\$ 4,300$ & $\$ 4,300$ & $\$ 4,300$ & $\$ 4,300$ & $\$ 4,300$ & $\$ 4,300$ \\
\hline Submersible pump operating life [p] & 2 & 2 & 2 & 2 & 2 & 2 & 2 & 2 \\
\hline $\begin{array}{r}\text { Taxes and Insurance (Plant \& Well } \\
\text { Field Capital Costs) (\%) }\end{array}$ & $0.75 \%$ & $0.75 \%$ & $0.75 \%$ & $0.75 \%$ & $0.75 \%$ & $0.75 \%$ & $0.75 \%$ & $0.75 \%$ \\
\hline \multicolumn{9}{|l|}{ POWER PLANT } \\
\hline \multicolumn{9}{|l|}{$\begin{array}{l}\text { Transmission Cost (included in plant } \\
\text { cost) }\end{array}$} \\
\hline $\begin{array}{r}\text { Are transmission line costs to be } \\
\text { included? }\end{array}$ & No & No & No & No & No & No & No & No \\
\hline
\end{tabular}




\begin{tabular}{|c|c|c|c|c|c|c|c|c|}
\hline \multirow[b]{2}{*}{ Resource Type (Hydrothermal/EGS) } & \multicolumn{4}{|c|}{ GREENFIELD } & \multicolumn{4}{|c|}{ BROWNFIELD } \\
\hline & Hydrothermal & Hydrothermal & EGS & EGS & Hydrothermal & Hydrothermal & EGS & EGS \\
\hline Plant Type (Binary/Flash) & Binary & Flash & Binary & Flash & Binary & Flash & Binary & Flash \\
\hline Transmission Line Voltage & $\leq 115 \mathrm{kV}$ & $\leq 115 \mathrm{kV}$ & $\leq 115 \mathrm{kV}$ & $\leq 115 \mathrm{kV}$ & $\leq 115 \mathrm{kV}$ & $\leq 115 \mathrm{kV}$ & $\leq 115 \mathrm{kV}$ & $\leq 115 \mathrm{kV}$ \\
\hline Terrain Conditions & Flat & Flat & Flat & Flat & Flat & Flat & Flat & Flat \\
\hline $\begin{array}{l}\text { Population Density } \\
\end{array}$ & Rural & Rural & Rural & Rural & Rural & Rural & Rural & Rural \\
\hline Length of Transmission Line (miles) & 0 & 0 & 0 & 0 & 0 & 0 & 0 & 0 \\
\hline $\begin{array}{r}\text { Permitting Process Costs for Power } \\
\text { Plant Construction }\end{array}$ & $\$ 0$ & $\$ 0$ & $\$ 0$ & $\$ 0$ & $\$ 0$ & $\$ 0$ & $\$ 0$ & $\$ 0$ \\
\hline \multicolumn{9}{|l|}{ Power Plant Parameters } \\
\hline $\begin{array}{r}\text { Are calculations to be based upon } \\
\text { Fixed Power Sales or Fixed Number } \\
\text { of Production Wells? }\end{array}$ & Power Sales & Power Sales & $\begin{array}{l}\text { Power } \\
\text { Sales }\end{array}$ & $\begin{array}{l}\text { Power } \\
\text { Sales }\end{array}$ & Power Sales & Power Sales & $\begin{array}{l}\text { Power } \\
\text { Sales }\end{array}$ & $\begin{array}{l}\text { Power } \\
\text { Sales }\end{array}$ \\
\hline Power Sales (MW) & 30 & 40 & 25 & 30 & 30 & 40 & 25 & 30 \\
\hline Enter Number of Wells (well count) & 4 & 4 & 4 & 4 & 4 & 4 & 4 & 4 \\
\hline Number of independent power units & 1 & 1 & 1 & 1 & 1 & 1 & 1 & 1 \\
\hline \multicolumn{9}{|l|}{ Binary Power Plant } \\
\hline $\begin{array}{r}\text { Use the calculated performance or } \\
\text { input brine effectiveness? }\end{array}$ & Calculate & Calculate & Calculate & Calculate & Calculate & Calculate & Calculate & Calculate \\
\hline \multicolumn{9}{|l|}{ Default Scenario Plant Cost } \\
\hline \multicolumn{9}{|l|}{ Major Component Costs } \\
\hline Material of Construction- GF heaters & carbon stl & & carbon stl & & carbon stl & & carbon stl & \\
\hline Enter tube material cost multiplier & 1.00 & & 1.00 & & 1.00 & & 1.00 & \\
\hline \multicolumn{9}{|l|}{ Direct Construction Costs } \\
\hline Tax & $5 \%$ & & $5 \%$ & & $5 \%$ & & $5 \%$ & \\
\hline $\begin{array}{lr} & \text { Freight } \\
\end{array}$ & $5 \%$ & & $5 \%$ & & $5 \%$ & & $5 \%$ & \\
\hline $\begin{array}{r}\text { Use Calculated Plant Cost for Default } \\
\text { Scenario? }\end{array}$ & Yes & NA & Yes & NA & Yes & NA & Yes & NA \\
\hline \multicolumn{9}{|l|}{ Flash-Steam Power Plant } \\
\hline \multicolumn{9}{|l|}{ Plant Performance } \\
\hline Number of flashes (1 or 2) & & 2 & & 2 & & 2 & & 2 \\
\hline $\begin{array}{r}\text { Use calculated flash P's or input } \\
\text { values }\end{array}$ & & Calculate & & Calculate & & Calculate & & Calculate \\
\hline \multicolumn{9}{|l|}{ Ambient Conditions } \\
\hline T,wet bulb (F) & & 60 & & 60 & & 60 & & 60 \\
\hline Atmospheric pressure (psi) & & 14.70 & & 14.70 & & 14.70 & & 14.70 \\
\hline \multicolumn{9}{|l|}{ Component Efficiencies } \\
\hline Turbine efficiency & & $80 \%$ & & $80 \%$ & & $80 \%$ & & $80 \%$ \\
\hline Generator efficiency & & $98 \%$ & & $98 \%$ & & $98 \%$ & & $98 \%$ \\
\hline $\begin{array}{r}\text { Cooling water and condensate pump } \\
\text { efficiency }\end{array}$ & & $75 \%$ & & $75 \%$ & & $75 \%$ & & $75 \%$ \\
\hline
\end{tabular}




\begin{tabular}{|c|c|c|c|c|c|c|c|c|}
\hline \multirow[b]{2}{*}{ Resource Type (Hydrothermal/EGS) } & \multicolumn{4}{|c|}{ GREENFIELD } & \multicolumn{4}{|c|}{ BROWNFIELD } \\
\hline & Hydrothermal & Hydrothermal & EGS & EGS & Hydrothermal & Hydrothermal & EGS & EGS \\
\hline Plant Type (Binary/Flash) & Binary & Flash & Binary & Flash & Binary & Flash & Binary & Flash \\
\hline \multicolumn{9}{|l|}{ Flash Pressure } \\
\hline $\begin{array}{l}\text { Is a constraint placed on the GF } \\
\text { temperature leaving plant? }\end{array}$ & & Yes & & Yes & & Yes & & Yes \\
\hline \multicolumn{9}{|l|}{ Define Steam Pressure Drops } \\
\hline $\begin{array}{l}\text { Input pressure drop between high } \\
\text { pressure flash and turbine (psi) }\end{array}$ & & 1.00 & & 1.00 & & 1.00 & & 1.00 \\
\hline $\begin{array}{l}\text { Input pressure drop between low } \\
\text { pressure flash and turbine (psi) }\end{array}$ & & 1.00 & & 1.00 & & 1.00 & & 1.00 \\
\hline \multicolumn{9}{|l|}{ Cooling System } \\
\hline $\begin{array}{r}\text { Condenser type (surface or direct } \\
\text { contact) }\end{array}$ & & surface & & surface & & surface & & surface \\
\hline CW pump head (ft) & & 65.00 & & 65.00 & & 65.00 & & 65.00 \\
\hline $\begin{array}{r}\text { Cooling Water temperature rise - } \\
\text { DT, cooling water (F) }\end{array}$ & & 25 & & 25 & & 25 & & 25 \\
\hline Pinch Point-condenser (F) & & 7.50 & & 7.50 & & 7.50 & & 7.50 \\
\hline Pinch Point-cooling tower (F) & & 5.00 & & 5.00 & & 5.00 & & 5.00 \\
\hline \multicolumn{9}{|l|}{$\begin{array}{r}\text { Non-Condensable Gas (NCG) } \\
\text { Removal } \\
\end{array}$} \\
\hline NCG level (ppm) & & 2,000 & & 2,000 & & 2,000 & & 2,000 \\
\hline Molecular Weight of NCG's & & 44.00 & & 44.00 & & 44.00 & & 44.00 \\
\hline H2S level (ppm) & & 20 & & 20 & & 20 & & 20 \\
\hline $\begin{array}{l}\text { Method of NCG removal } \\
\text { (Jet,VacPump or Hybrid) }\end{array}$ & & Hybrid & & Hybrid & & Hybrid & & Hybrid \\
\hline Number of stages: ncg removal & & 3 & & 3 & & 3 & & 3 \\
\hline NCG vacuum pump efficiency & & $70 \%$ & & $70 \%$ & & $70 \%$ & & $70 \%$ \\
\hline \multicolumn{9}{|l|}{ Flash-Steam Plant Cost } \\
\hline \multicolumn{9}{|l|}{ Equipment Related Input } \\
\hline $\begin{array}{r}\text { Steam condenser heat transfer } \\
\text { coefficient }(U) \text { (btu/h-sqft-F) }\end{array}$ & & 350.00 & & 350.00 & & 350.00 & & 350.00 \\
\hline $\begin{array}{r}\text { Max droplet size in flash vessel } \\
\text { (micron) }\end{array}$ & & 200.00 & & 200.00 & & 200.00 & & 200.00 \\
\hline \multicolumn{9}{|l|}{ Direct Construction Costs } \\
\hline Tax & & $5.0 \%$ & & $5.0 \%$ & & $5.0 \%$ & & $5.0 \%$ \\
\hline $\begin{array}{lr}\text { Freight } \\
\end{array}$ & & $5 \%$ & & $5 \%$ & & $5 \%$ & & $5 \%$ \\
\hline Use Calculated Flash Plant Cost? & & Yes & & Yes & & Yes & & Yes \\
\hline \multicolumn{9}{|l|}{ Indirect Plant Costs } \\
\hline Inputted \% Multiplier for Indirect Cost & $12 \%$ & $12 \%$ & $12 \%$ & $12 \%$ & $12 \%$ & $12 \%$ & $12 \%$ & $12 \%$ \\
\hline
\end{tabular}

${ }^{a}$ Not all inputs have an impact on the GETEM outputs used for GeoVision, but they are included for completeness. 
Table A-2. Summary of GETEM Input Changes for TI Scenario ${ }^{a}$

\begin{tabular}{|c|c|c|c|c|c|c|c|c|}
\hline & \multicolumn{4}{|c|}{ GREENFIELD } & \multicolumn{4}{|c|}{ BROWNFIELD } \\
\hline Resource Type (Hydrothermal/EGS) & Hydrothermal & Hydrothermal & EGS & EGS & Hydrothermal & Hydrothermal & EGS & EGS \\
\hline Plant Type (Binary/Flash) & Binary & Flash & Binary & Flash & Binary & Flash & Binary & Flash \\
\hline \multicolumn{9}{|l|}{ RESOURCE EXPLORATION } \\
\hline \multicolumn{9}{|l|}{ Exploration: Predrilling Costs } \\
\hline $\begin{array}{l}\text { Lump sum cost for predrilling } \\
\text { exploration activities at each site }\end{array}$ & $\$ 1,045,000$ & $\$ 1,045,000$ & $\$ 370,000$ & $\$ 370,000$ & $\$ 695,000$ & $\$ 695,000$ & $\$ 170,000$ & $\$ 170,000$ \\
\hline \multicolumn{9}{|l|}{ Exploration: Drilling Costs } \\
\hline $\begin{array}{r}\text { Site exploration drilling cost } \\
\text { (includes all temperature gradient, } \\
\text { slim hole, core hole wells drilled) }\end{array}$ & $\$ 3,591,000$ & $\$ 3,591,000$ & $\$ 3,591,000$ & $\$ 3,591,000$ & $\$ 2,194,500$ & $\$ 2,194,500$ & $\$ 3,790,500$ & $\$ 3,790,500$ \\
\hline $\begin{array}{r}\text { Number of full-sized wells } \\
\text { drilled at each unsuccessful site }\end{array}$ & 1.0 & 1.0 & 1.0 & 1.0 & 0.0 & 0.0 & 0.0 & 0.0 \\
\hline $\begin{array}{r}\text { Number of full-sized test wells } \\
\text { drilled to get successful well }\end{array}$ & 1.3333333 & 1.3333333 & 1.3333333 & 1.3333333 & 1.3333333 & 1.3333333 & 1.3333333 & 1.3333333 \\
\hline Multiplier for test well costs $(>=1)$ & 1 & 1 & 1 & 1 & 1 & 1 & 1 & 1 \\
\hline $\begin{array}{r}\text { Number of successful } \\
\text { full-sized wells needed }\end{array}$ & 3 & 3 & 3 & 3 & 3 & 3 & 3 & 3 \\
\hline Number of full-sized wells stimulated & 2 & 2 & 2 & 2 & 2 & 2 & 2 & 2 \\
\hline \multicolumn{9}{|l|}{ DRILLING } \\
\hline \multicolumn{9}{|l|}{ Well Field Details } \\
\hline $\begin{array}{r}\text { Drilling success rate during } \\
\text { well field development }\end{array}$ & $90 \%$ & $90 \%$ & $90 \%$ & $90 \%$ & $90 \%$ & $90 \%$ & $90 \%$ & $90 \%$ \\
\hline Well drilling costs & Ideal & Ideal & Ideal & Ideal & Ideal & Ideal & Ideal & Ideal \\
\hline \multicolumn{9}{|l|}{ Well stimulation } \\
\hline Are wells stimulated? & Yes & Yes & Yes & Yes & Yes & Yes & Yes & Yes \\
\hline Wells to be stimulated & Both & Both & Injection & Injection & Both & Both & Injection & Injection \\
\hline Input fixed stimulation cost per well & $\$ 1,250,000$ & $\$ 1,250,000$ & $\$ 1,250,000$ & $\$ 1,250,000$ & $\$ 1,250,000$ & $\$ 1,250,000$ & $\$ 1,250,000$ & $\$ 1,250,000$ \\
\hline Stimulation success rate & $90 \%$ & $90 \%$ & $90 \%$ & $90 \%$ & $90 \%$ & $90 \%$ & $90 \%$ & $90 \%$ \\
\hline \multicolumn{9}{|l|}{ RESERVOIR DEFINITION } \\
\hline \multicolumn{9}{|l|}{ Well flow rate } \\
\hline Production well flow rate & 110 & 80 & 110 & 80 & 110 & 80 & 110 & 80 \\
\hline \multicolumn{9}{|l|}{ Hydraulic drawdown } \\
\hline Input production well drawdown & 0.4 & 0.4 & 0.4 & 0.4 & 0.4 & 0.4 & 0.4 & 0.4 \\
\hline
\end{tabular}

${ }^{a}$ All other inputs are the same as in the BAU scenario. 